\title{
Cyclic Peptidyl Inhibitors against CAL-CFTR Interaction for Treatment of Cystic Fibrosis
}

Patrick G. Dougherty, Jack H. Wellmerling, Amritendu Koley, Jessica K. Lukowski, Amanda B.

Hummon, Estelle Cormet-Boyaka,* and Dehua Pei*

\section{Supporting Information}

\section{Table of Contents}

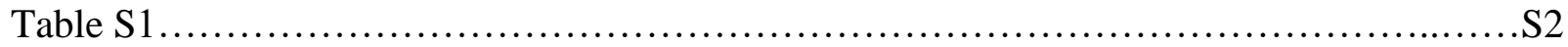

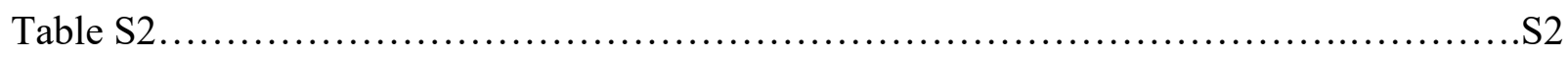

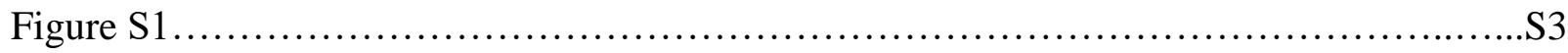

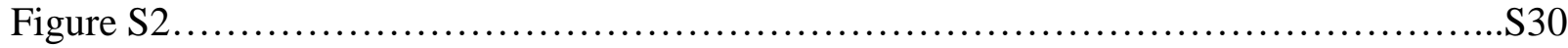

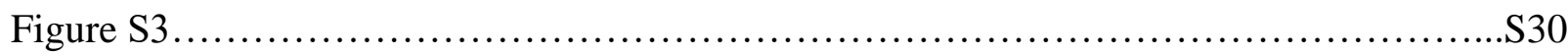

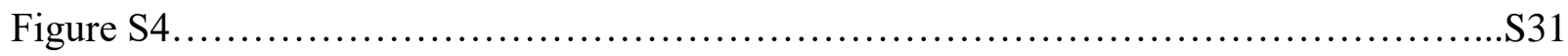

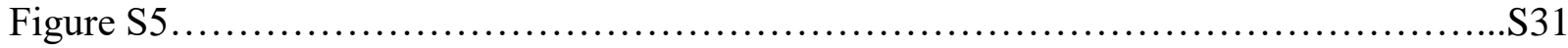

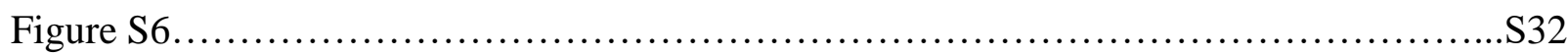

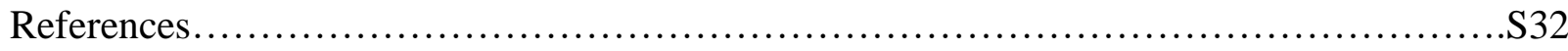


Table S1: Purity and MS data of compounds 2-24

\begin{tabular}{|c|c|c|c|c|}
\hline $\begin{array}{l}\text { Compound } \\
\text { ID }\end{array}$ & $\begin{array}{l}\text { Molecular formula } \\
\qquad[\mathrm{M}+\mathrm{H}]^{+}\end{array}$ & Purity (\%) & $\begin{array}{l}\text { Calculated Mass } \\
\qquad[\mathrm{M}+\mathrm{H}]^{+}\end{array}$ & $\begin{array}{l}\text { Observed Mass } \\
{[\mathrm{M}+\mathrm{H}]^{+}}\end{array}$ \\
\hline 2 & $\mathrm{C}_{57} \mathrm{H}_{89} \mathrm{~N}_{20} \mathrm{O}_{13} \mathrm{~S}^{+}$ & 98.6 & 1293.6633 & 1293.660 \\
\hline 3 & $\mathrm{C}_{58} \mathrm{H}_{91} \mathrm{~N}_{20} \mathrm{O}_{13} \mathrm{~S}^{+}$ & $98.2^{\#}$ & 1307.6790 & 1307.674 \\
\hline 4 & $\mathrm{C}_{58} \mathrm{H}_{91} \mathrm{~N}_{20} \mathrm{O}_{13} \mathrm{~S}^{+}$ & 95.2 & 1307.6790 & 1307.676 \\
\hline 5 & $\mathrm{C}_{61} \mathrm{H}_{95} \mathrm{~N}_{20} \mathrm{O}_{13} \mathrm{~S}^{+}$ & $96.3^{\#}$ & 1347.7103 & 1347.705 \\
\hline 6 & $\mathrm{C}_{59} \mathrm{H}_{93} \mathrm{~N}_{20} \mathrm{O}_{13} \mathrm{~S}^{+}$ & $98.9^{\#}$ & 1321.6946 & 1321.690 \\
\hline 7 & $\mathrm{C}_{64} \mathrm{H}_{94} \mathrm{~N}_{19} \mathrm{O}_{14} \mathrm{~S}^{+}$ & $97.5^{\#}$ & 1384.6943 & 1384.689 \\
\hline 8 & $\mathrm{C}_{60} \mathrm{H}_{90} \mathrm{~F}_{3} \mathrm{~N}_{18} \mathrm{O}_{14} \mathrm{~S}^{+}$ & $99.2^{\#}$ & 1375.6551 & 1375.661 \\
\hline 9 & $\mathrm{C}_{58} \mathrm{H}_{90} \mathrm{~N}_{19} \mathrm{O}_{12} \mathrm{~S}^{+}$ & $98.8^{\#}$ & 1276.6732 & 1276.669 \\
\hline 10 & $\mathrm{C}_{56} \mathrm{H}_{88} \mathrm{~N}_{19} \mathrm{O}_{12} \mathrm{~S}^{+}$ & $99.3^{\#}$ & 1282.6296 & 1282.625 \\
\hline 11 & $\mathrm{C}_{56} \mathrm{H}_{88} \mathrm{~N}_{19} \mathrm{O}_{12} \mathrm{~S}^{+}$ & $99.2^{\#}$ & 1282.6296 & 1282.626 \\
\hline $12 \mathrm{c}$ & $\mathrm{C}_{69} \mathrm{H}_{107} \mathrm{~N}_{24} \mathrm{O}_{15} \mathrm{~S}_{2}{ }^{+}$ & 96.9 & 1575.7789 & 1575.773 \\
\hline 13c & $\mathrm{C}_{69} \mathrm{H}_{107} \mathrm{~N}_{24} \mathrm{O}_{15} \mathrm{~S}_{2}{ }^{+}$ & 98.6 & 1575.7789 & 1575.773 \\
\hline $14 c$ & $\mathrm{C}_{69} \mathrm{H}_{110} \mathrm{~N}_{25} \mathrm{O}_{15} \mathrm{~S}_{2}{ }^{+}$ & 96.5 & 1592.8055 & 1592.800 \\
\hline 15 & $\mathrm{C}_{73} \mathrm{H}_{114} \mathrm{~N}_{25} \mathrm{O}_{15} \mathrm{~S}_{2}{ }^{+}$ & $98.4^{\#}$ & 1644.8362 & 1644.830 \\
\hline 16 & $\mathrm{C}_{73} \mathrm{H}_{114} \mathrm{~N}_{25} \mathrm{O}_{15} \mathrm{~S}_{2}{ }^{+}$ & $99.0^{\#}$ & 1644.8362 & 1644.831 \\
\hline 17 & $\mathrm{C}_{73} \mathrm{H}_{114} \mathrm{~N}_{25} \mathrm{O}_{15} \mathrm{~S}_{2}{ }^{+}$ & 98.7 & 1644.8362 & 1644.831 \\
\hline 18 & $\mathrm{C}_{73} \mathrm{H}_{114} \mathrm{~N}_{25} \mathrm{O}_{15} \mathrm{~S}_{2}{ }^{+}$ & $98.1^{\#}$ & 1644.8362 & 1644.832 \\
\hline 19 & $\mathrm{C}_{73} \mathrm{H}_{114} \mathrm{~N}_{25} \mathrm{O}_{15} \mathrm{~S}_{2}{ }^{+}$ & 98.3 & 1644.8362 & 1644.830 \\
\hline FAM-19 & $\mathrm{C}_{95} \mathrm{H}_{128} \mathrm{~N}_{27} \mathrm{O}_{20} \mathrm{~S}_{3}{ }^{+}$ & $97.8^{\#}$ & 2062.8986 & 2062.907 \\
\hline 20 & $\mathrm{C}_{73} \mathrm{H}_{114} \mathrm{~N}_{25} \mathrm{O}_{15} \mathrm{~S}_{2}{ }^{+}$ & 96.3 & 1644.8362 & 1644.832 \\
\hline 21c & $\mathrm{C}_{74} \mathrm{H}_{115} \mathrm{~N}_{24} \mathrm{O}_{14} \mathrm{~S}_{2}{ }^{+}$ & 97.2 & 1627.8466 & 1627.852 \\
\hline $22 c$ & $\mathrm{C}_{74} \mathrm{H}_{114} \mathrm{~N}_{23} \mathrm{O}_{14} \mathrm{~S}_{3}{ }^{+}$ & 95.6 & 1644.8078 & 1644.814 \\
\hline FAM-22 & $\mathrm{C}_{99} \mathrm{H}_{135} \mathrm{~N}_{24} \mathrm{O}_{22} \mathrm{~S}_{3}{ }^{+}$ & $99.1^{\#}$ & 2107.9339 & 2107.946 \\
\hline 23 & $\mathrm{C}_{73} \mathrm{H}_{112} \mathrm{~N}_{23} \mathrm{O}_{14} \mathrm{~S}_{3}{ }^{+}$ & $99.4^{\#}$ & 1630.7910 & 1630.784 \\
\hline FAM-23 & $\mathrm{C}_{98} \mathrm{H}_{132} \mathrm{~N}_{25} \mathrm{O}_{21} \mathrm{~S}_{4}{ }^{+}$ & $97.6^{\#}$ & 2122.8912 & 2122.898 \\
\hline $24 c$ & $\mathrm{C}_{74} \mathrm{H}_{112} \mathrm{~N}_{23} \mathrm{O}_{14} \mathrm{~S}_{3}{ }^{+}$ & 95.8 & 1642.7921 & 1642.797 \\
\hline FAM-24 & $\mathrm{C}_{99} \mathrm{H}_{134} \mathrm{~N}_{25} \mathrm{O}_{21} \mathrm{~S}_{4}{ }^{+}$ & $98.8^{\#}$ & 2136.9063 & 2136.899 \\
\hline
\end{tabular}

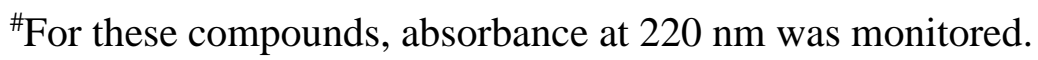

Table S2: Docking scores for C-terminal hydrophobic substitutions

\begin{tabular}{|l|c|}
\hline C-Terminal Residue & Docking Score \\
\hline tert-L-leucine & -9.114 \\
\hline 3-cyclohexyl-L-alanine & -8.592 \\
\hline L-valine & -8.012 \\
\hline L-isoleucine & -7.799 \\
\hline 2-phenyl-L-glycine & -6.787 \\
\hline 2-cyclohexyl-L-glycine & -6.779 \\
\hline 3-cyclopropyl-L-alanine & -5.257 \\
\hline L-phenylalanine & -4.055 \\
\hline L-alanine & -1.932 \\
\hline
\end{tabular}


Figure S1. Structures, purity and MS data of peptides used in the work. Peptide purity was assessed to be $\geq 95 \%$ by reverse-phase HPLC or UPLC equipped with an analytical $\mathrm{C}_{18}$ column eluted with linear gradients of $\mathrm{CH}_{3} \mathrm{CN}$ in water containing $0.05 \%$ TFA (monitored at $214 \mathrm{~nm}$ or $220 \mathrm{~nm}$ ). The authenticity of peptides was confirmed by high-resolution mass spectrometry (HR-MS) on a MALDI-FT-ICR instrument.

\section{Compound 2}

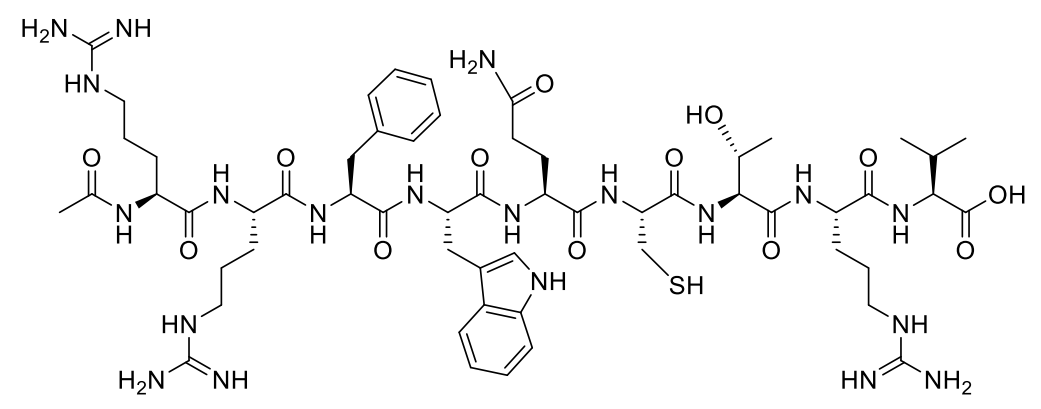

Purity assessment by analytical HPLC (214 $\mathrm{nm})$ :

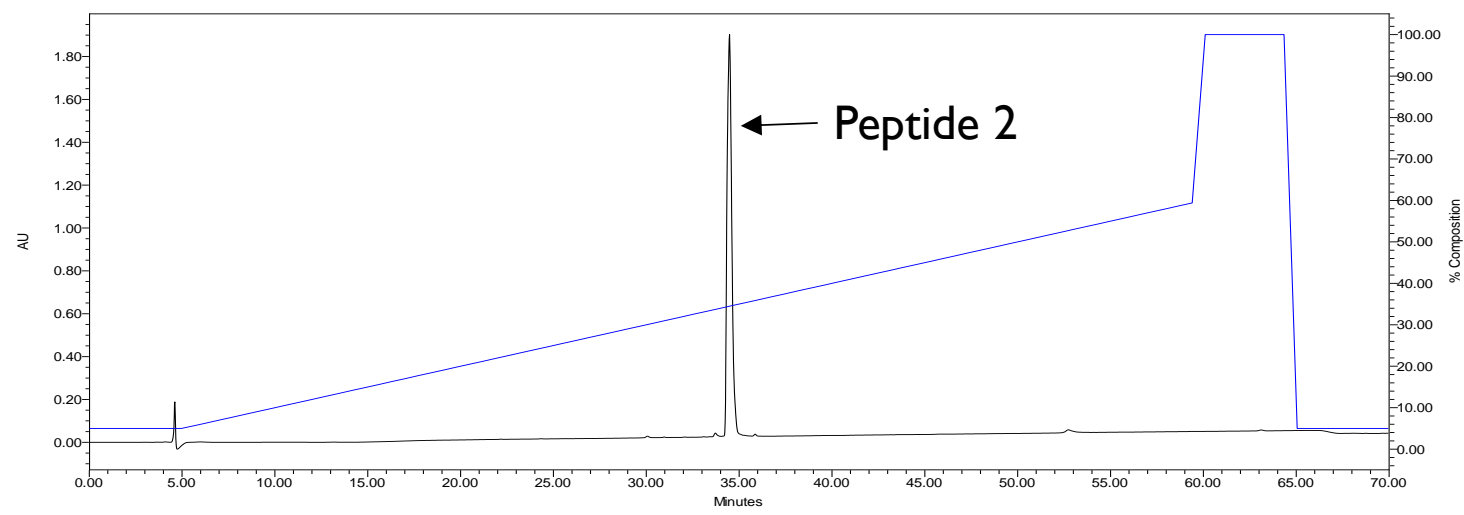

HR-MS: Calculated $[\mathrm{M}+\mathrm{H}]^{+}$1293.6633, found 1293.6605

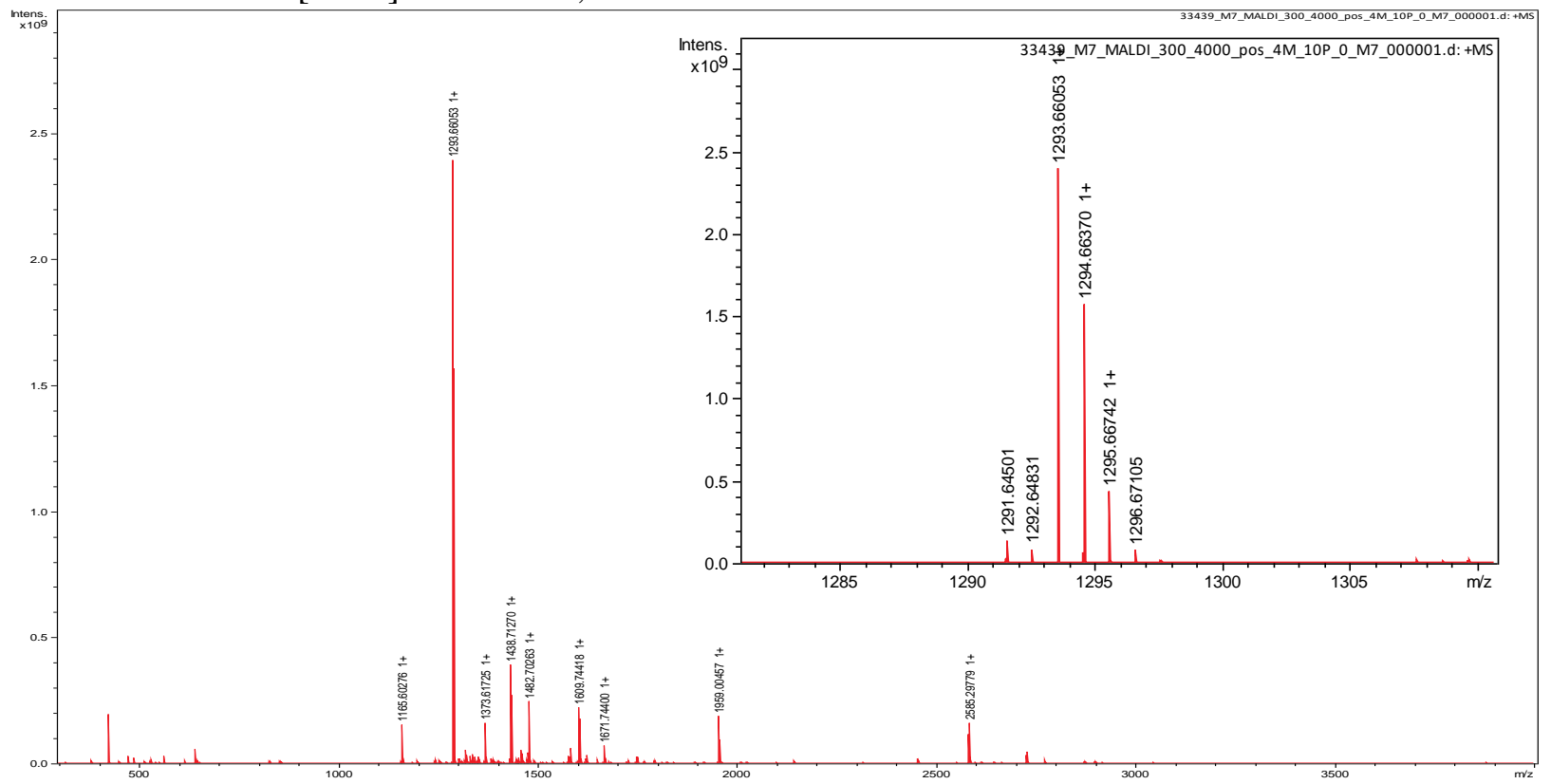




\section{Compound $\mathbf{3}$}

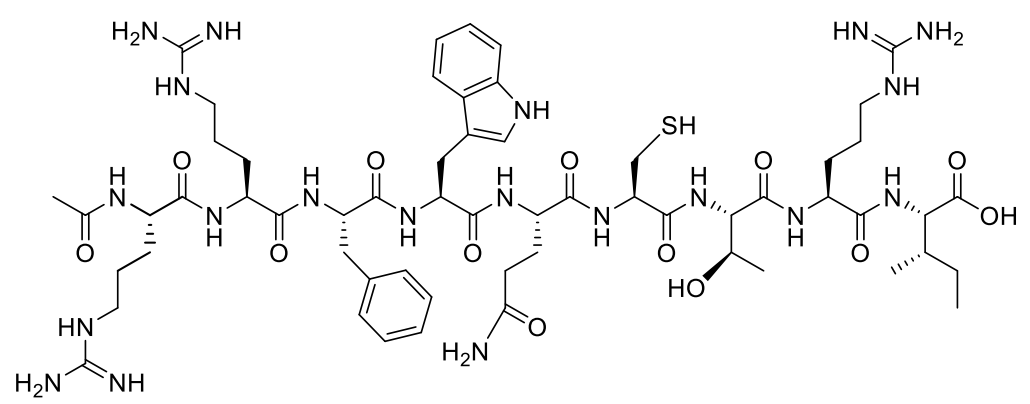

Purity assessment by UPLC (220 nm):

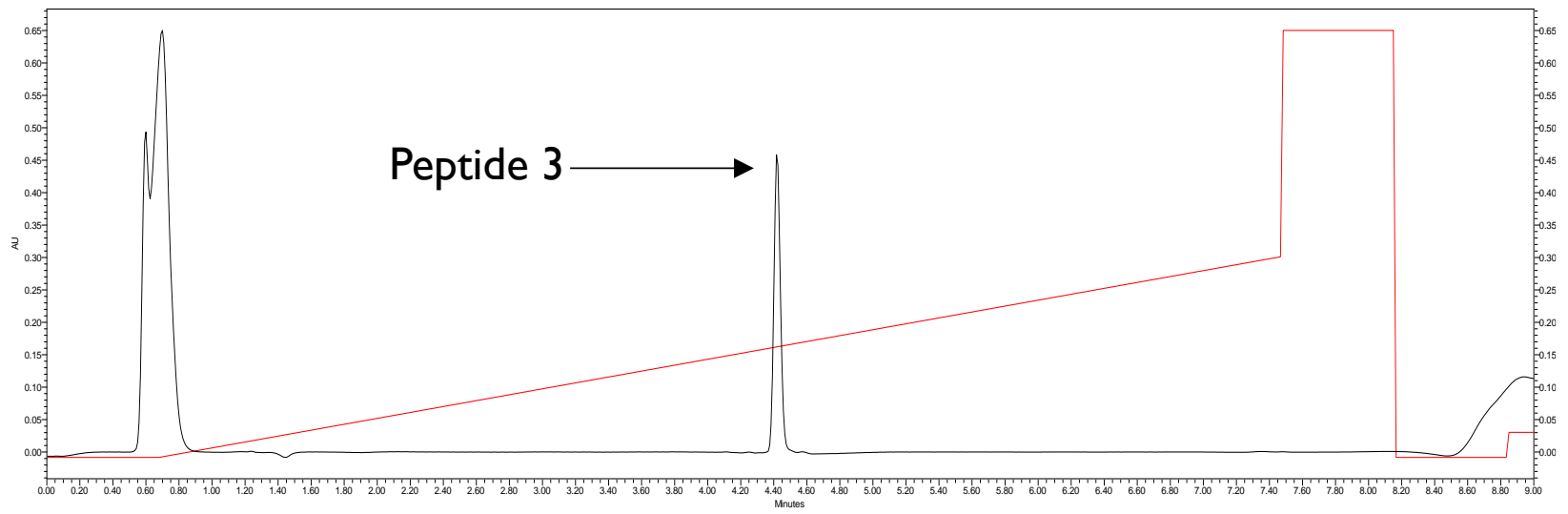

HR-MS: Calculated $[\mathrm{M}+\mathrm{H}]^{+}$1307.679, found 1307.674

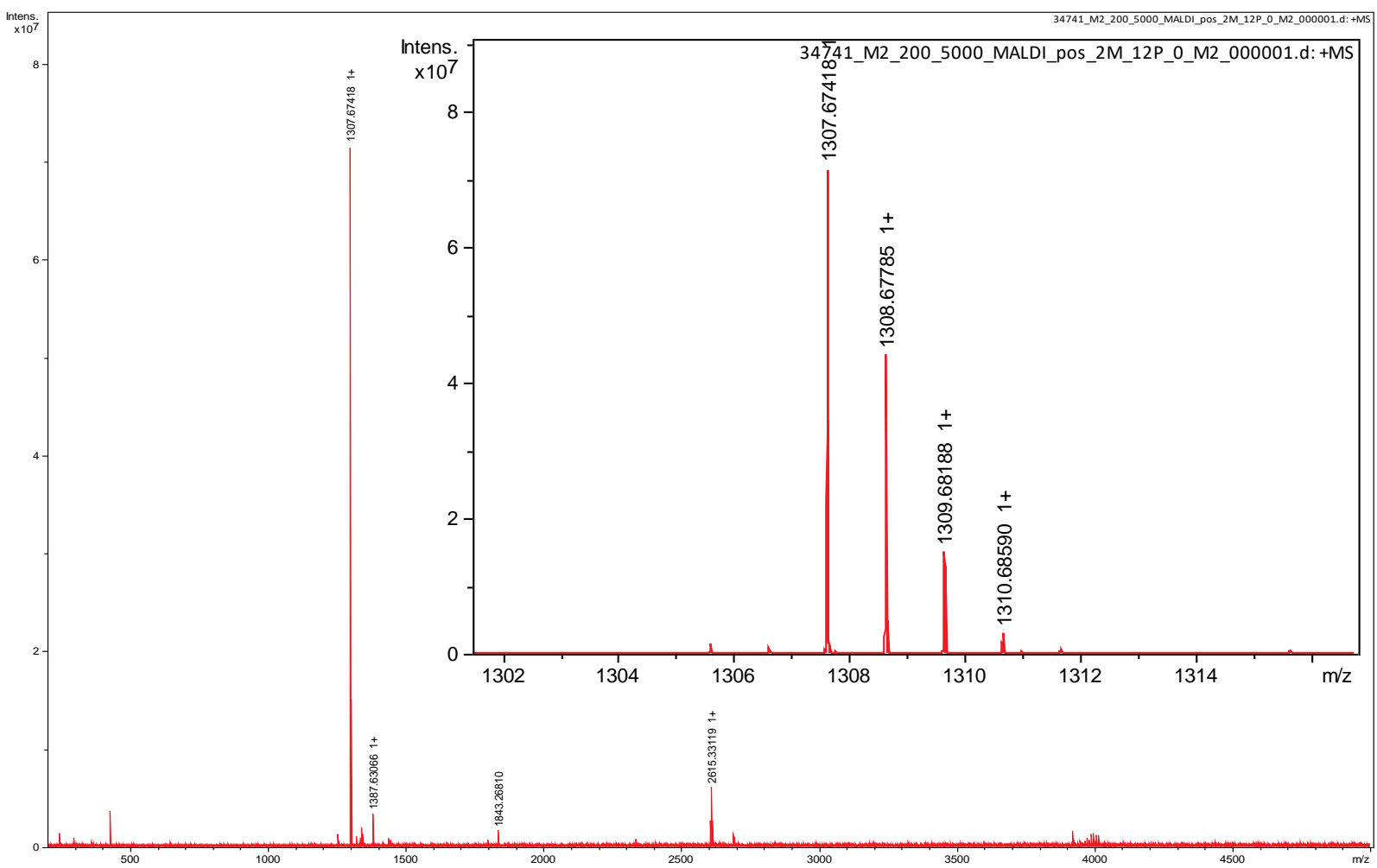




\section{Compound 4}

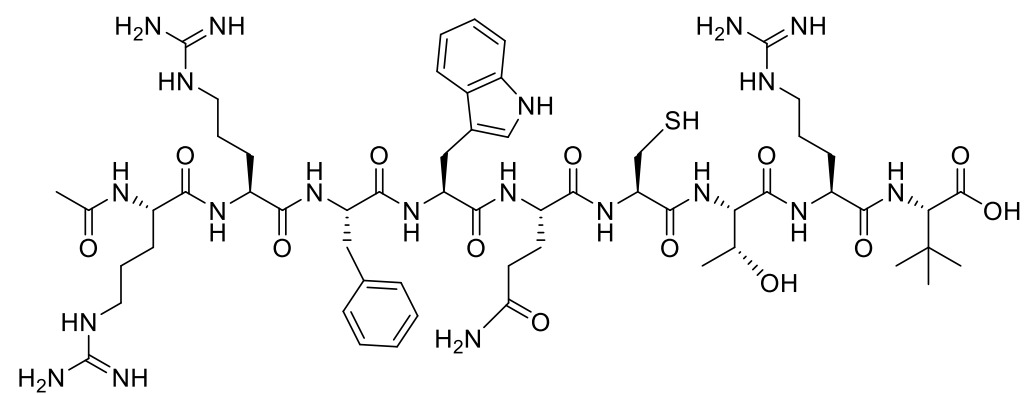

Purity assessment by analytical HPLC (214 nm):

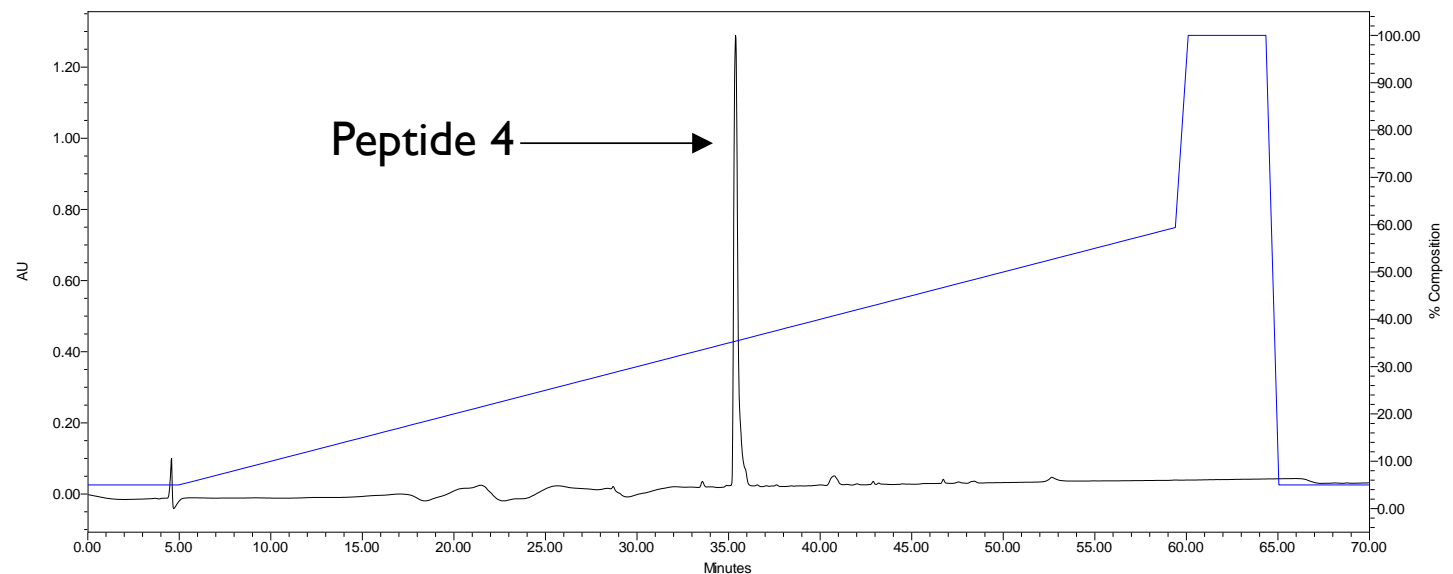

HR-MS: Calculated $[\mathrm{M}+\mathrm{H}]^{+} 1307.6790$, found 1307.6759

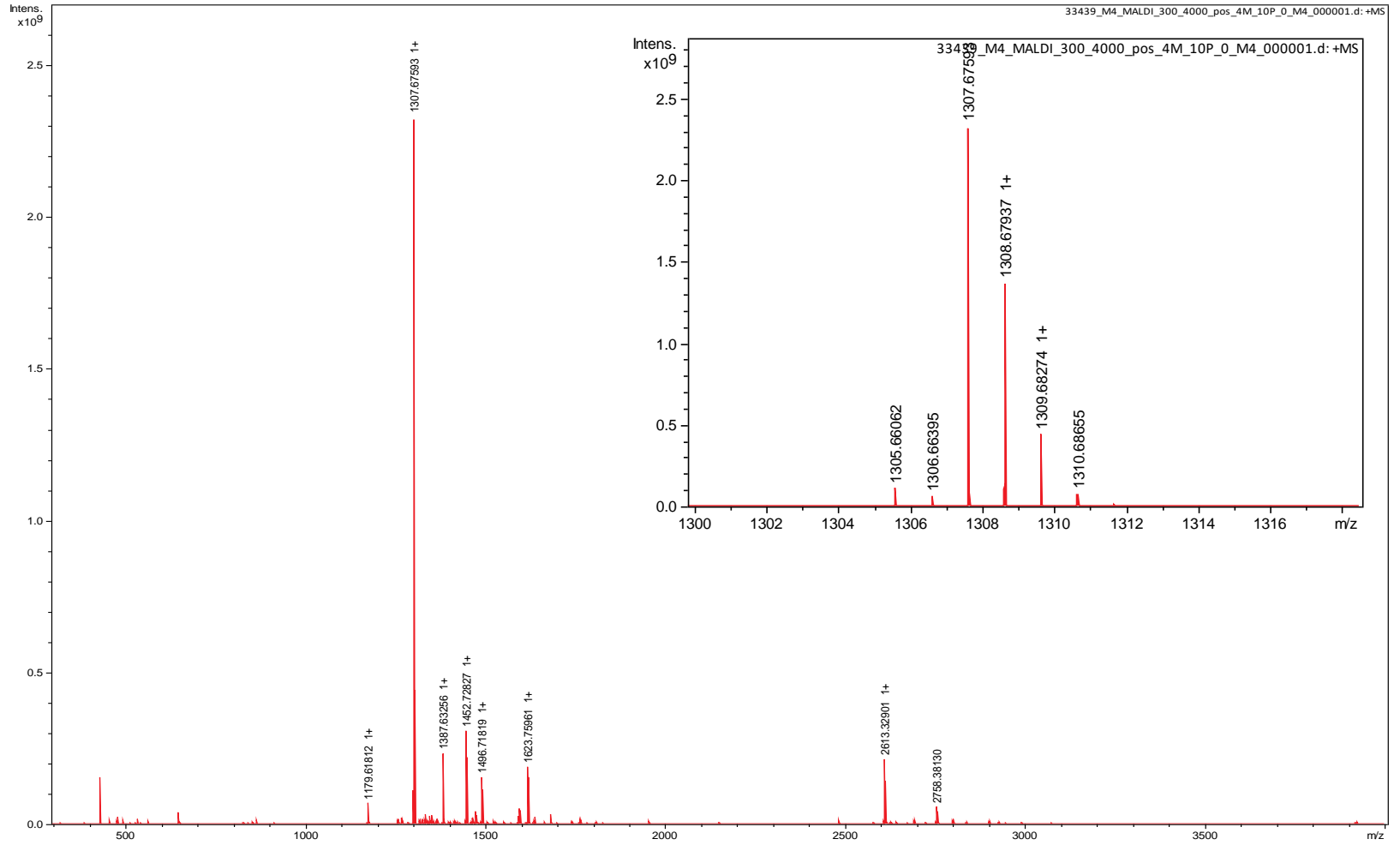




\section{Compound 5}

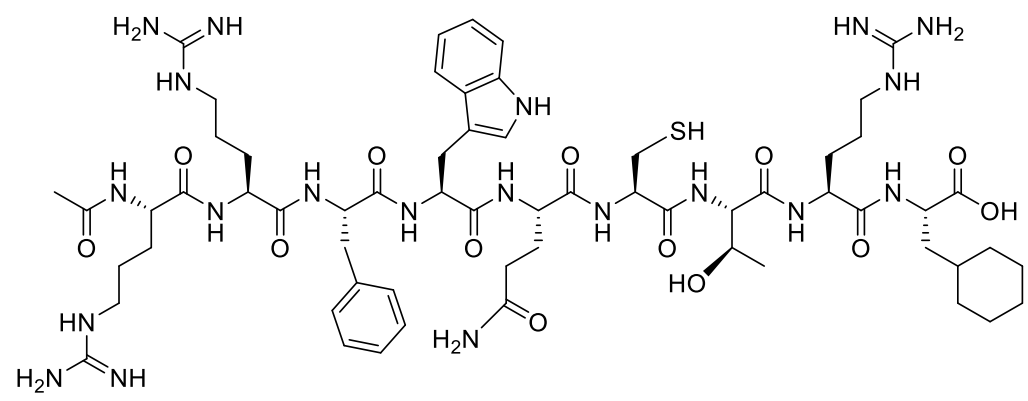

Purity assessment by UPLC (220 nm):

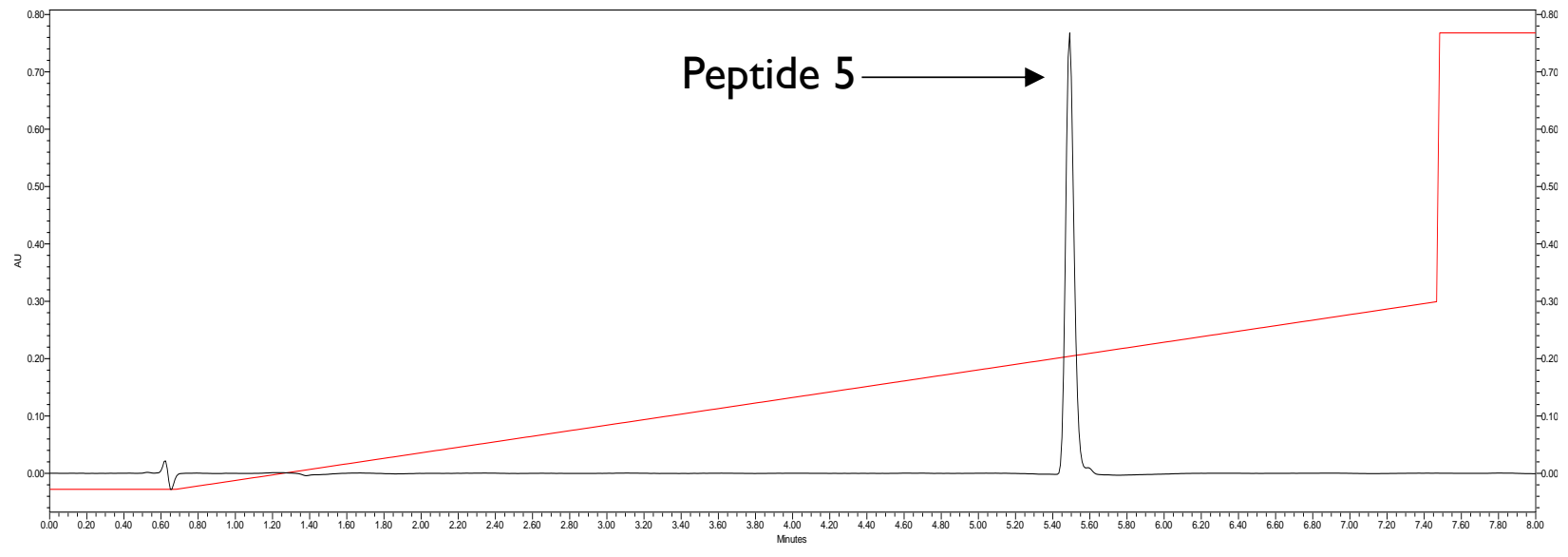

HR-MS: Calculated $[\mathrm{M}+\mathrm{H}]^{+} 1347.7103$, found 1347.7055

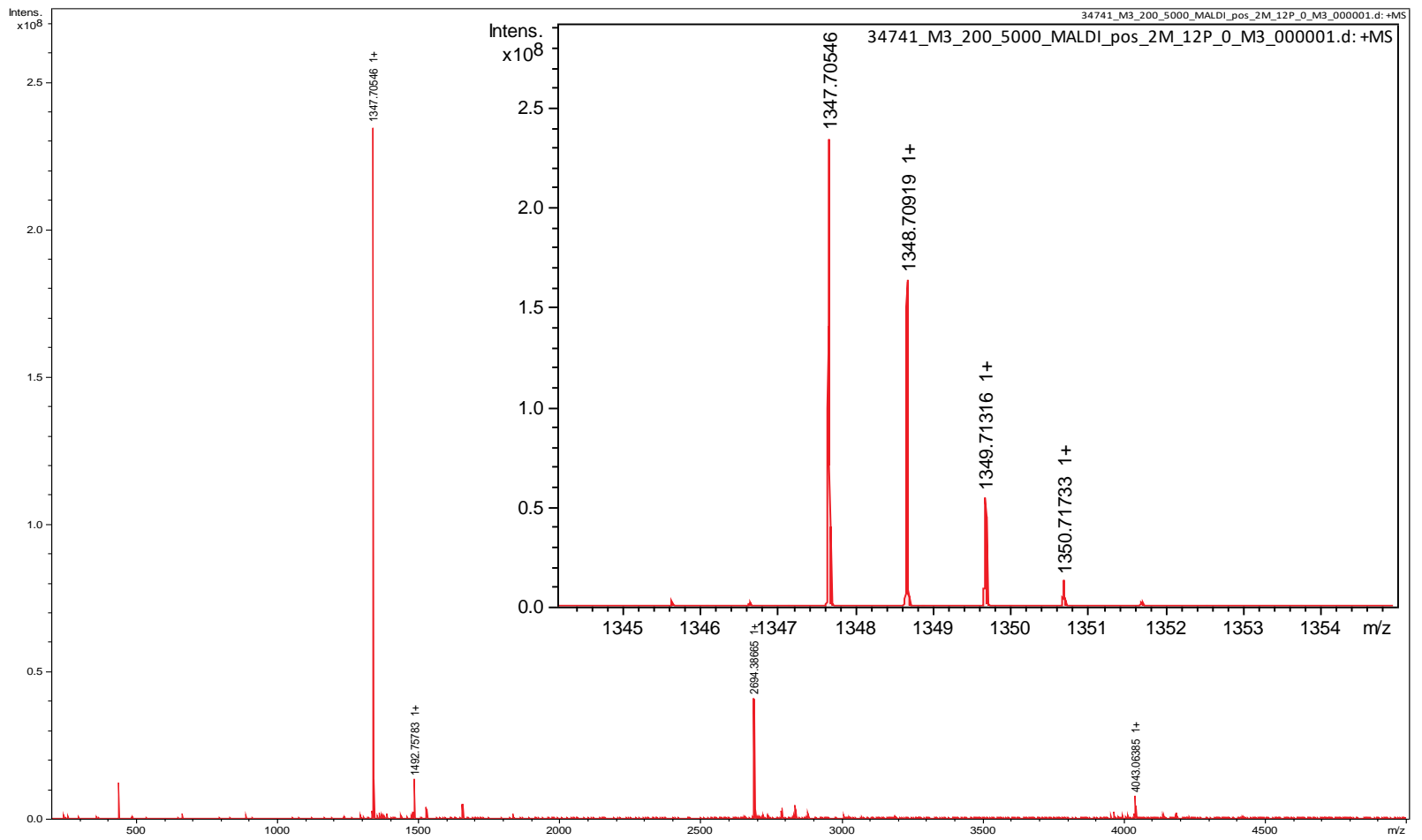




\section{Compound 6}

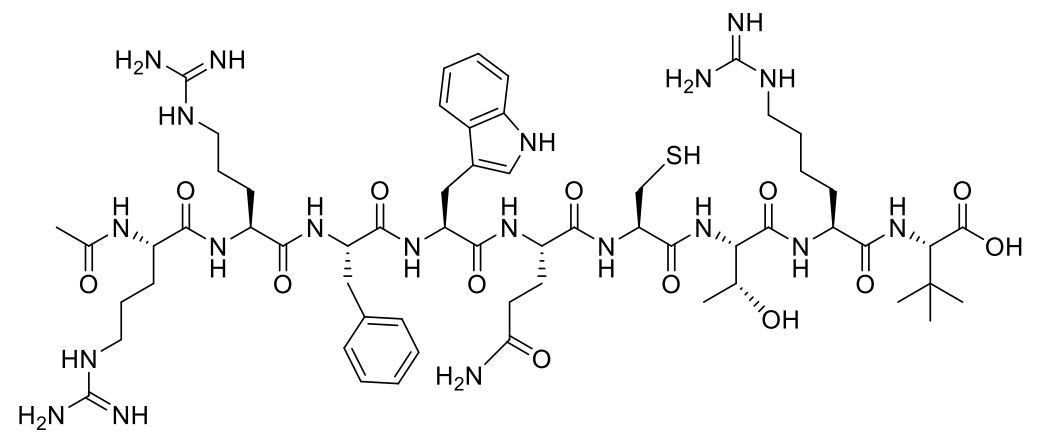

Purity assessment by UPLC $(220 \mathrm{~nm})$ :

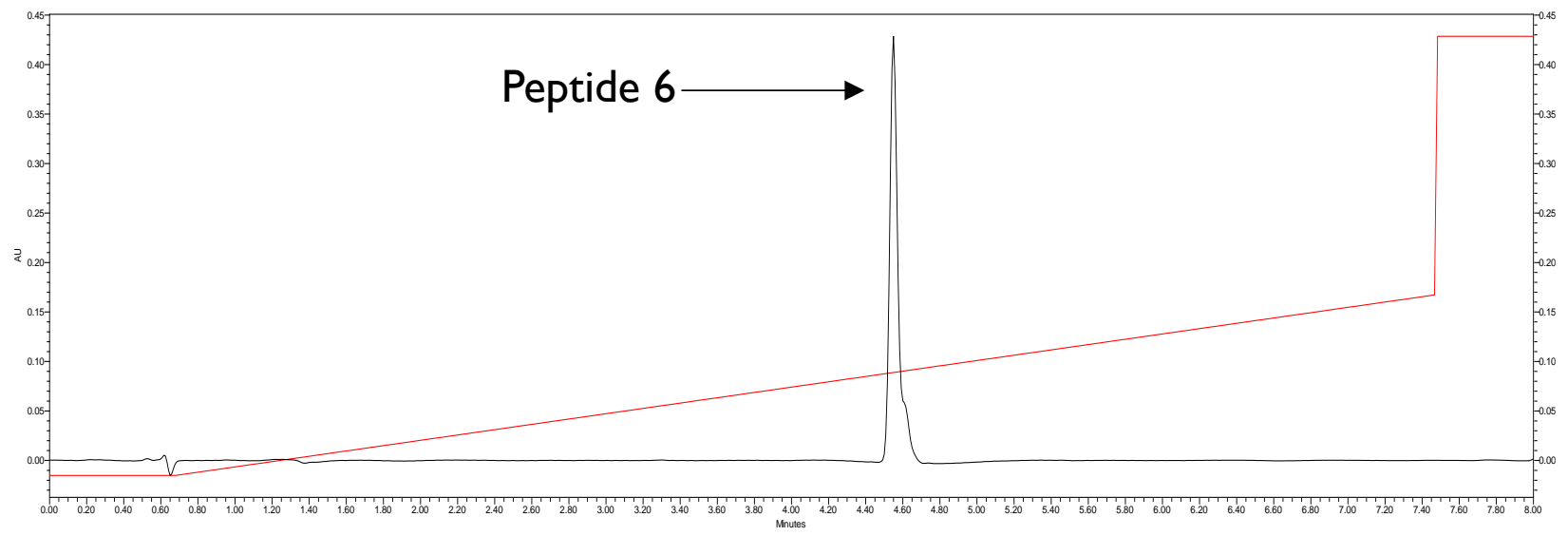

HR-MS: Calculated [M+H] ${ }^{+}$1321.6946, found 1321.6898

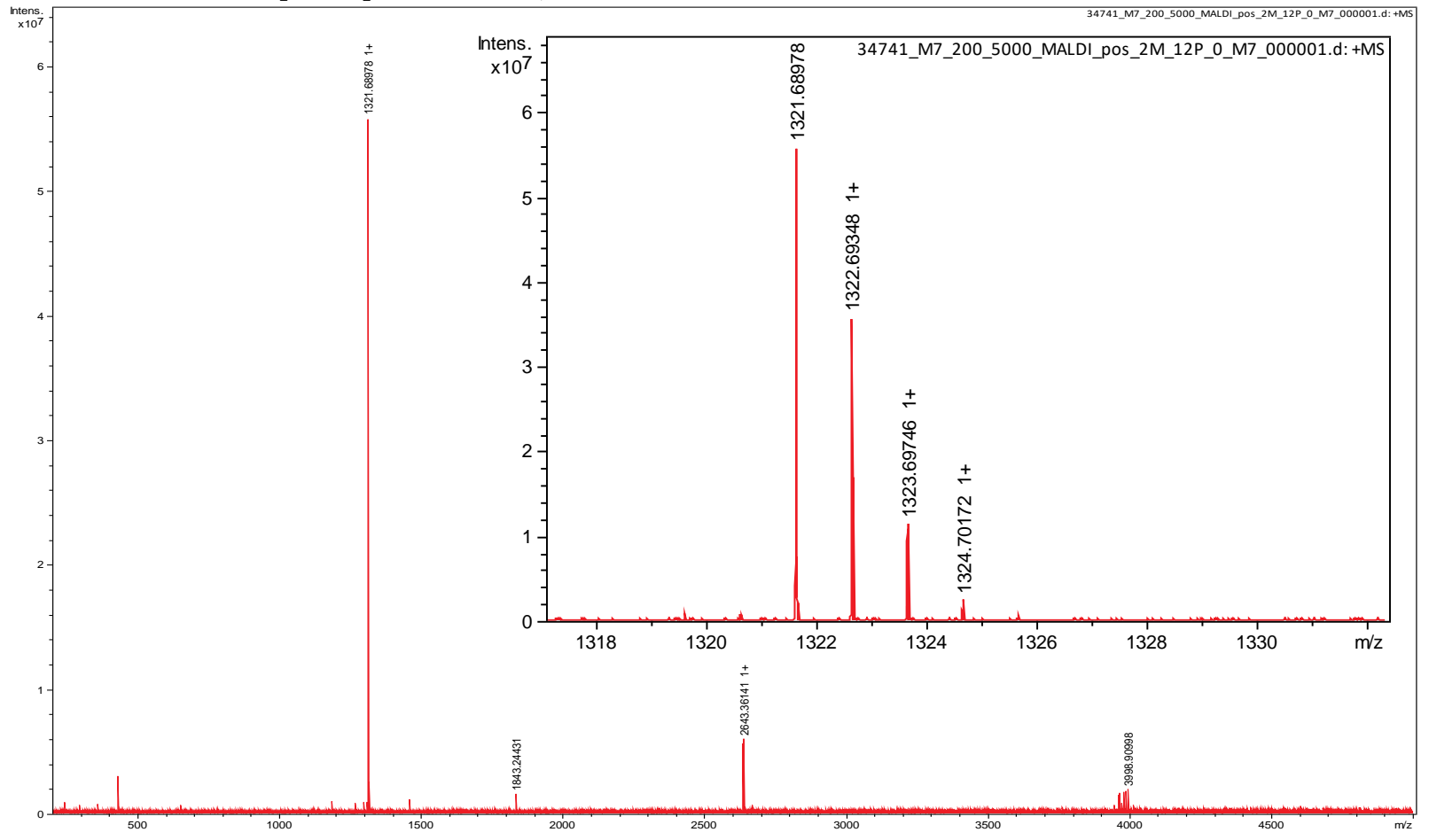




\section{Compound 7}

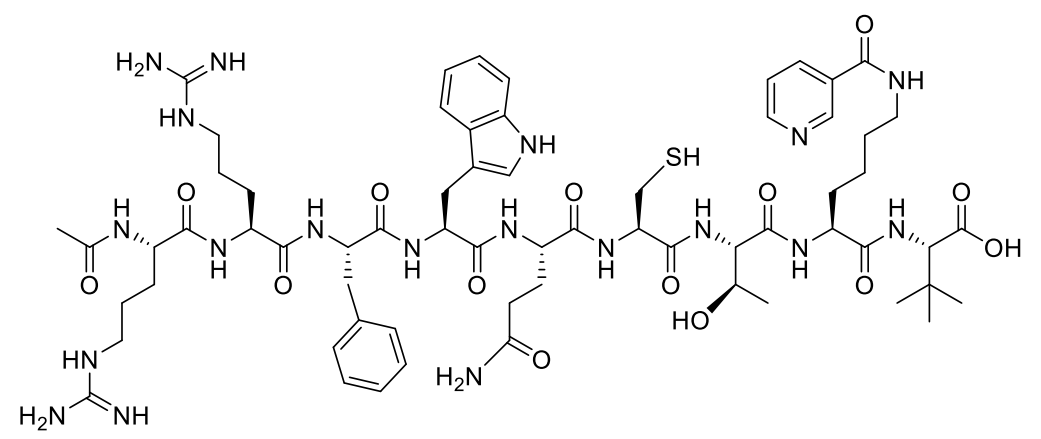

Purity assessment by UPLC (220 nm):

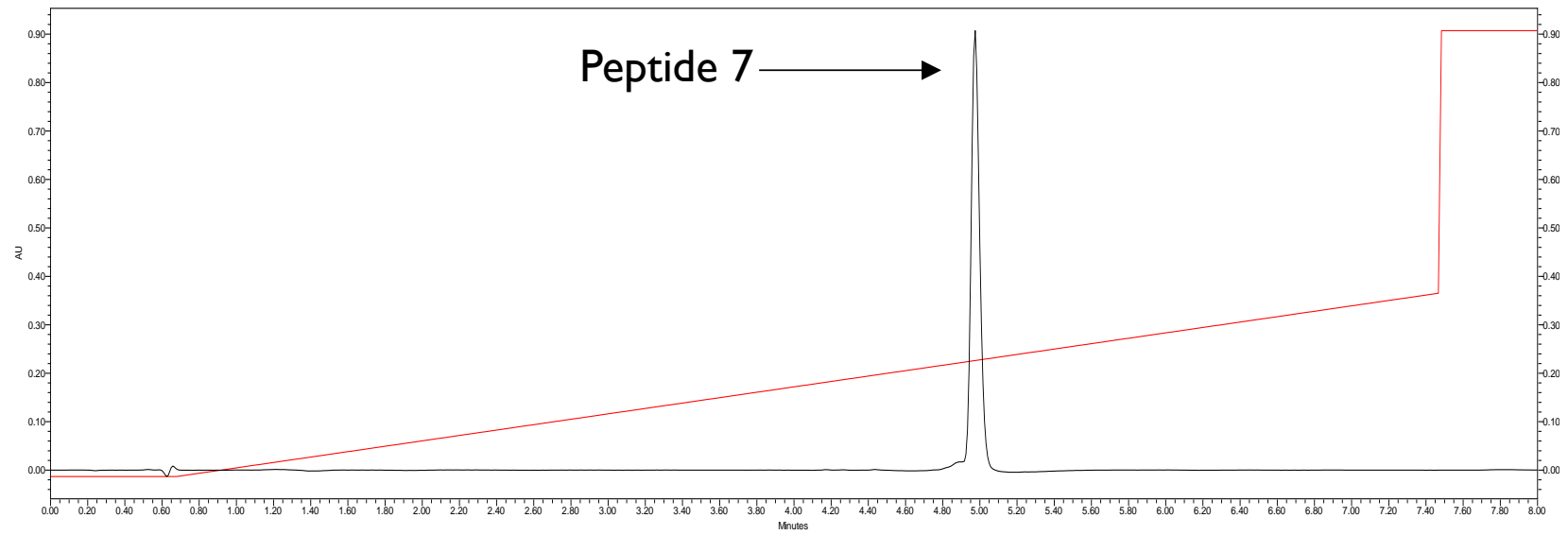

HR-MS: Calculated $[\mathrm{M}+\mathrm{H}]^{+}$1384.6943, found 1384.6895

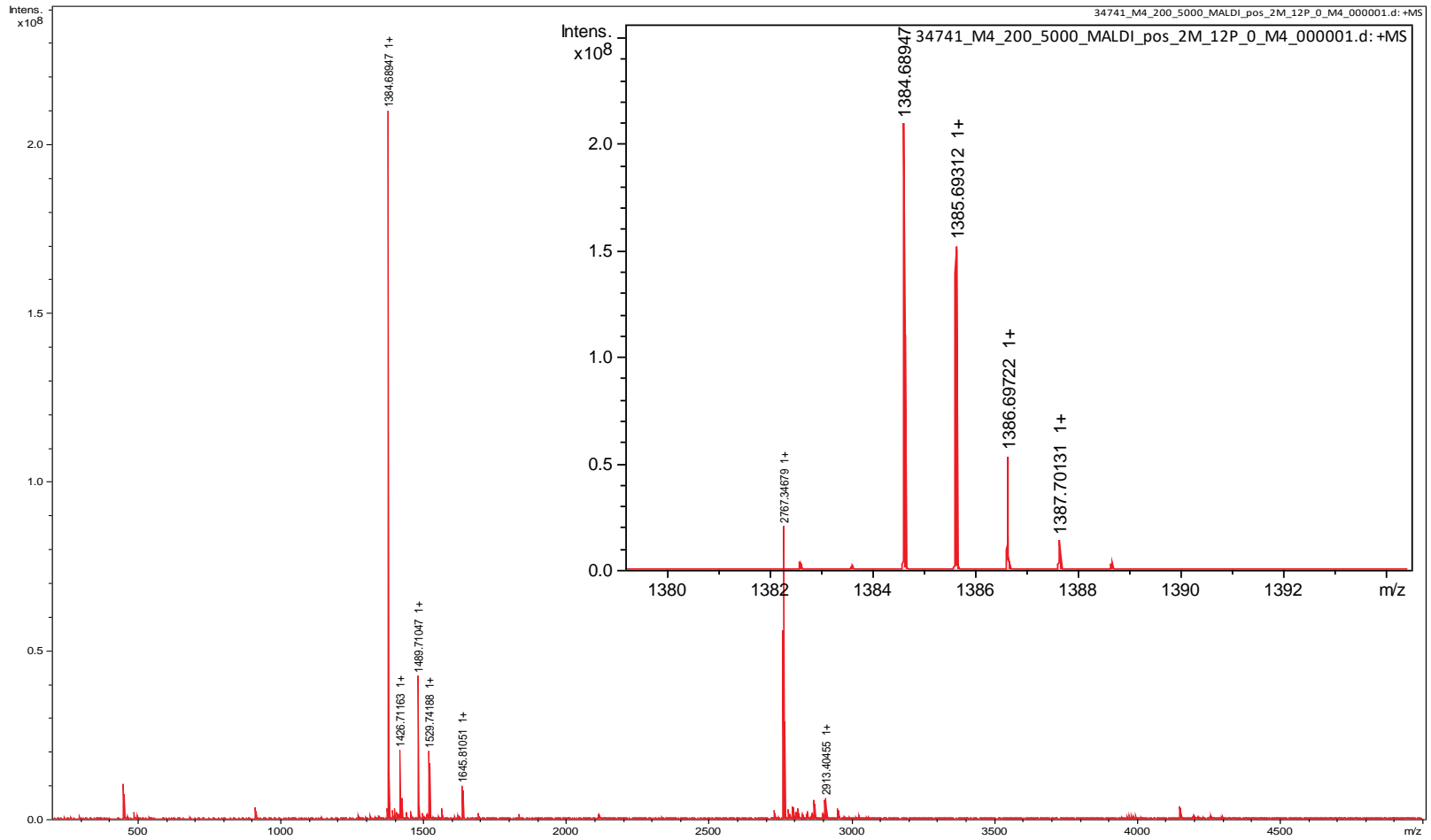




\section{Compound 8}

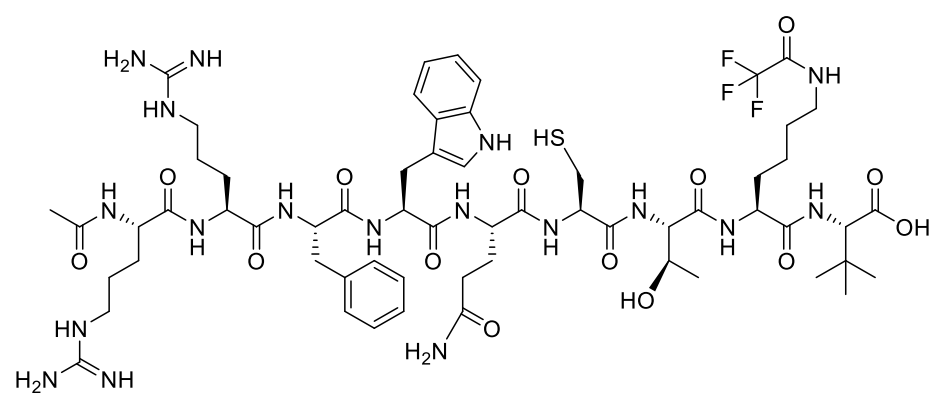

Purity assessment by UPLC $(220 \mathrm{~nm})$ :

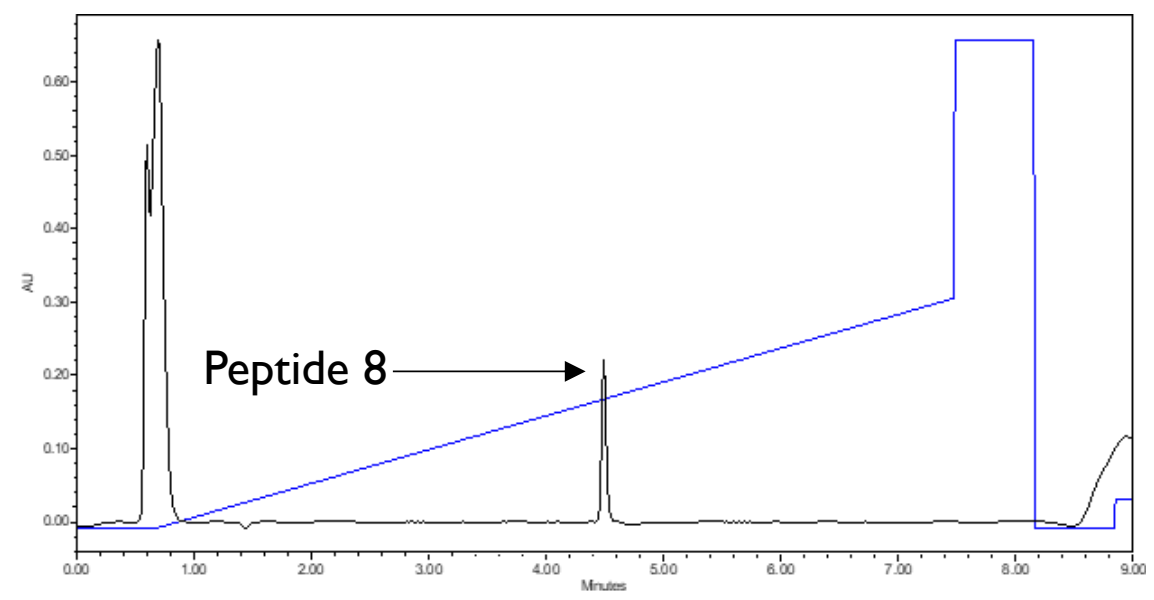

HR-MS: Calculated $[\mathrm{M}+\mathrm{H}]^{+}$1375.6551, found 1375.6606

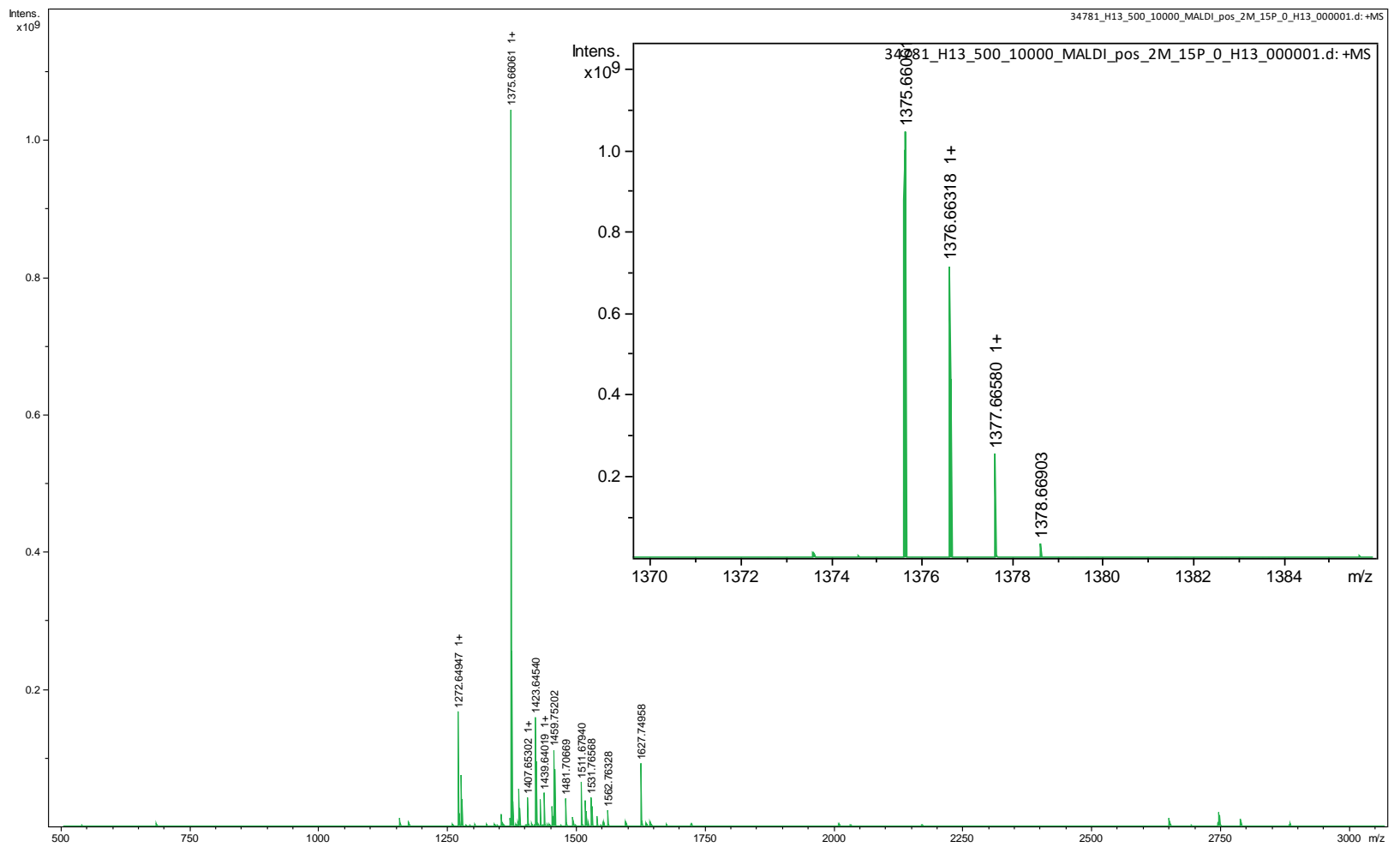




\section{Compound 9}<smiles>CC(=O)N[C@@H](CCCNC(=N)N)C(=O)N[C@@H](CCCNC(=N)N)C(=O)NC(Cc1ccccc1)C(=O)N[C@@H](Cc1c[nH]c2ccccc12)C(=O)N1CCC[C@H]1C(=O)N[C@@H](CS)C(=O)N[C@H](C(=O)N[C@H](CCCNC(=N)N)C(=O)NC(C(=O)O)C(C)(C)C)C(C)O</smiles>

Purity assessment by UPLC (220 nm):

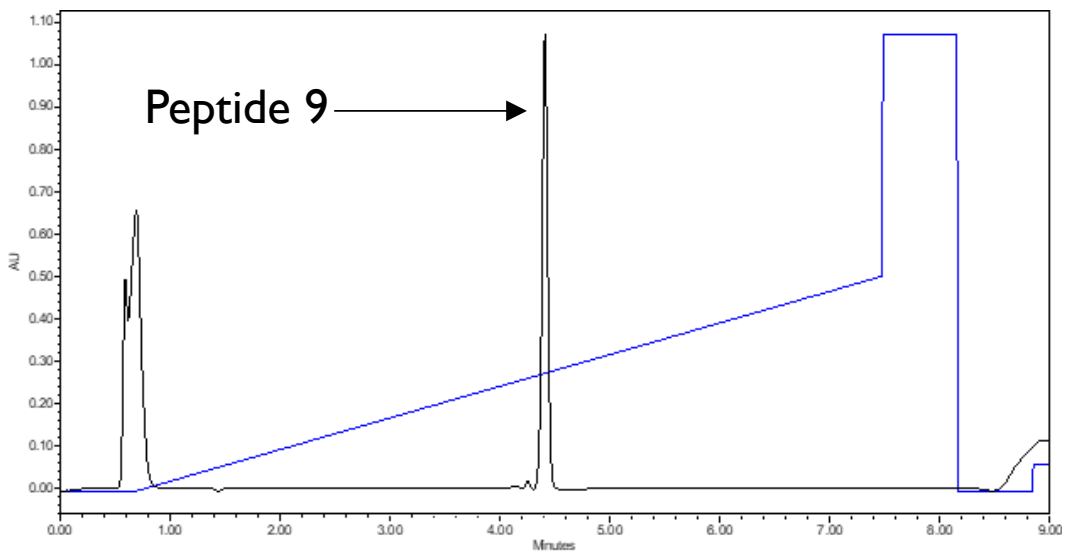

HR-MS: Calculated [M+H] $]^{+}$1276.6732, found 1276.6693

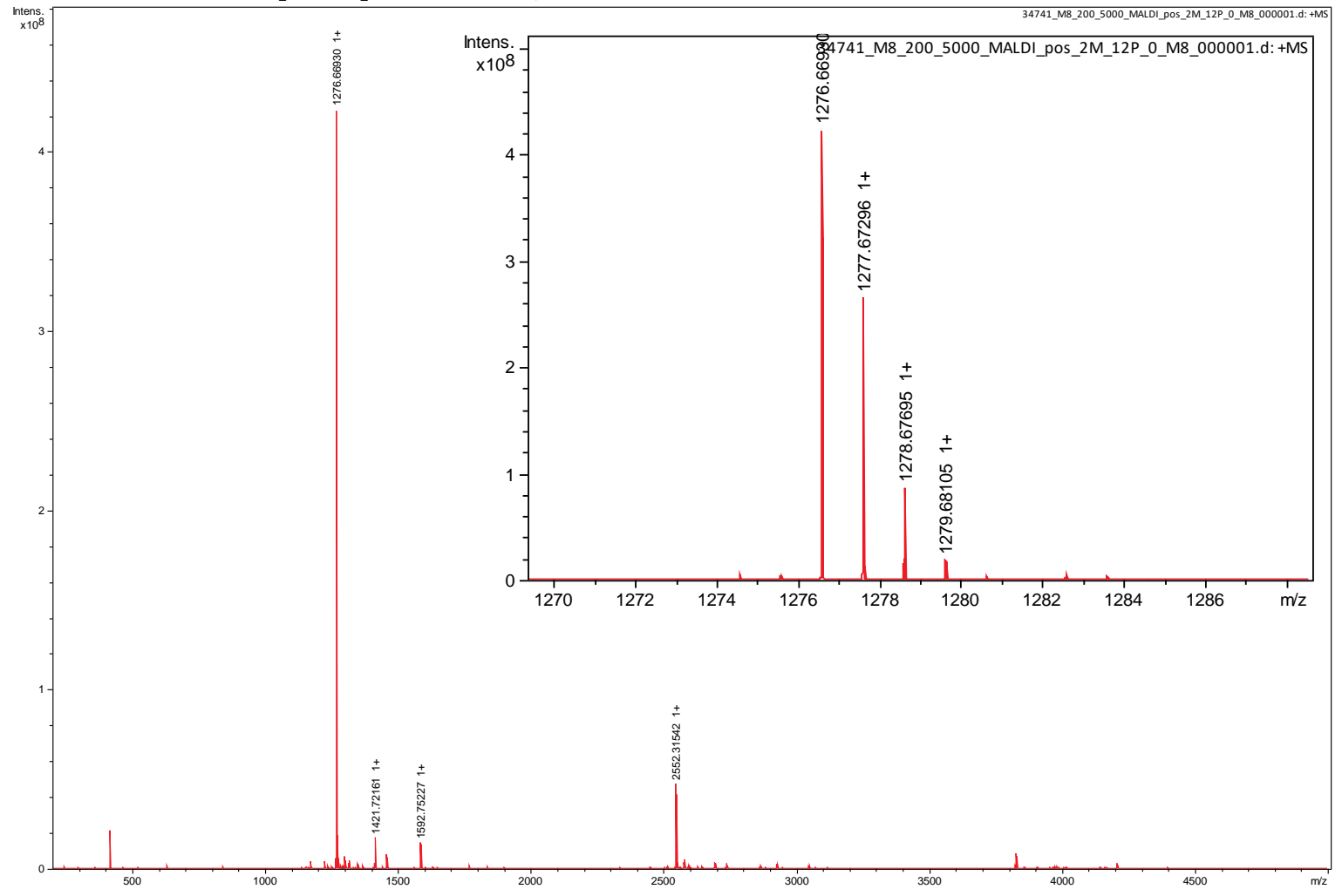




\section{Compound 10}

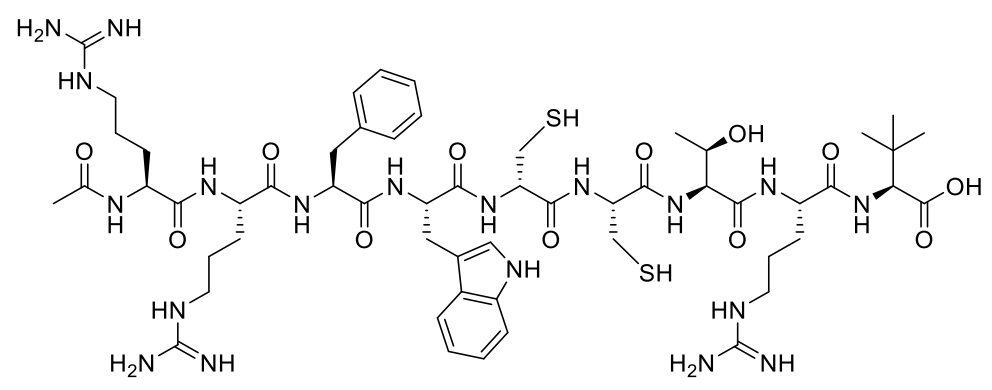

Purity assessment by UPLC (220 nm):

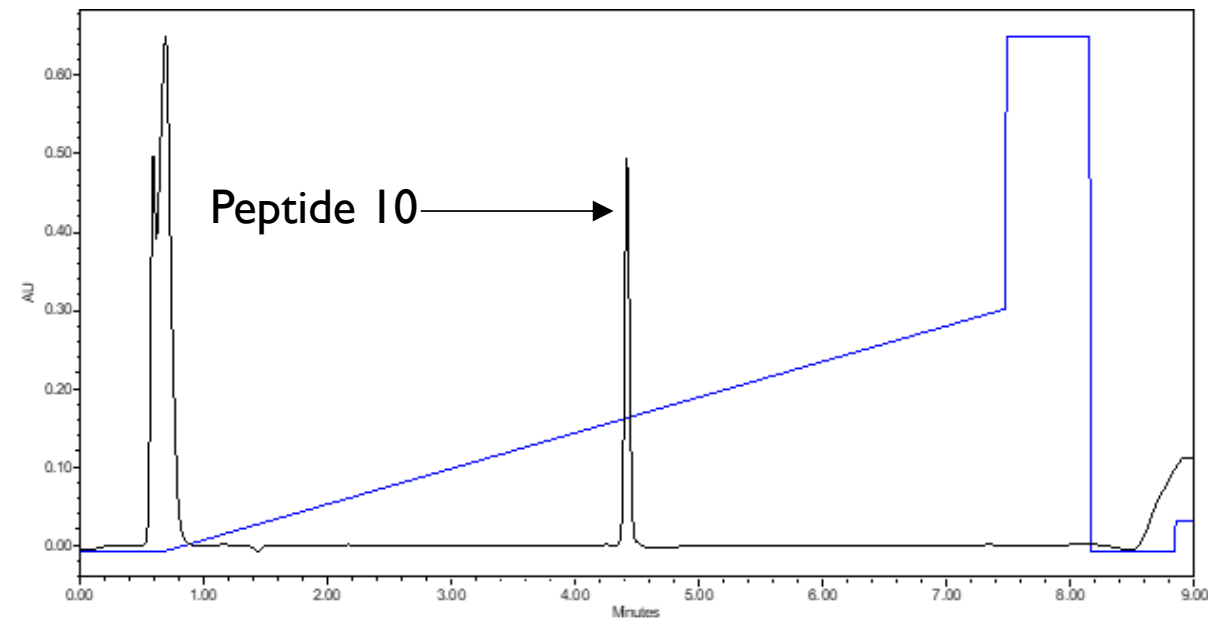

HR-MS: Calculated $[\mathrm{M}+\mathrm{H}]^{+}$1282.6296, found 1282.6255

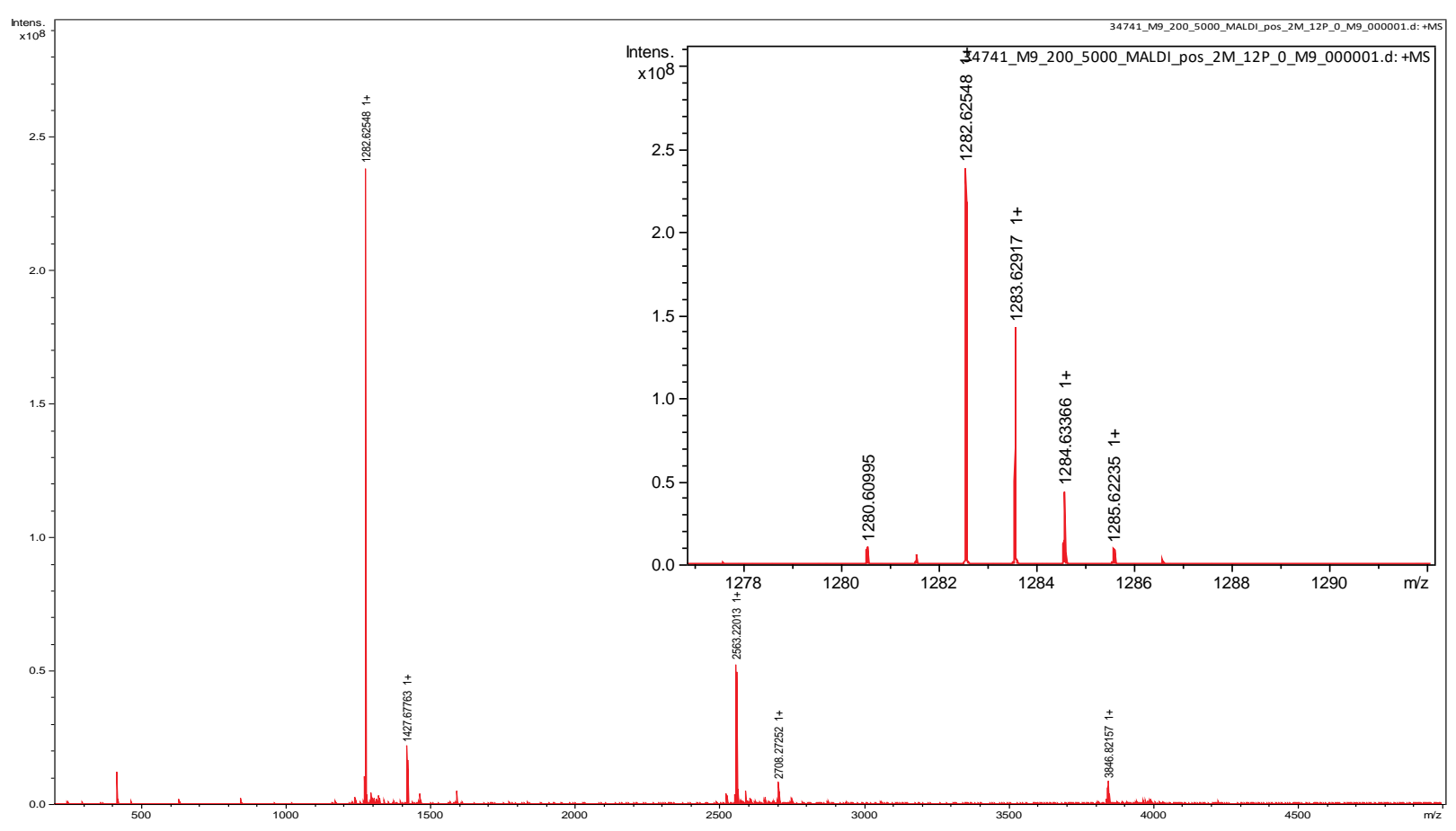




\section{Compound 11}

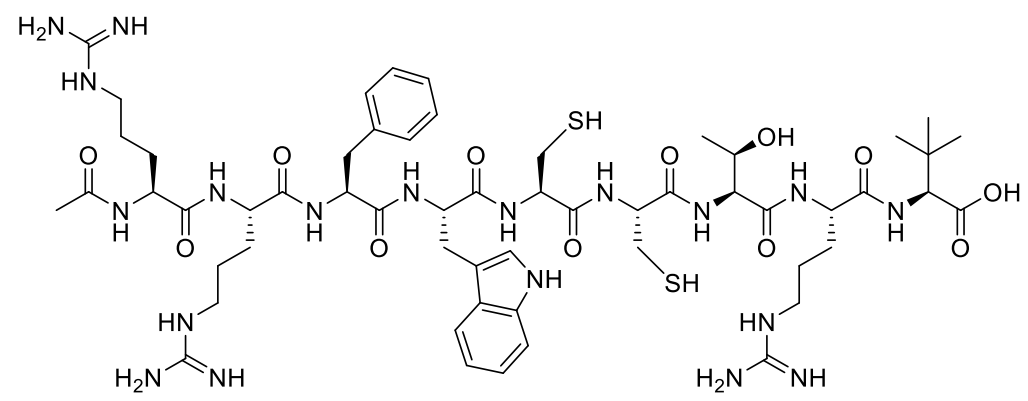

Purity assessment by UPLC ( $220 \mathrm{~nm})$ :

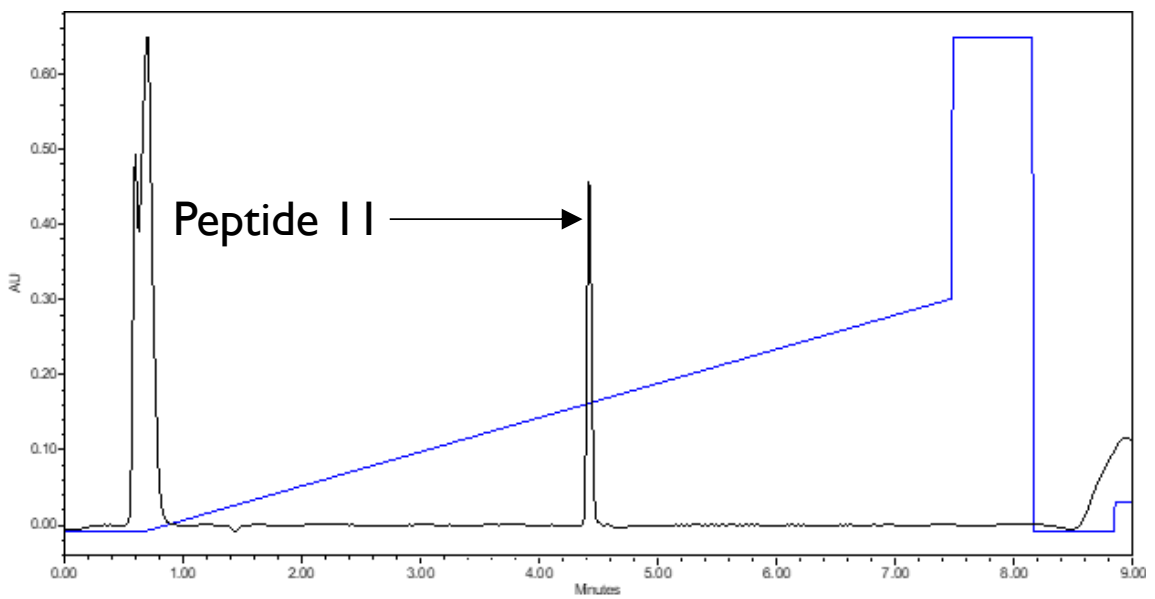

HR-MS: Calculated $[\mathrm{M}+\mathrm{H}]^{+}$1282.6296, found 1282.6262

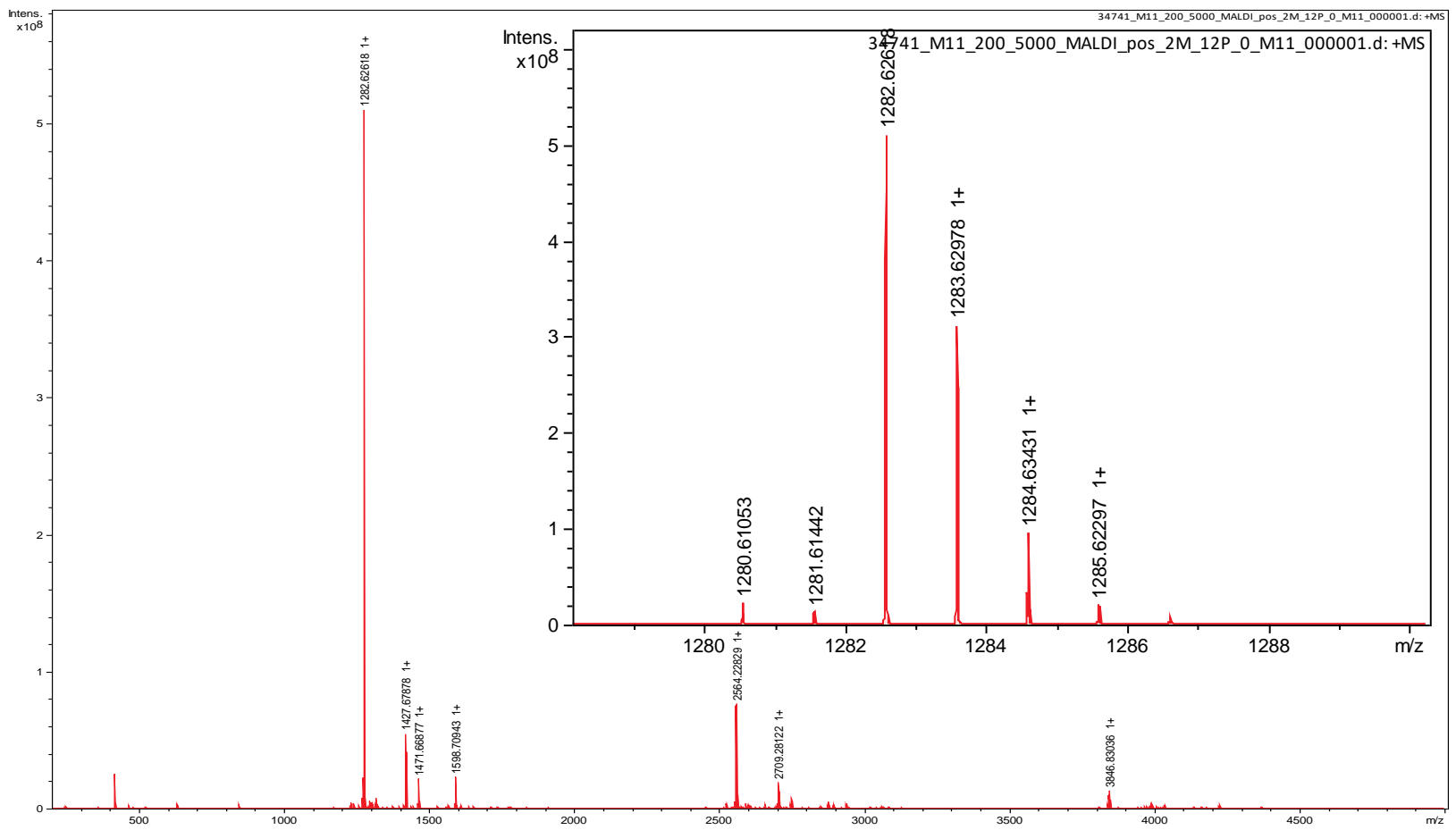




\section{Compound 12c}

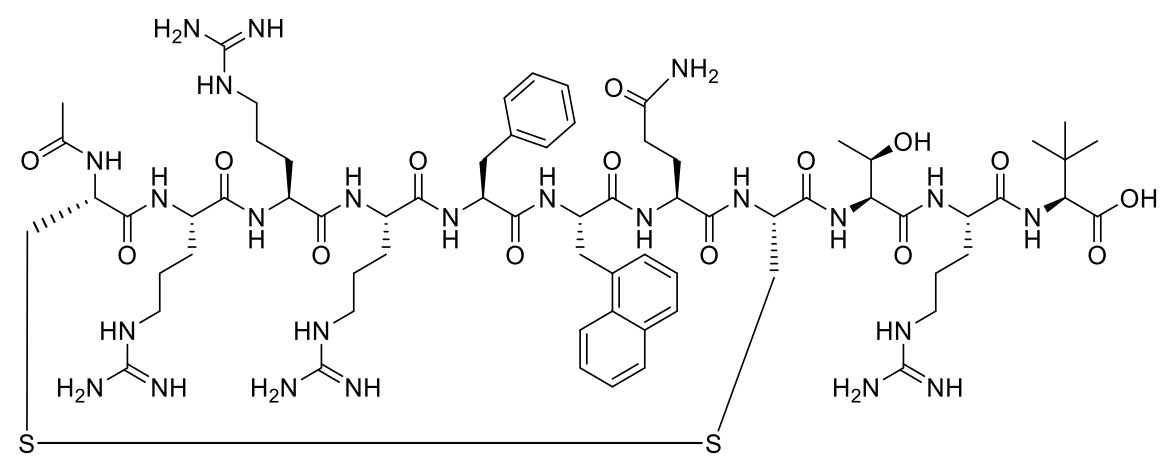

Purity assessment by analytical HPLC (214 nm):

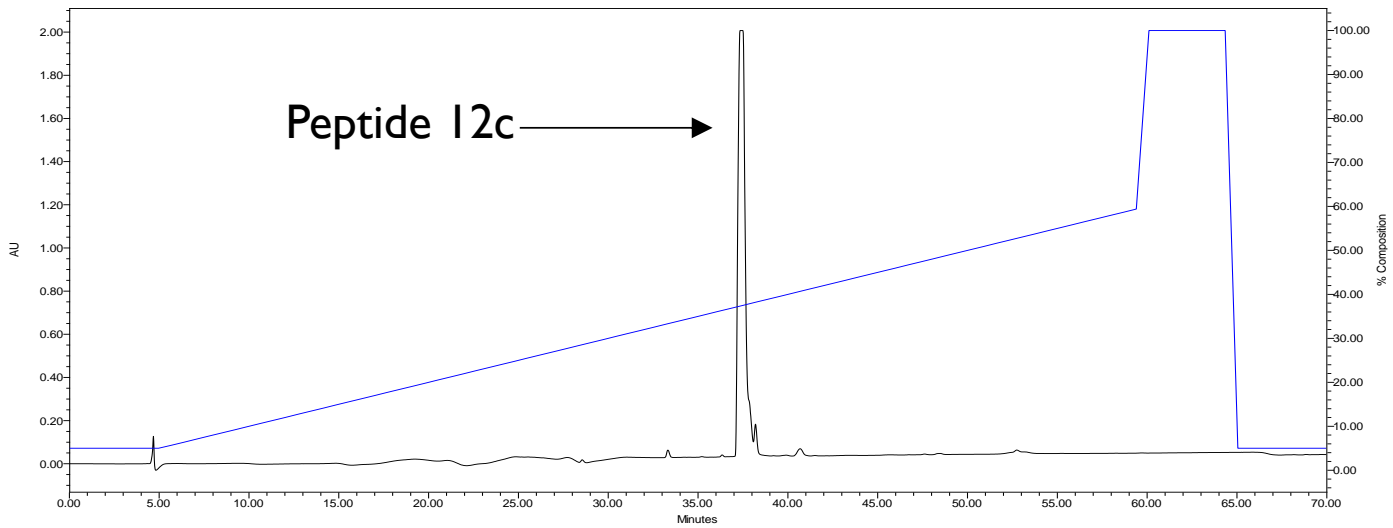

HR Mass spectrum: Calculated $[\mathrm{M}+\mathrm{H}]^{+}$1575.7789, found 1575.7728

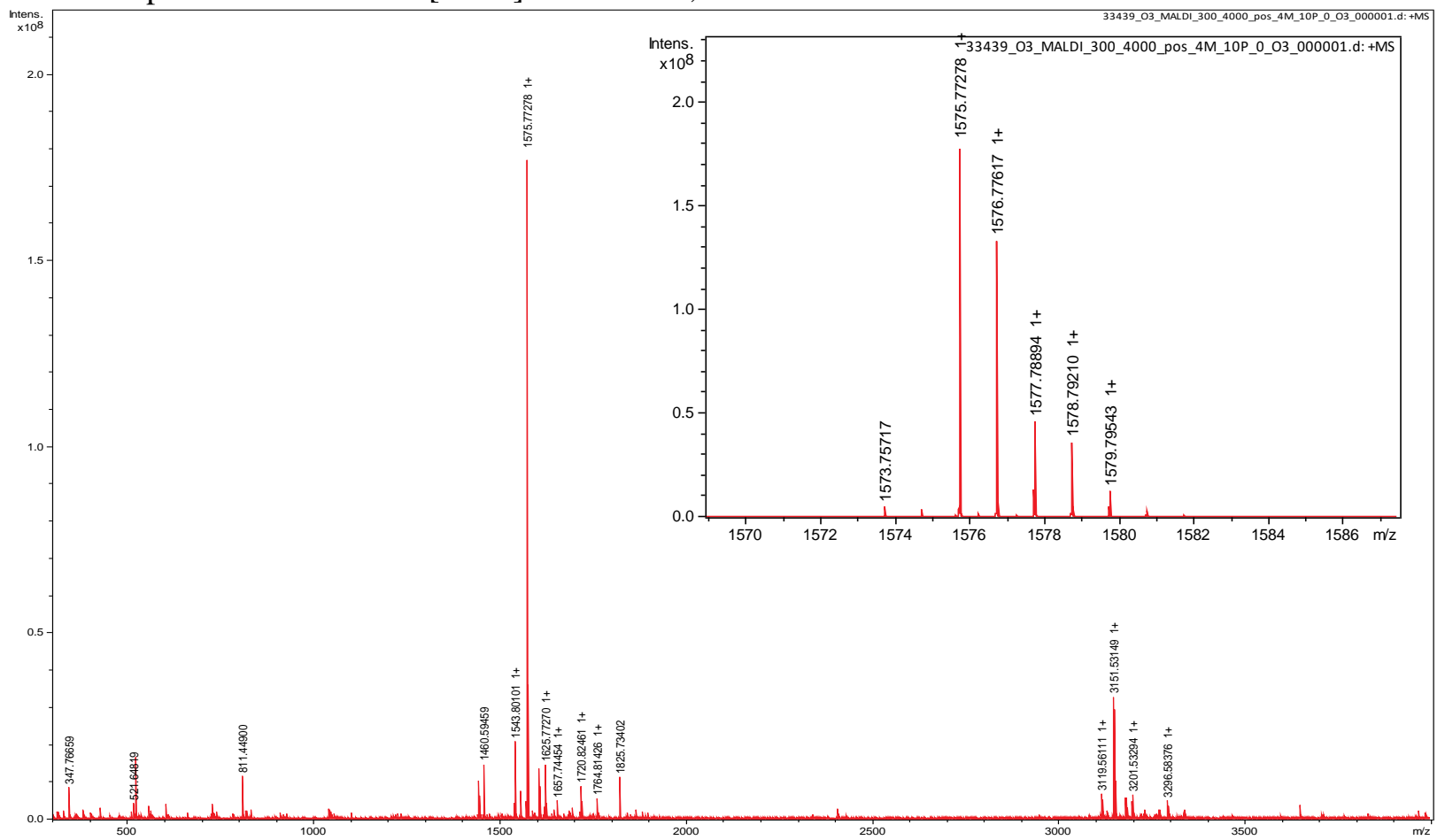




\section{Compound 13c}

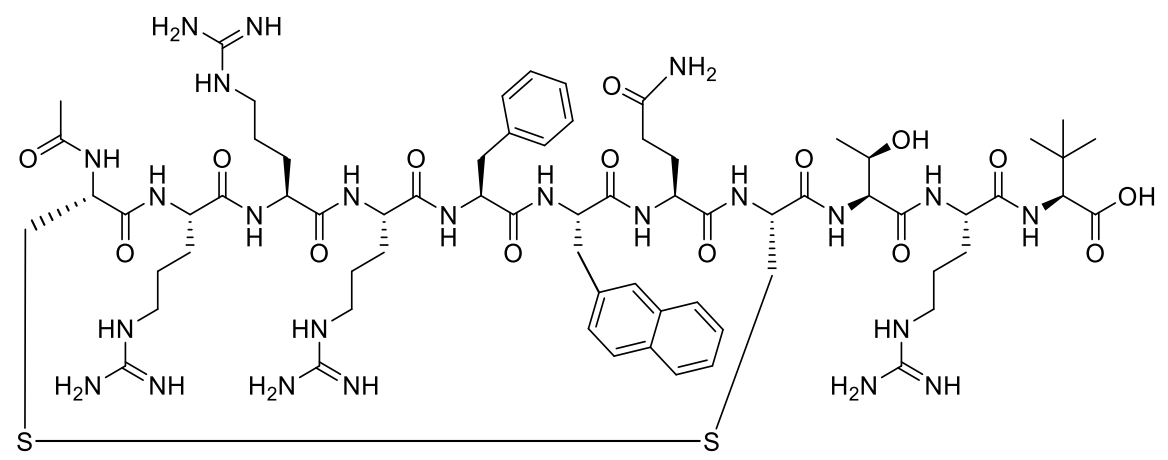

Purity assessment by analytical HPLC (214 nm):

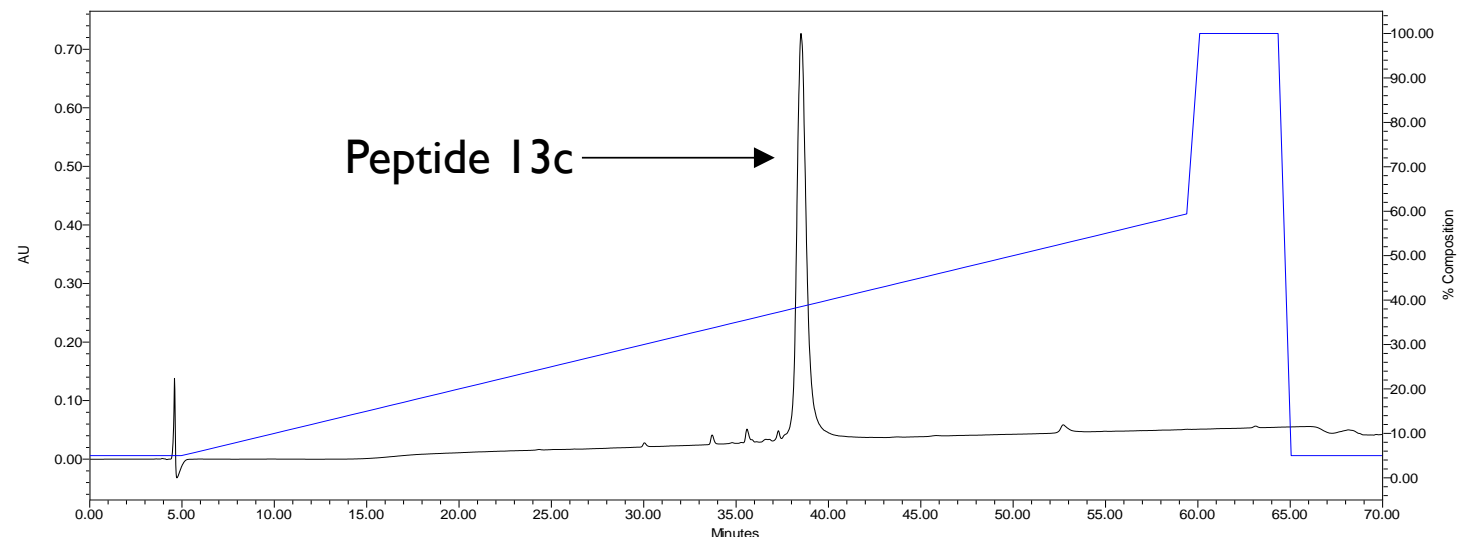

HR-MS: Calculated $[\mathrm{M}+\mathrm{H}]^{+}$1575.7789, found 1575.7731

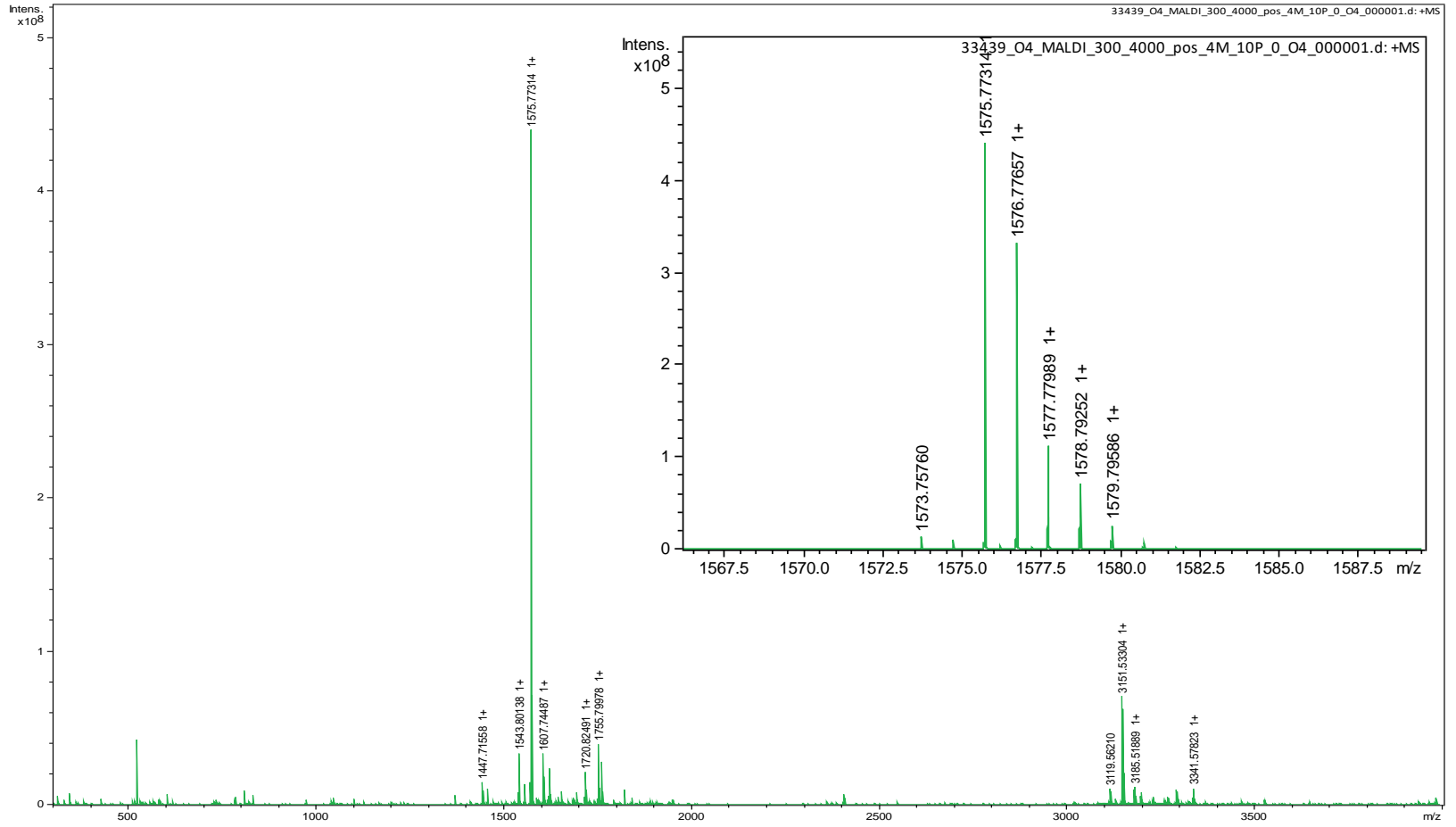




\section{Compound 14c}

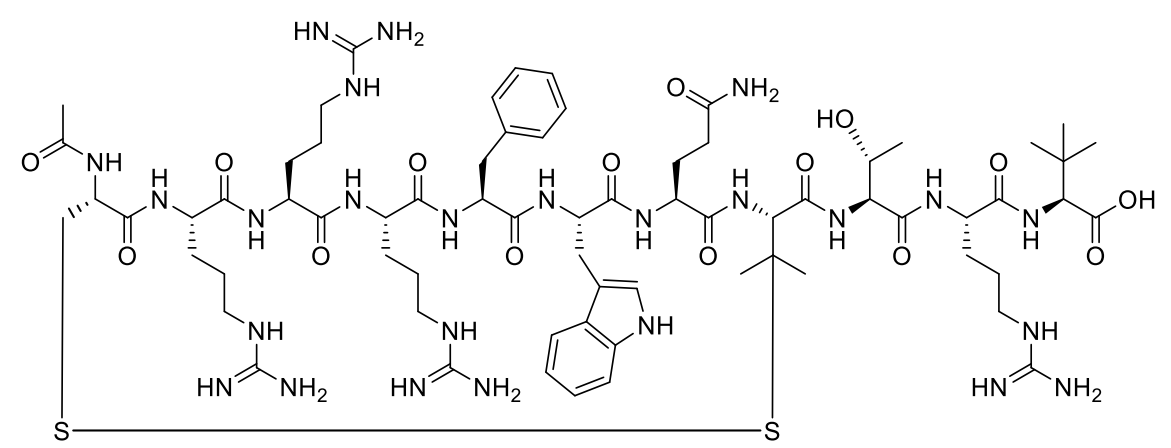

Purity assessment by analytical HPLC (214 nm):

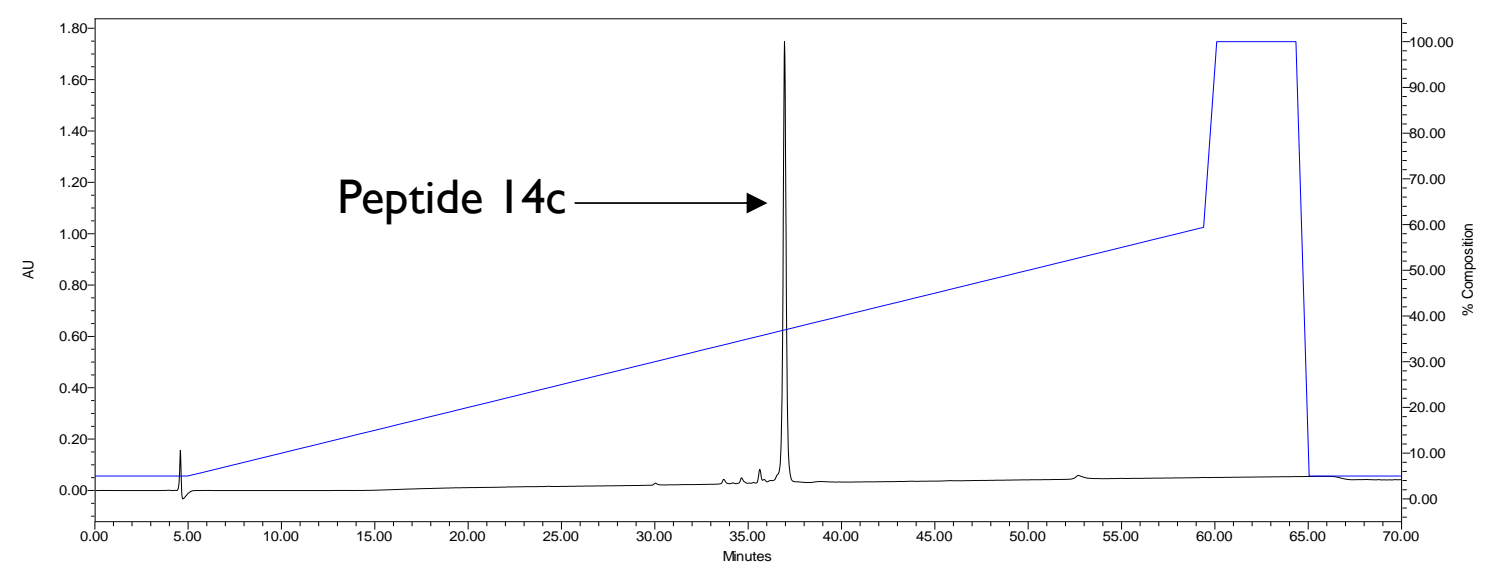

HR-MS: Calculated $[\mathrm{M}+\mathrm{H}]^{+} 1592.8055$, found 1592.8001

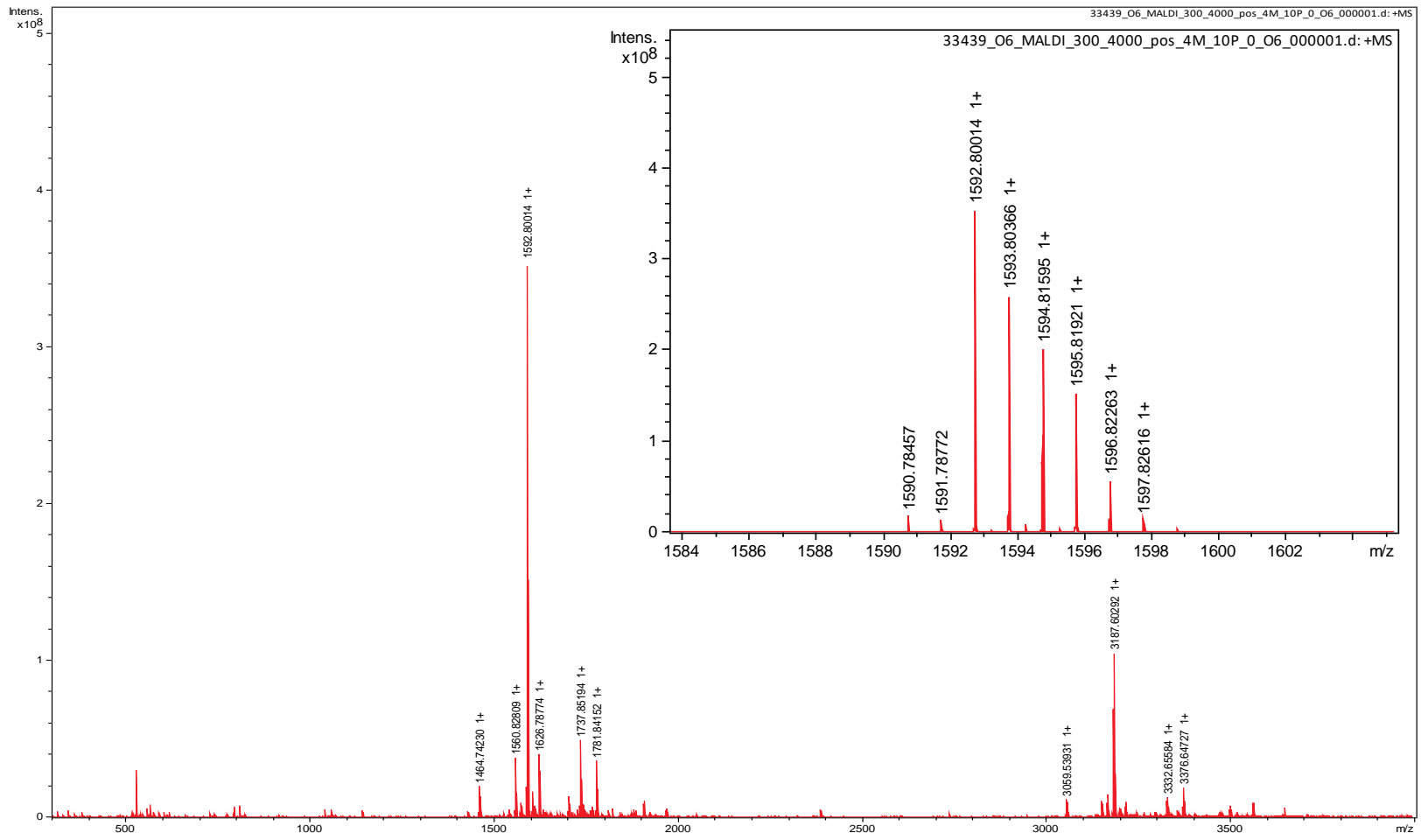




\section{Compound 15}

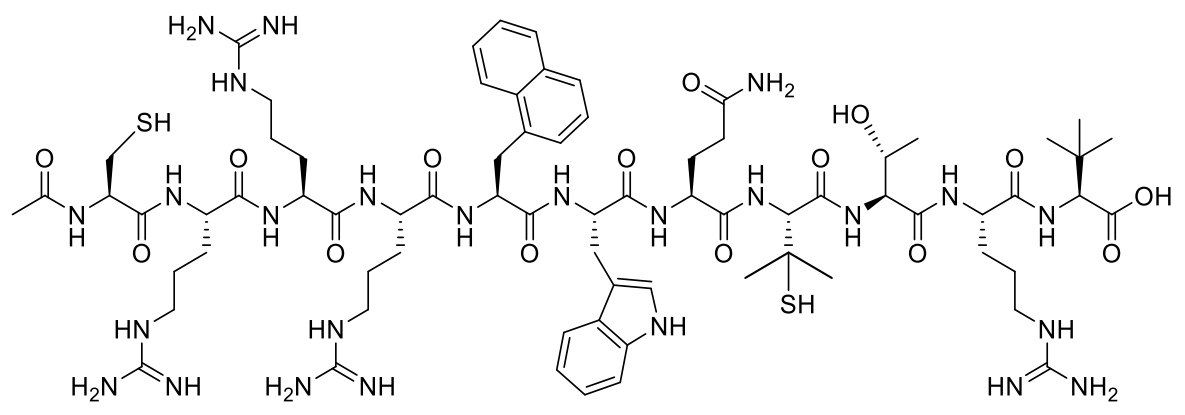

Purity assessment by UPLC (220 nm):

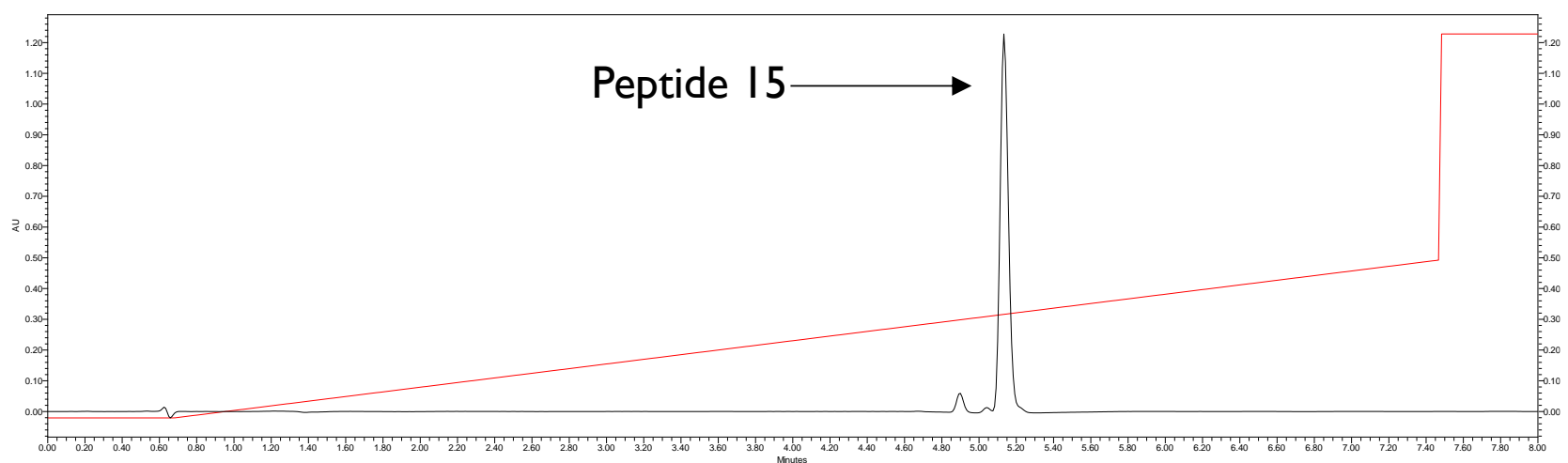

HR-MS: Calculated $[\mathrm{M}+\mathrm{H}]^{+}$1644.8362, found 1644.8304

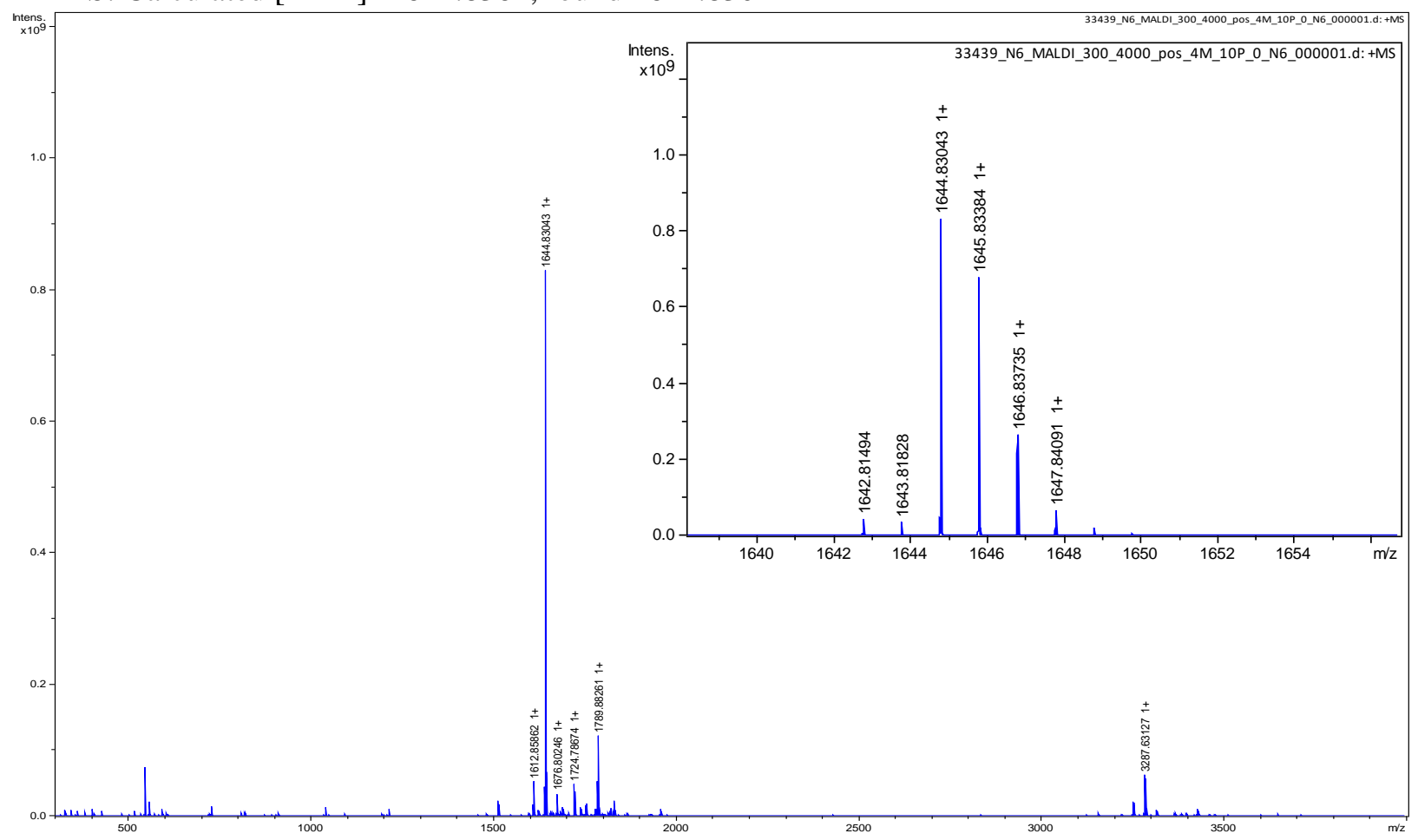




\section{Compound 16}

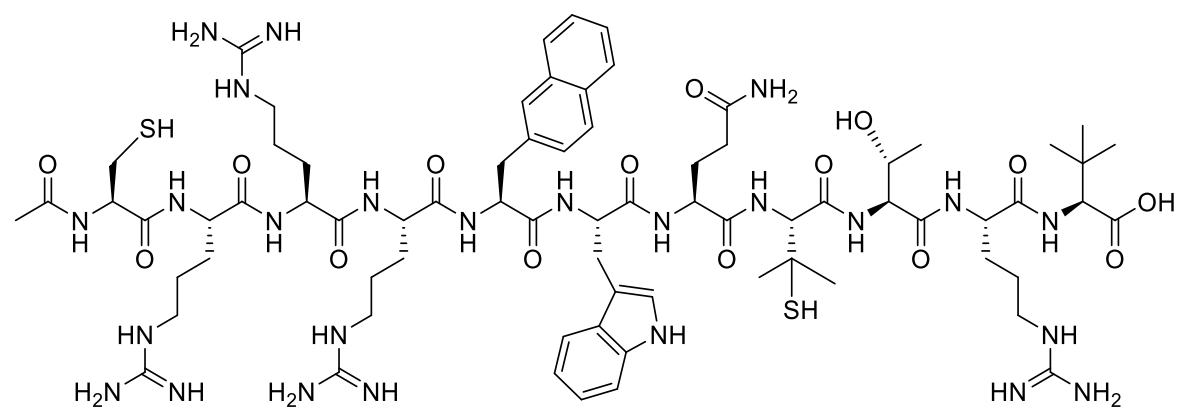

Purity assessment by UPLC (220 nm):

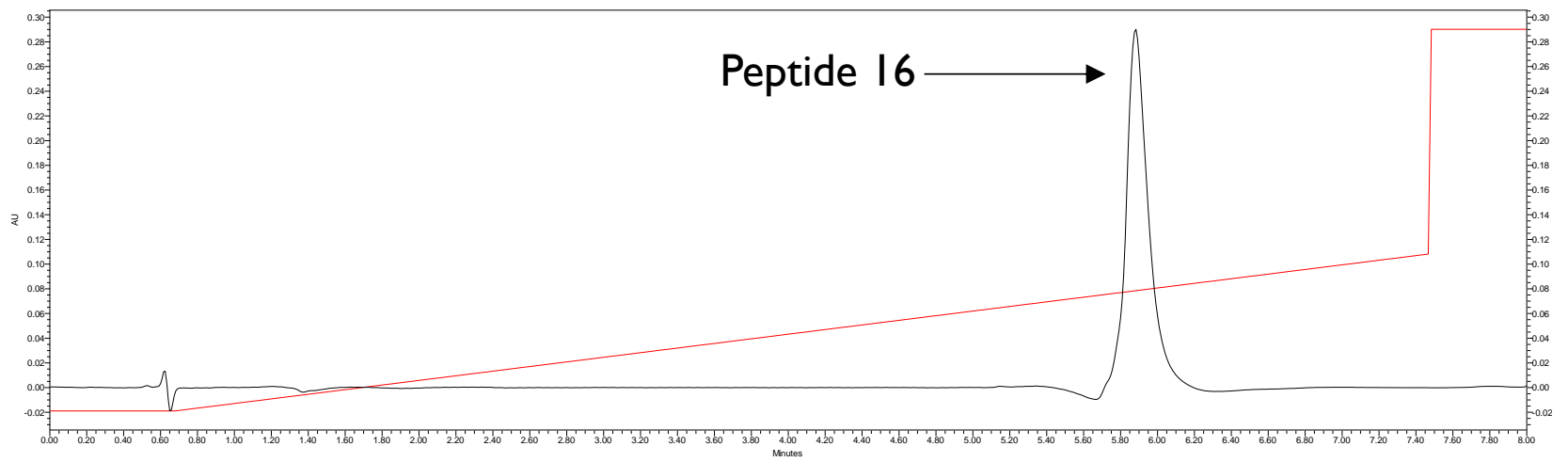

HR-MS: Calculated $[\mathrm{M}+\mathrm{H}]^{+}$1644.8362, found 1644.8314

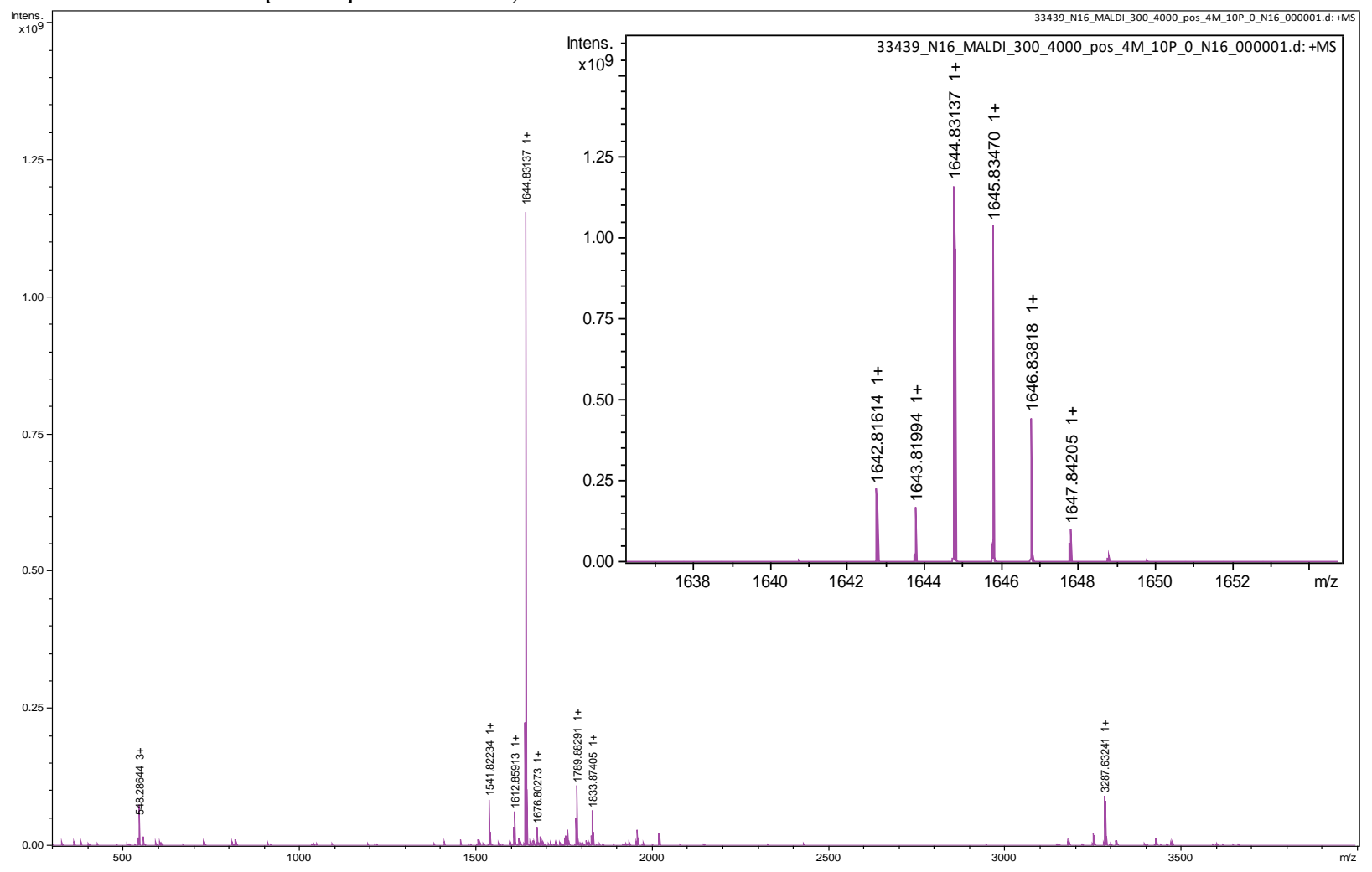




\section{Compound 17}

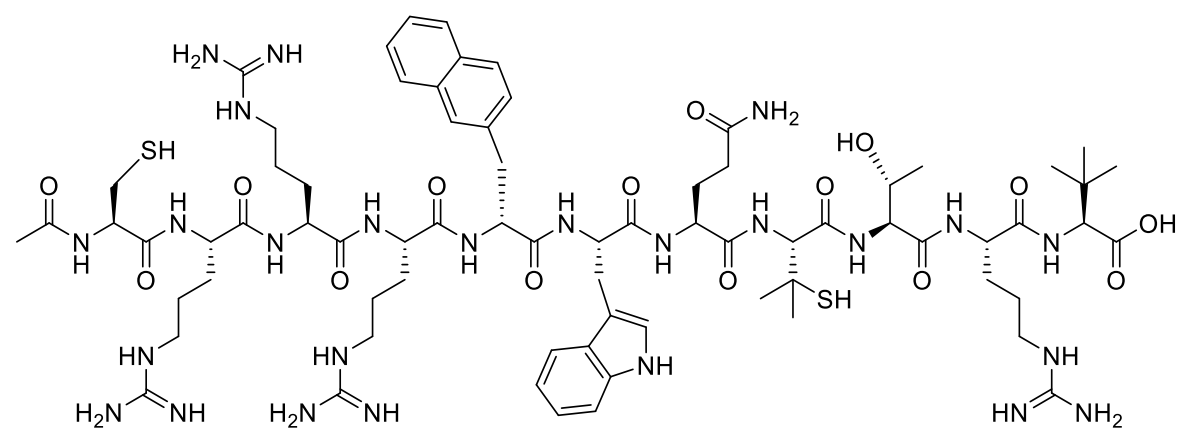

Purity assessment by analytical HPLC (214 nm):

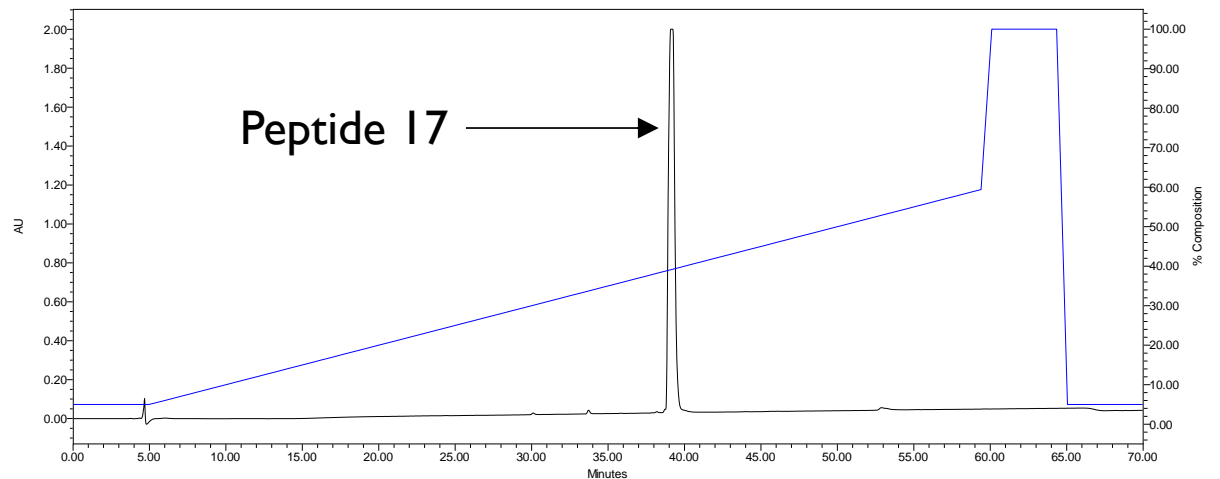

HR-MS: Calculated $[\mathrm{M}+\mathrm{H}]^{+} 1644.8362$, found 1644.8313

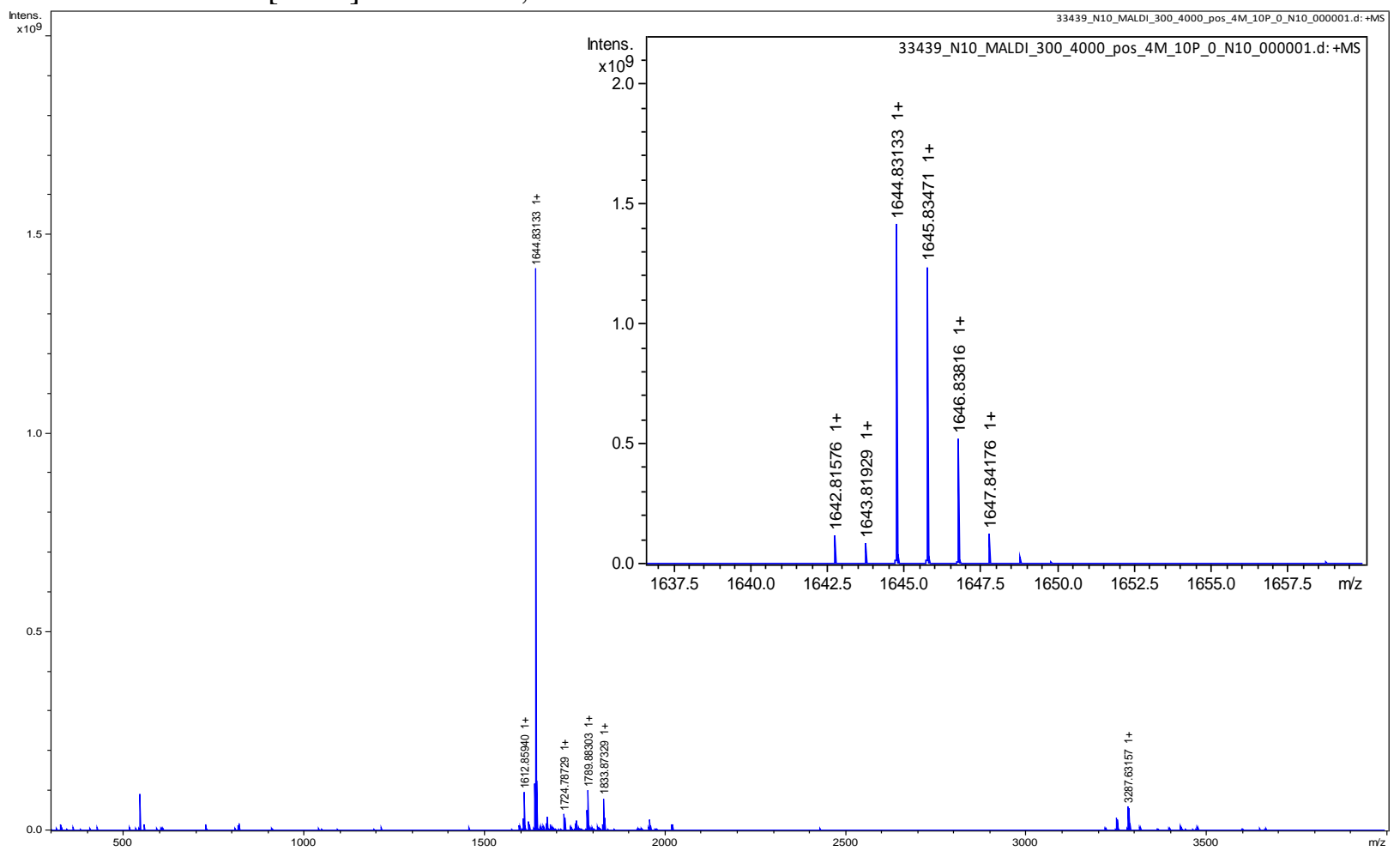




\section{Compound 18}

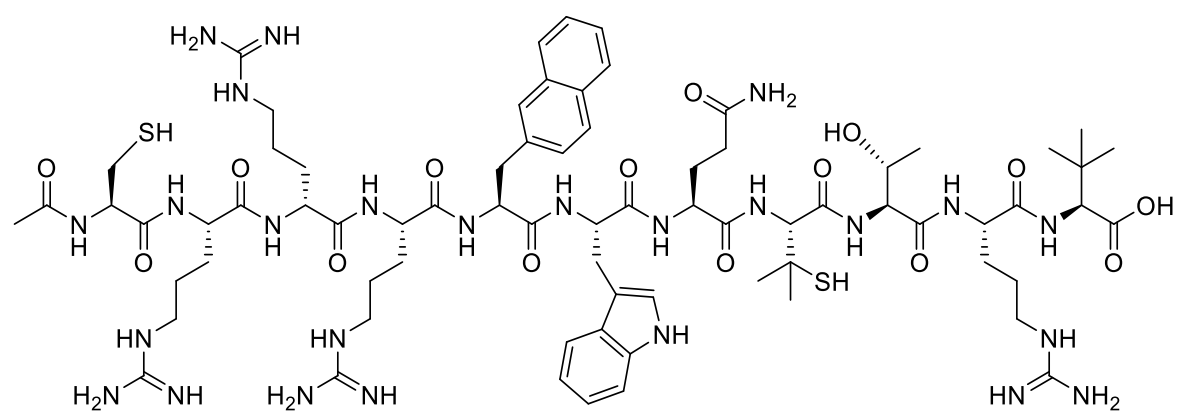

Purity assessment by UPLC (220 nm):

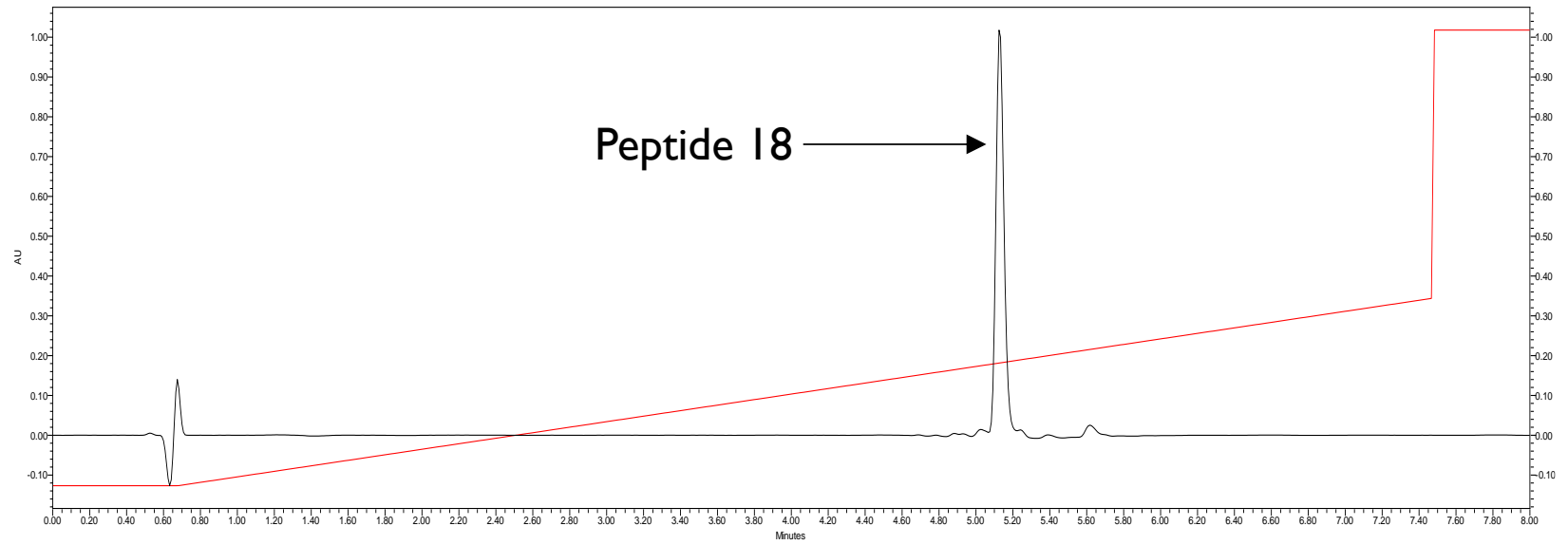

HR-MS: Calculated $[\mathrm{M}+\mathrm{H}]^{+}$1644.8362, found 1644.8321

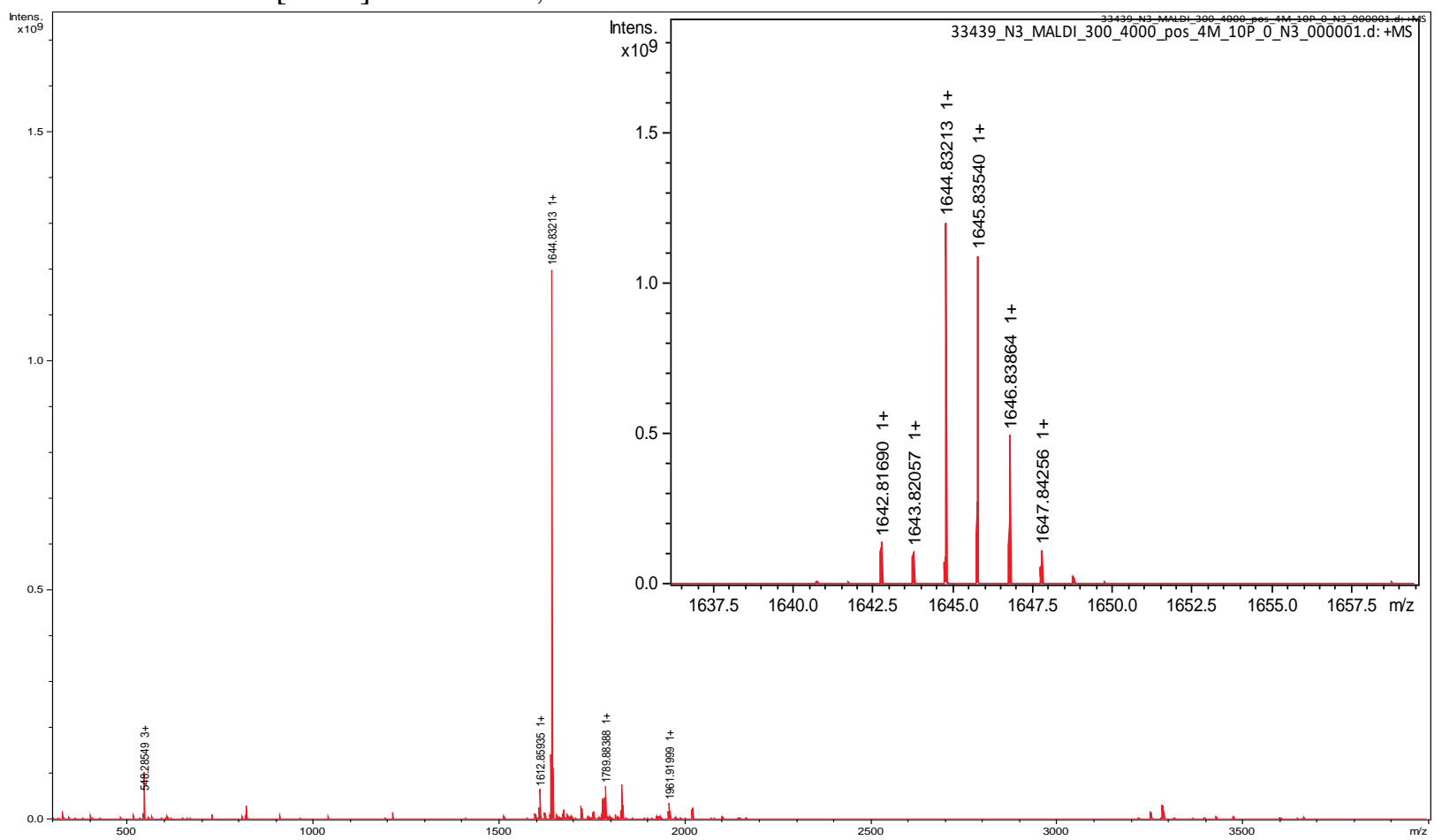




\section{Compound 19}

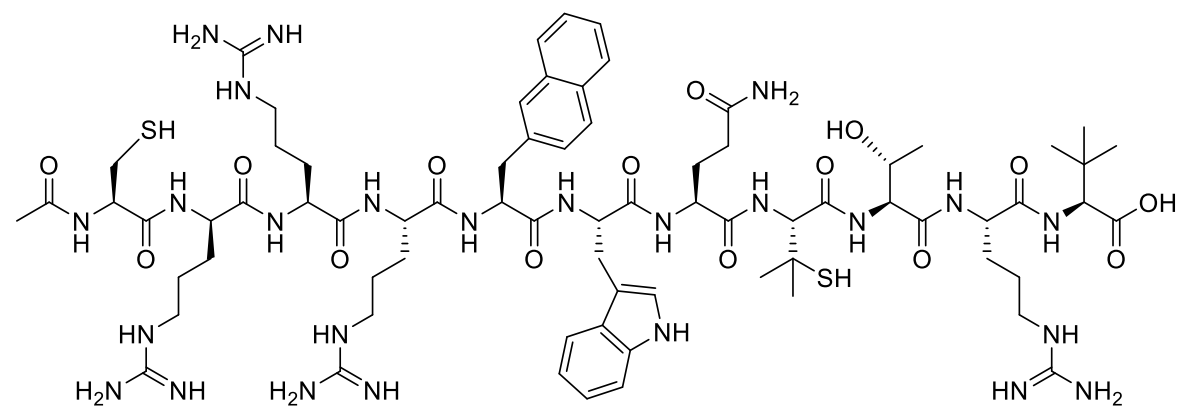

Purity assessment by analytical HPLC (214 nm):

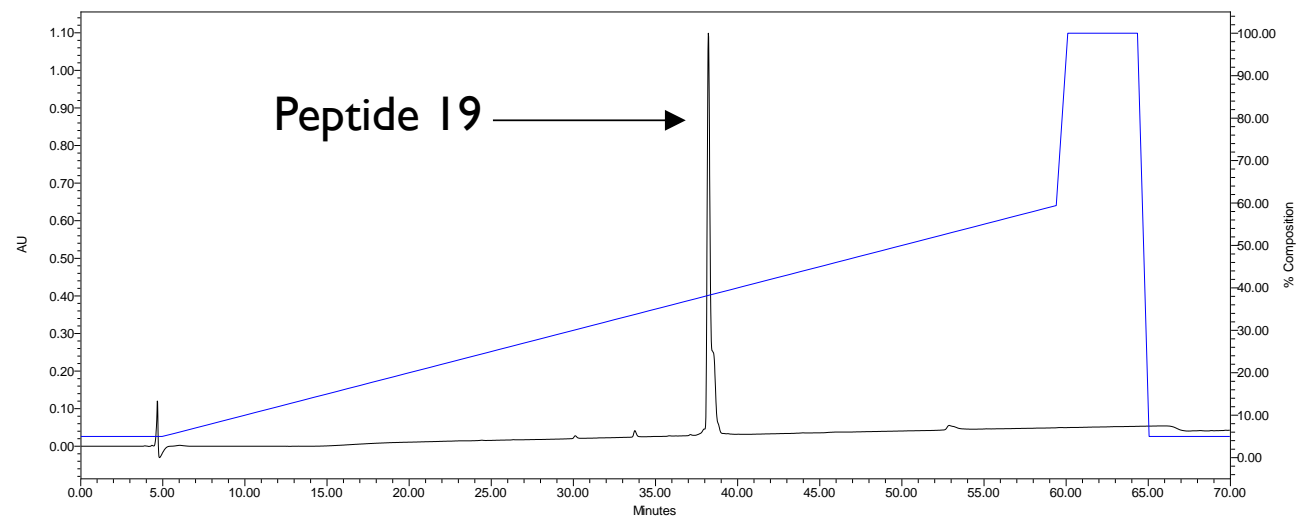

HR-MS: Calculated $[\mathrm{M}+\mathrm{H}]^{+}$1644.8362, found 1644.8301

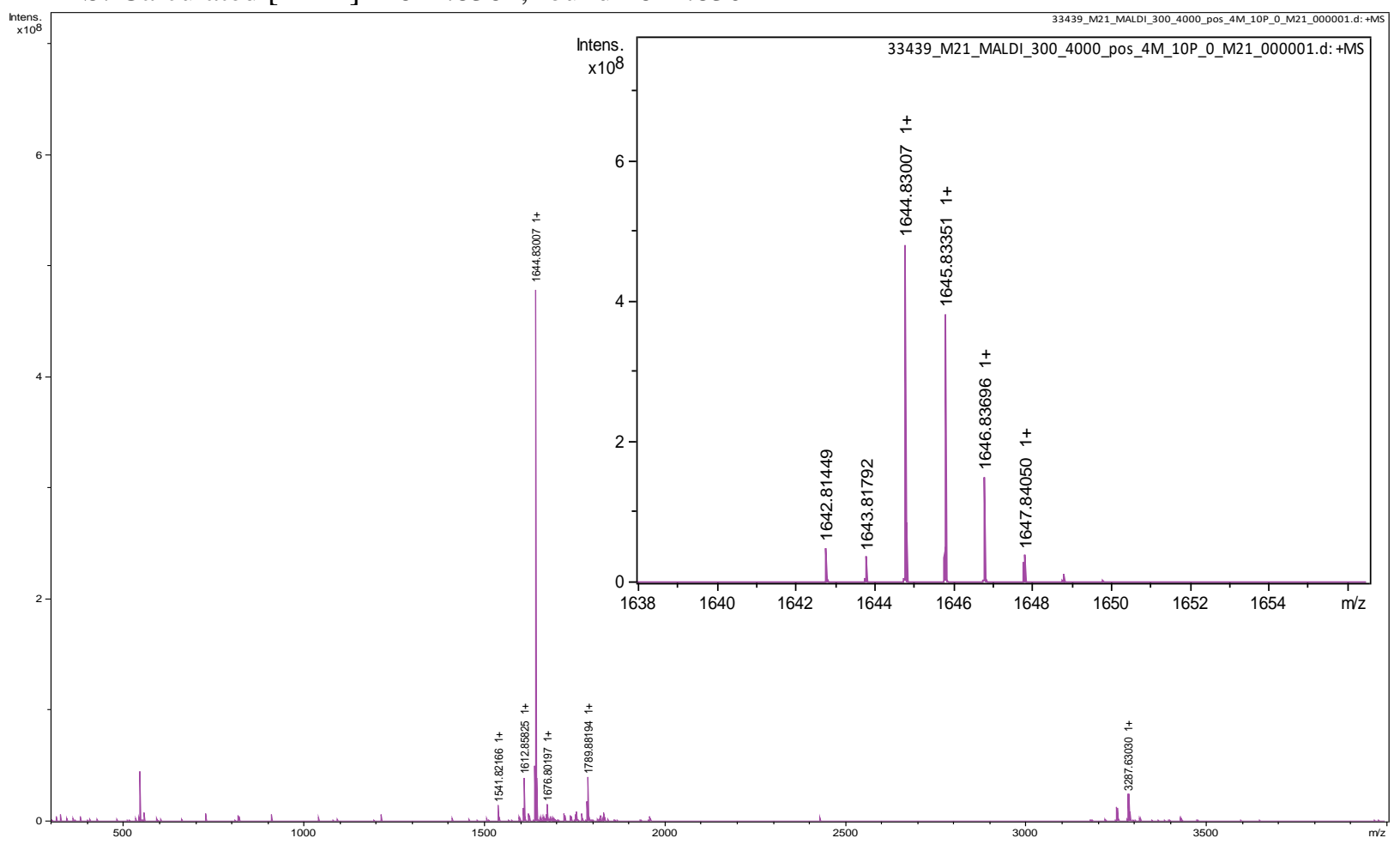




\section{Compound FAM-19}

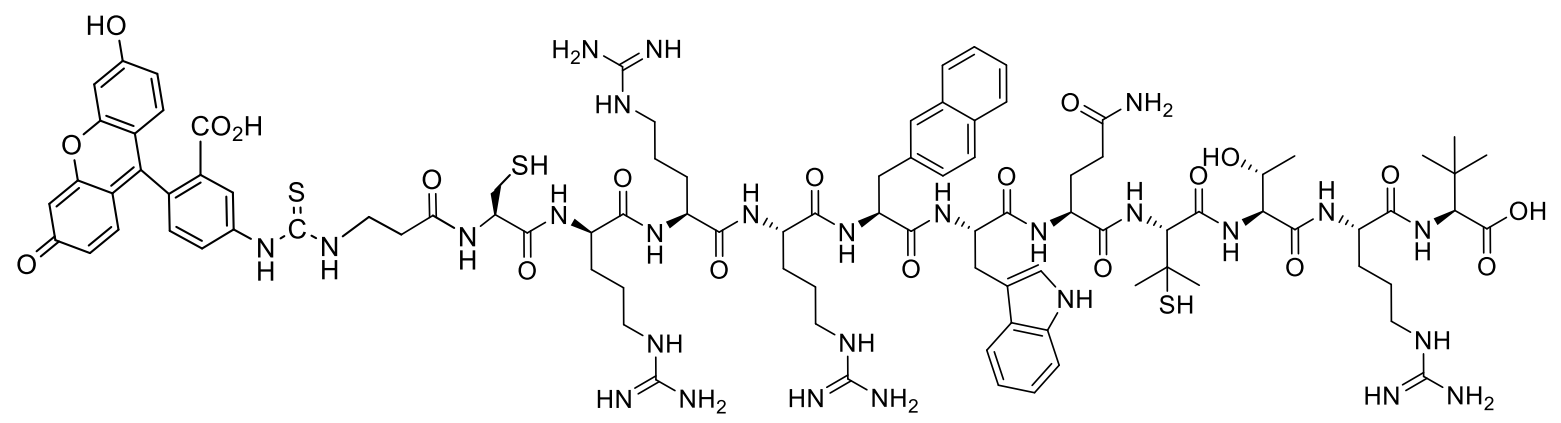

Purity assessment by UPLC $(220 \mathrm{~nm})$ :

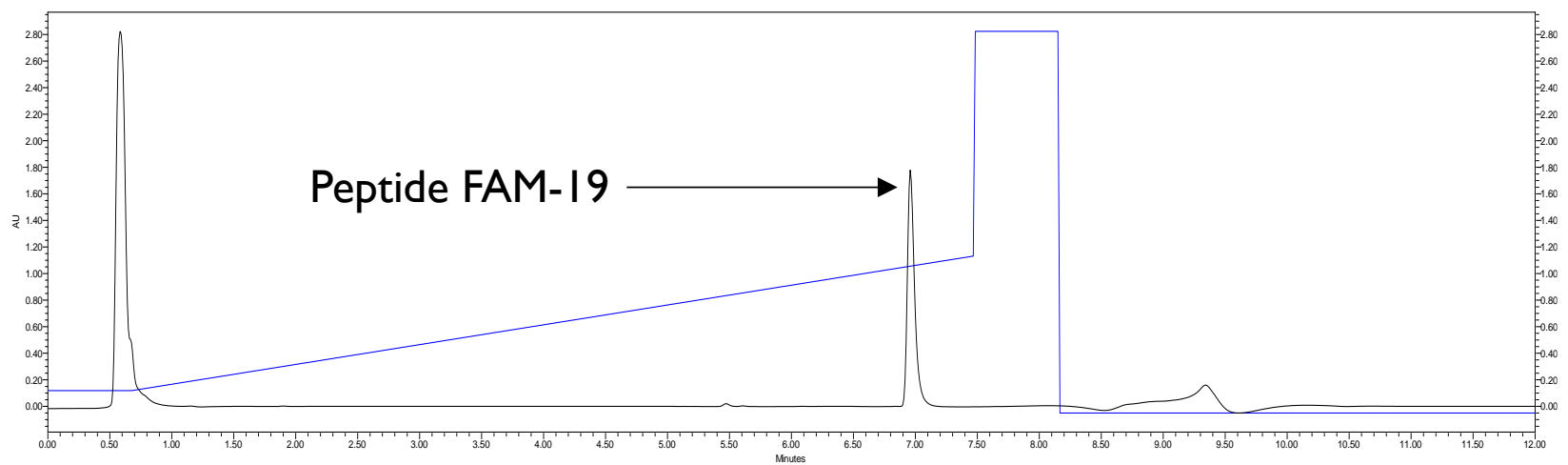

HR-MS: Calculated $[\mathrm{M}+\mathrm{H}]^{+}$2062.8986, found 2062.9066 (reduced) and 2060.8976 (oxidized)

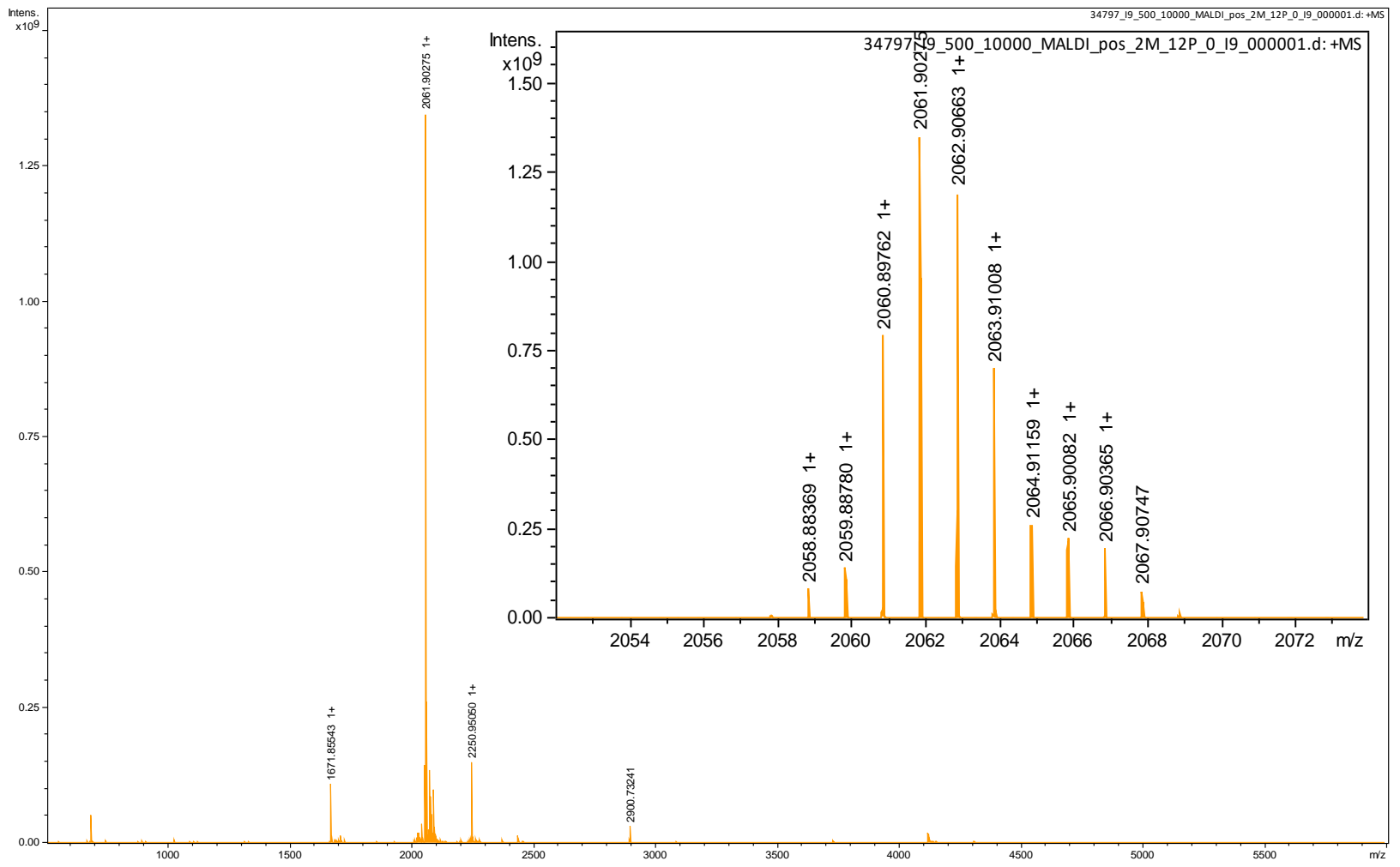




\section{Compound 20}

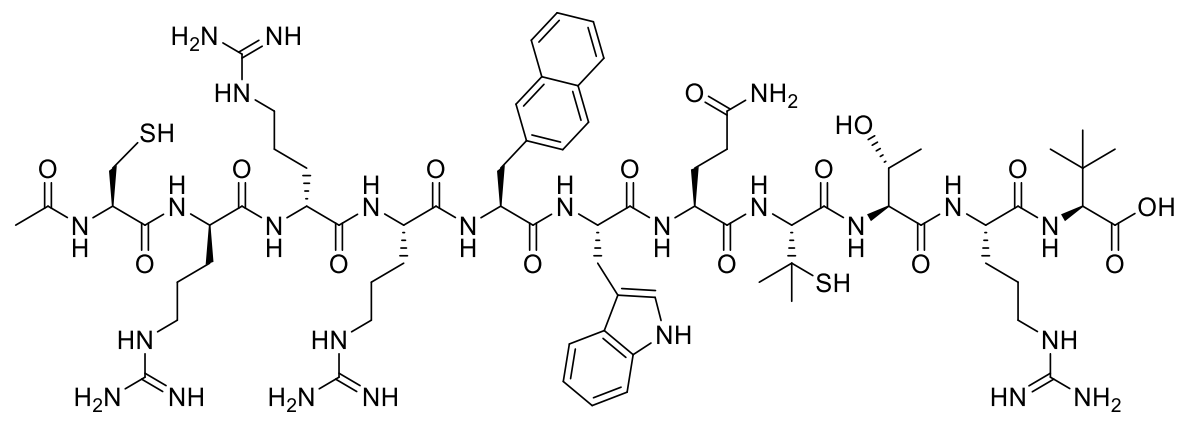

Purity assessment by analytical HPLC (214 nm):

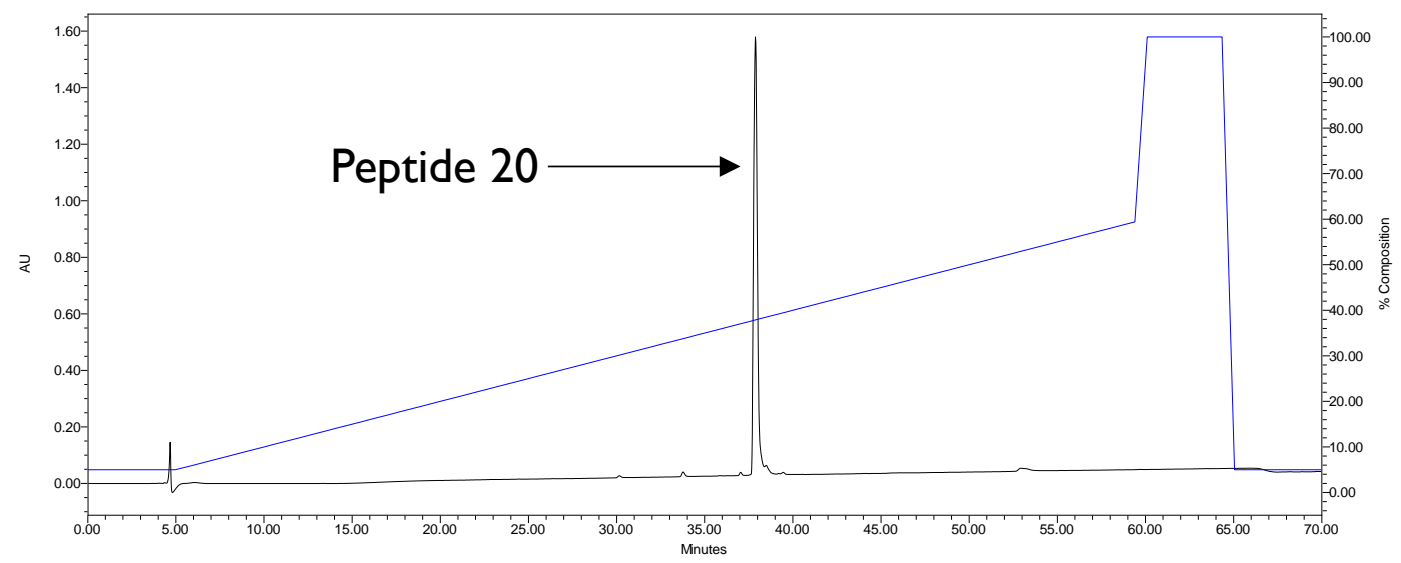

HR-MS: Calculated $[\mathrm{M}+\mathrm{H}]^{+}$1644.8362, found 1644.8321

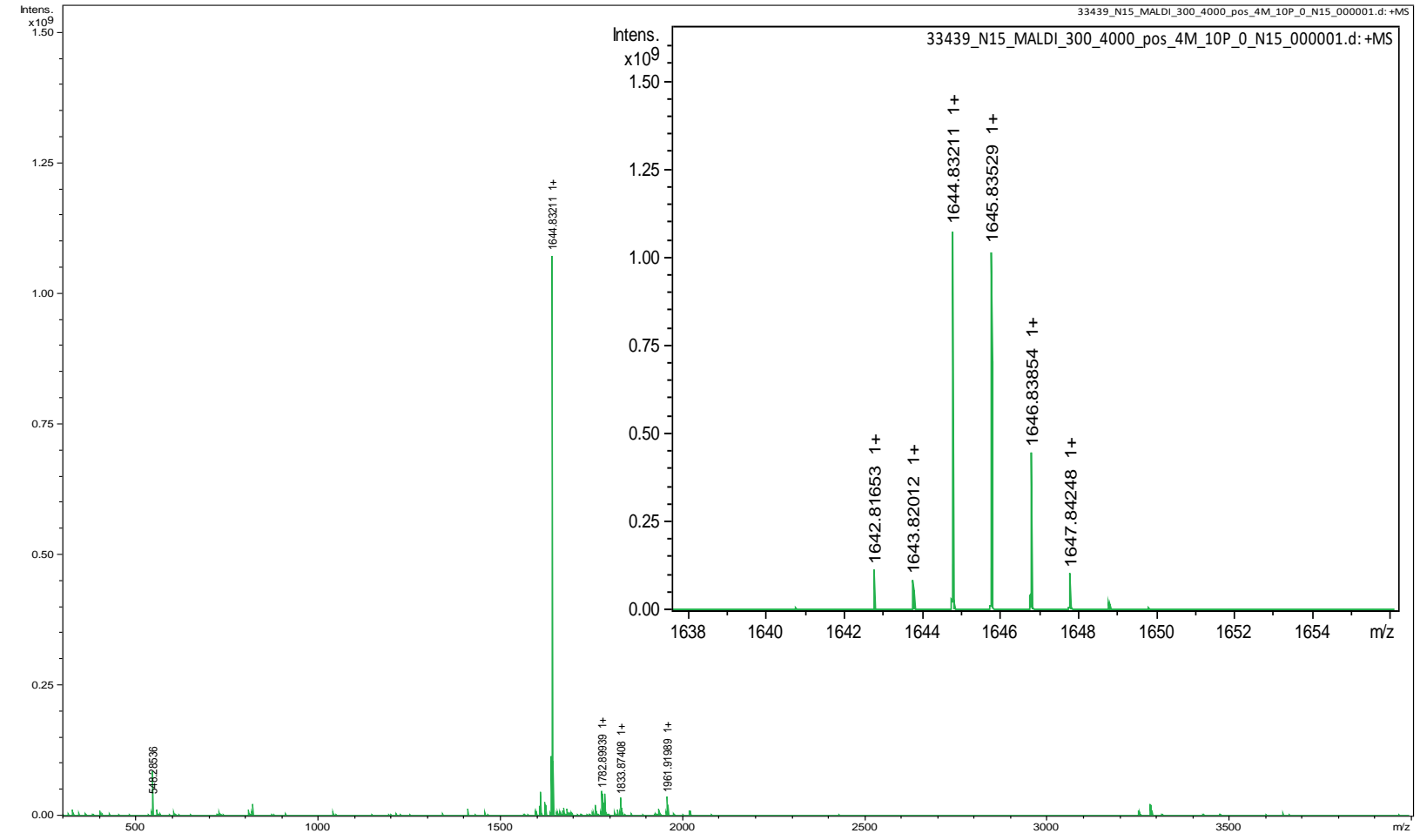




\section{Compound 21c}

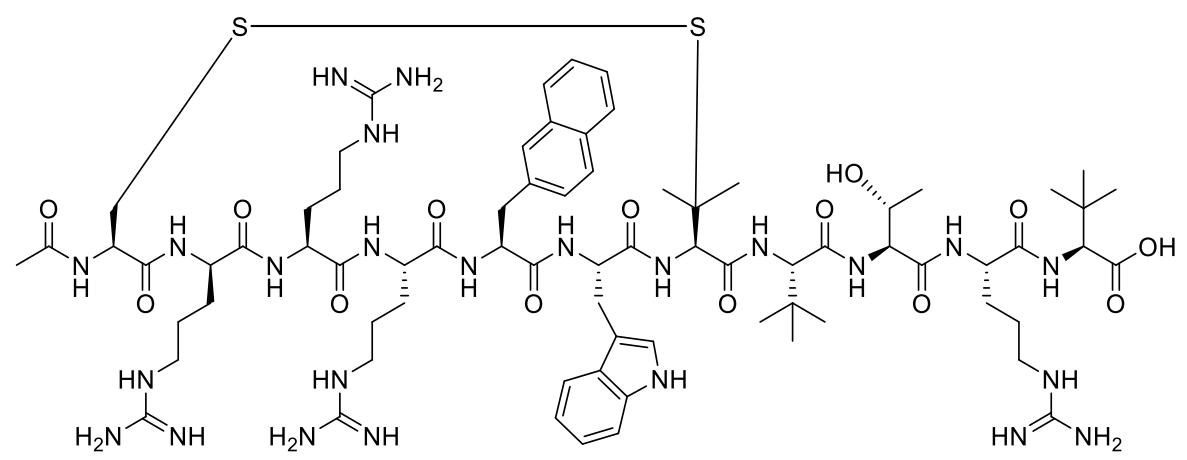

Purity assessment by analytical HPLC (214 nm):

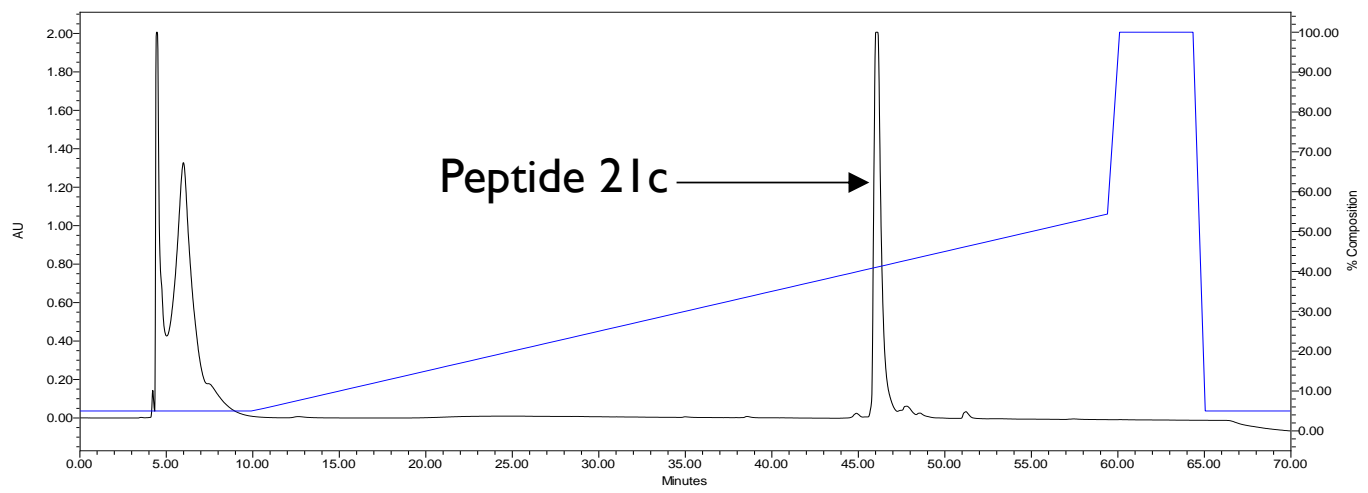

HR-MS: Calculated $[\mathrm{M}+\mathrm{H}]^{+} 1627.8466$, found 1627.8521

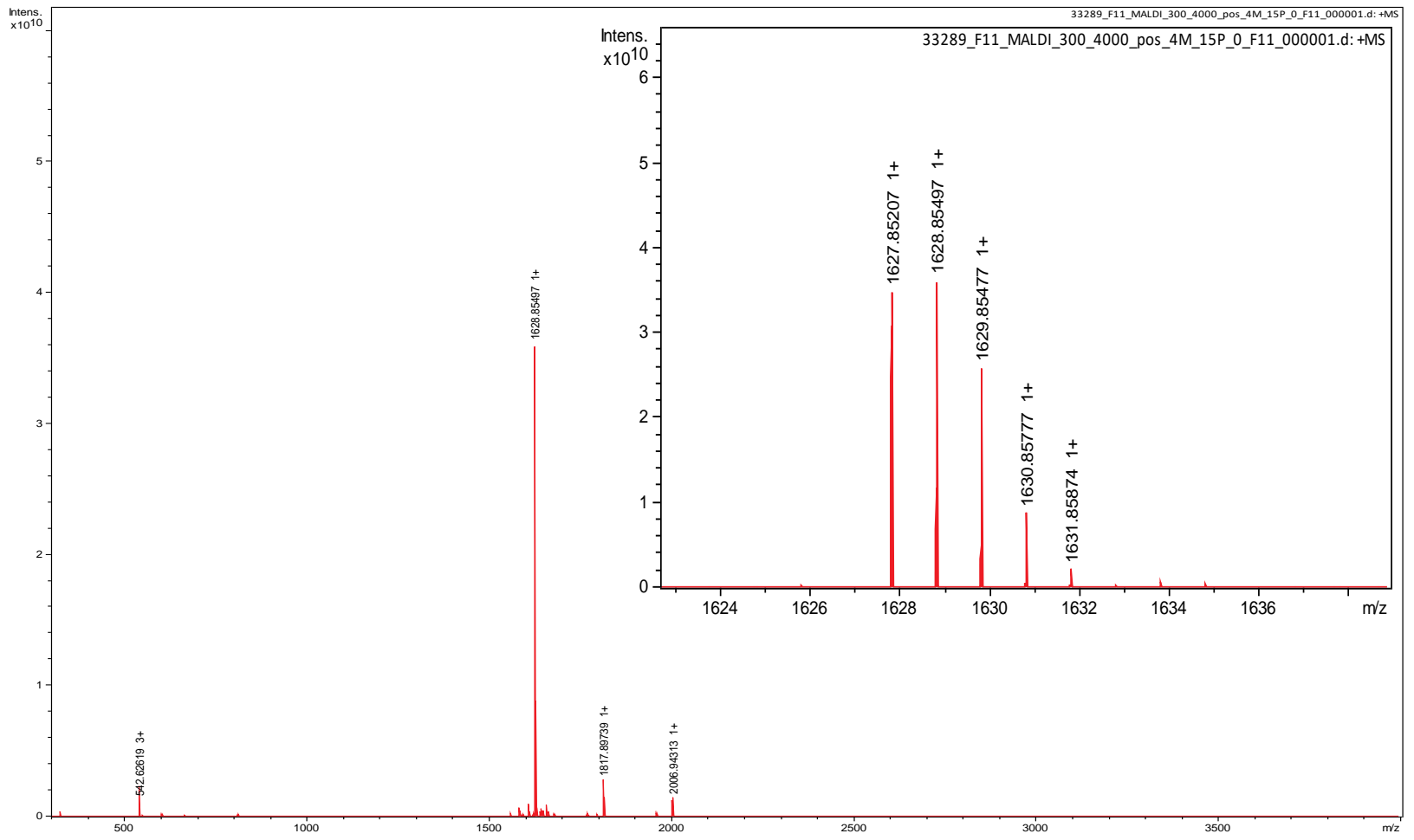




\section{Compound 22c}

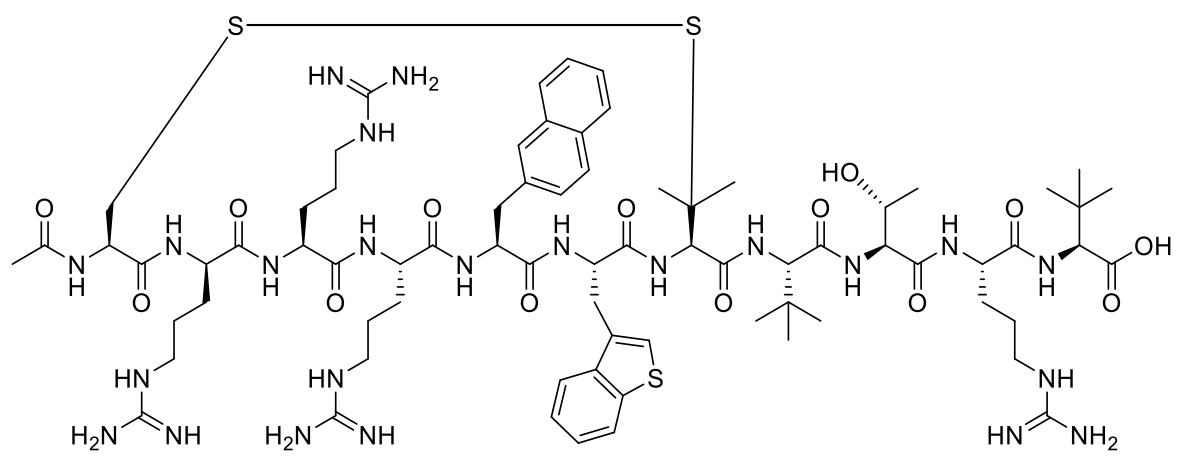

Purity assessment by analytical HPLC (214 nm):

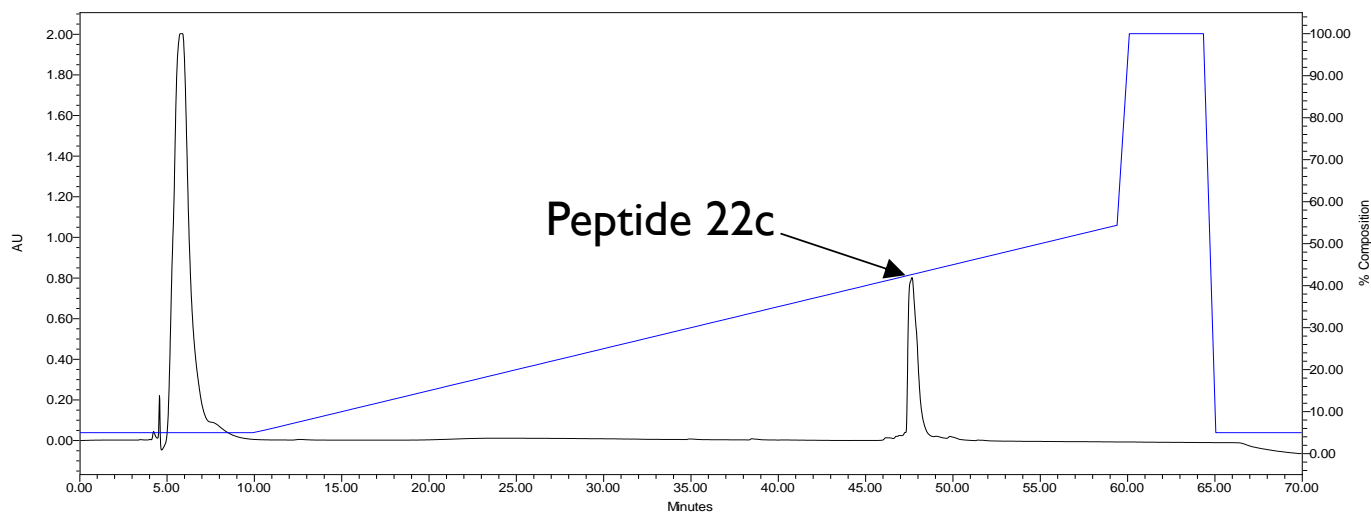

HR-MS: Calculated $[\mathrm{M}+\mathrm{H}]^{+}$1644.8078, found 1644.8140

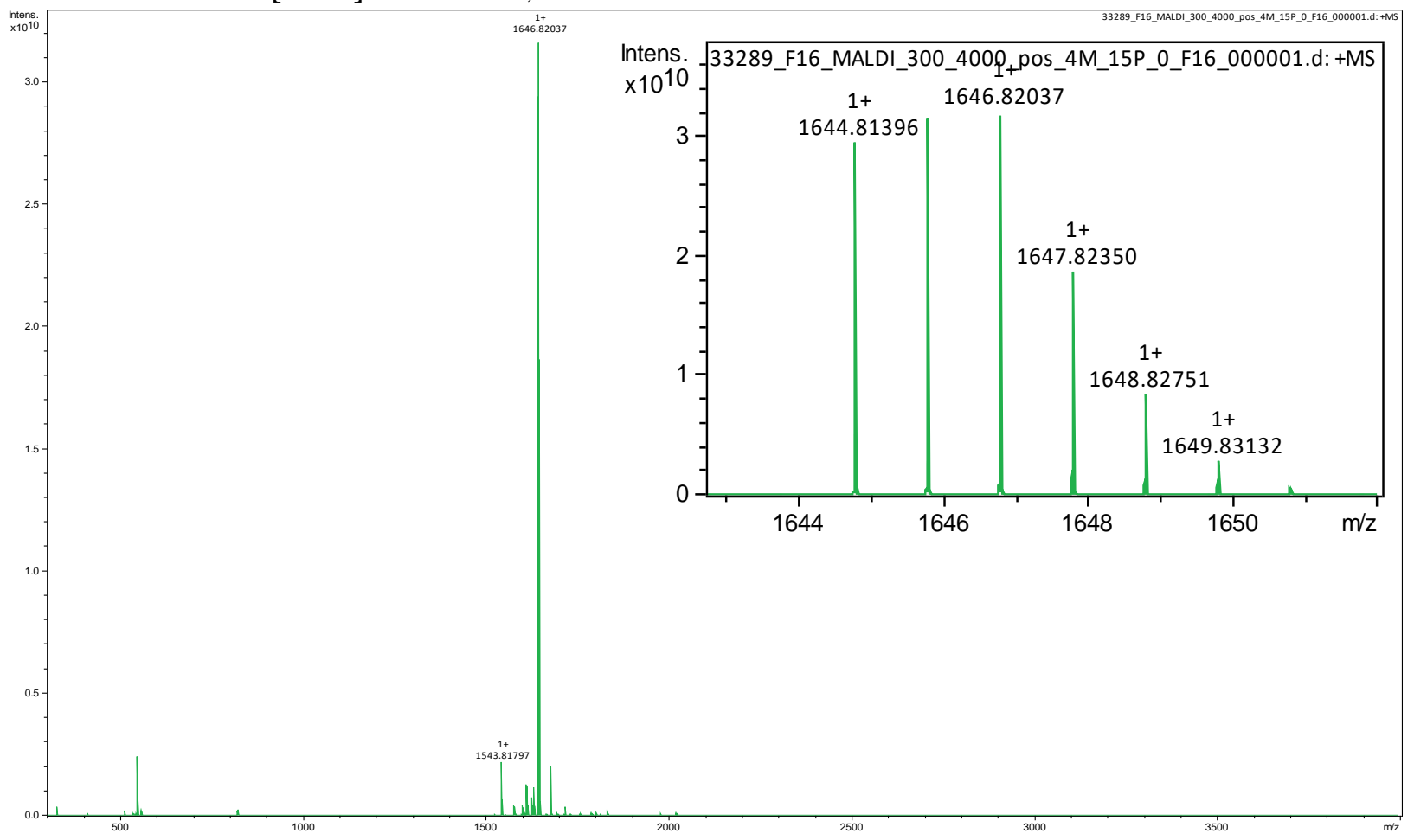




\section{Compound FAM-22}

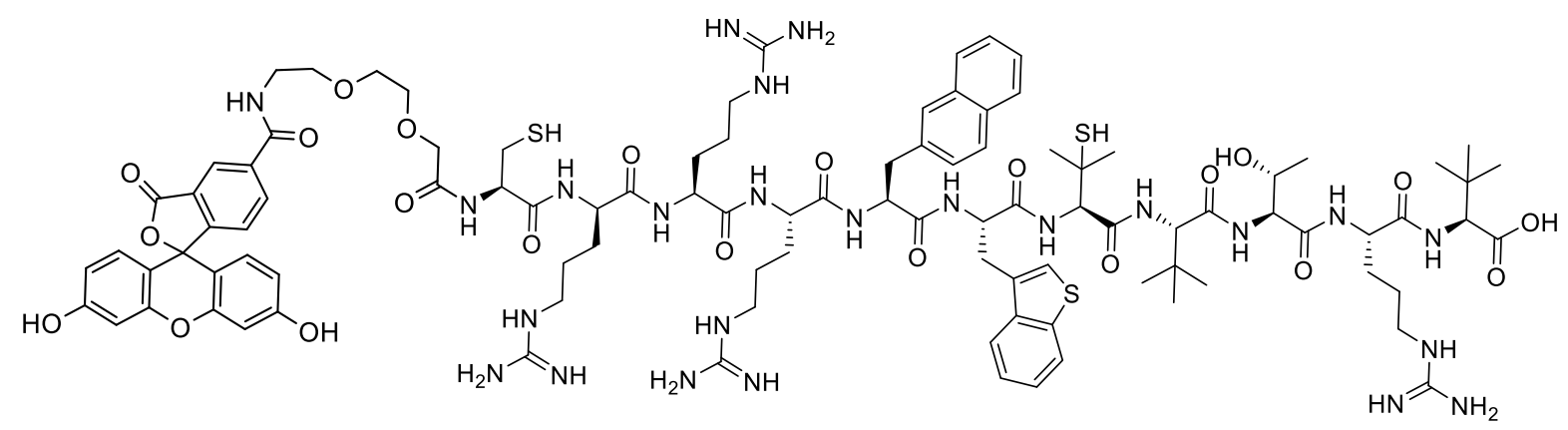

Purity assessment by UPLC (220 nm; mixture of reduced/oxidized and 5-/6-FAM isomers):

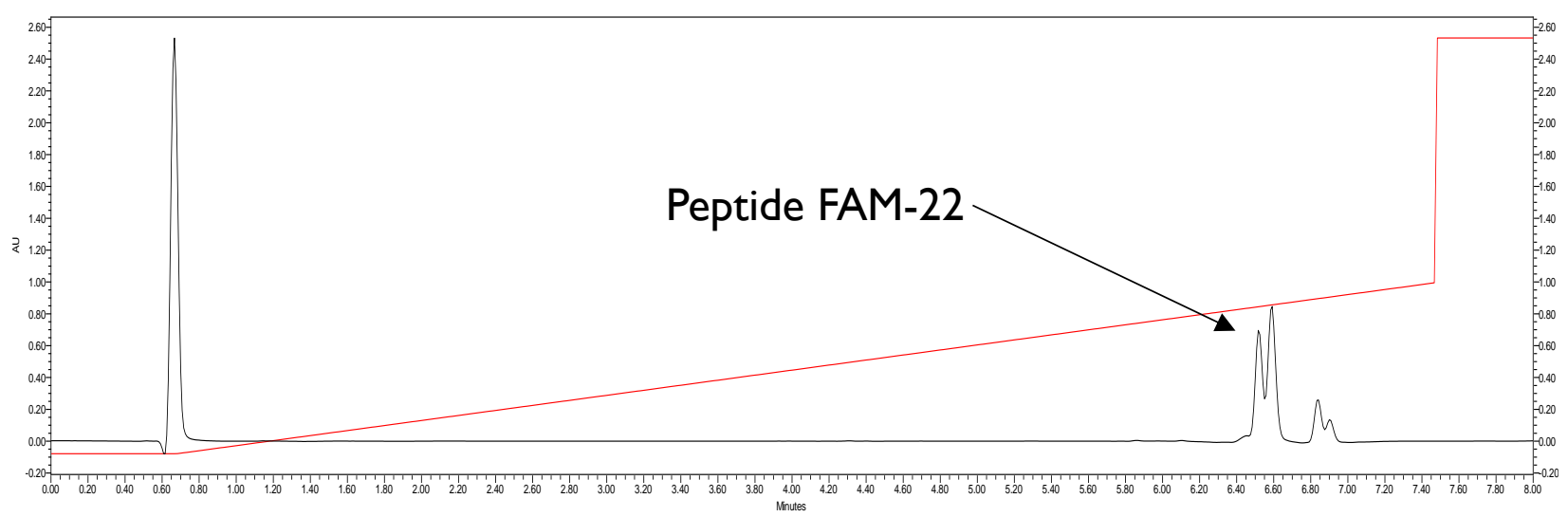

HR-MS: Calculated $[\mathrm{M}+\mathrm{H}]^{+}$2107.9339, found 2107.9457 (reduced) and 2105.9389 (oxidized)

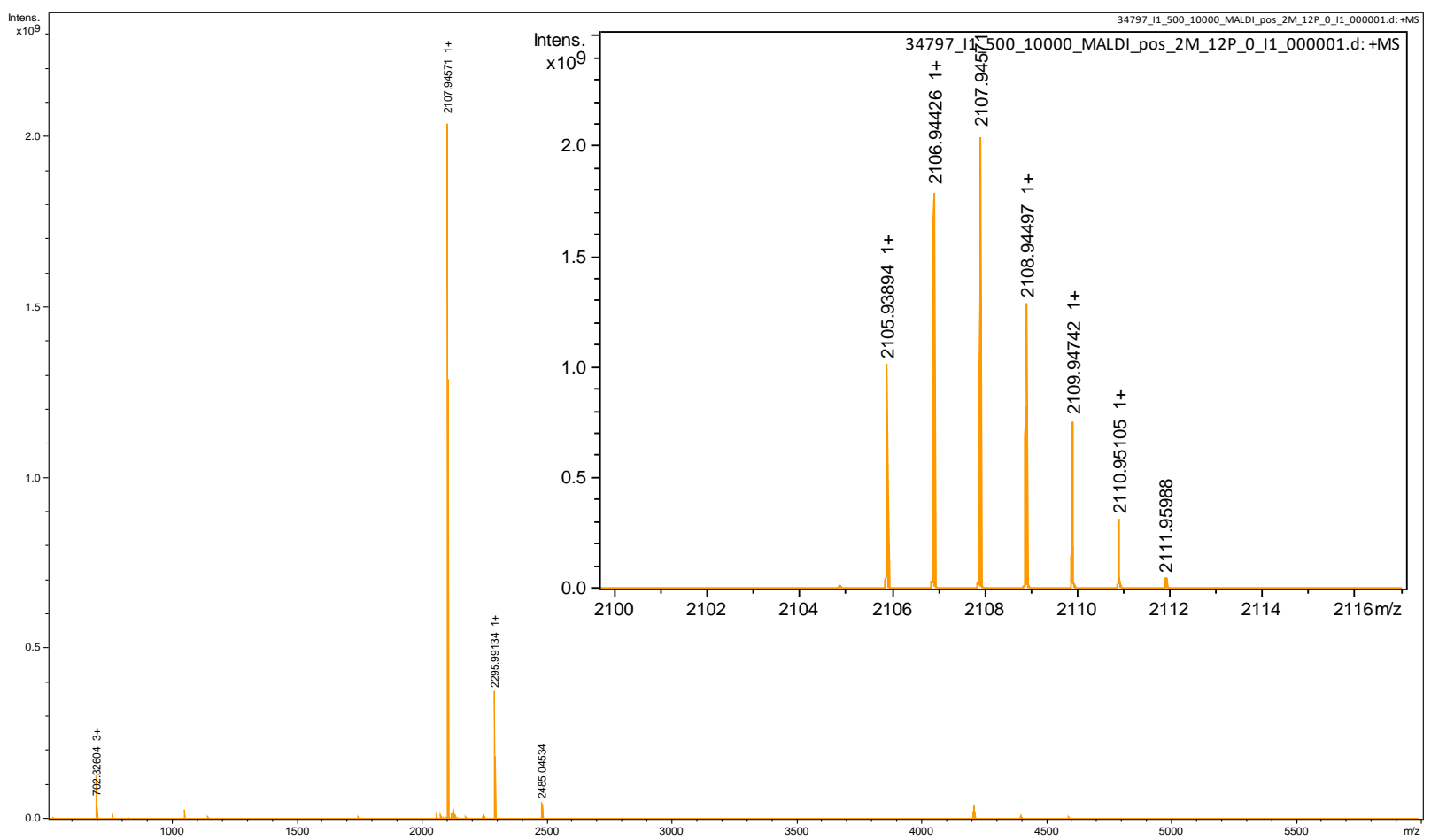




\section{Compound 23}

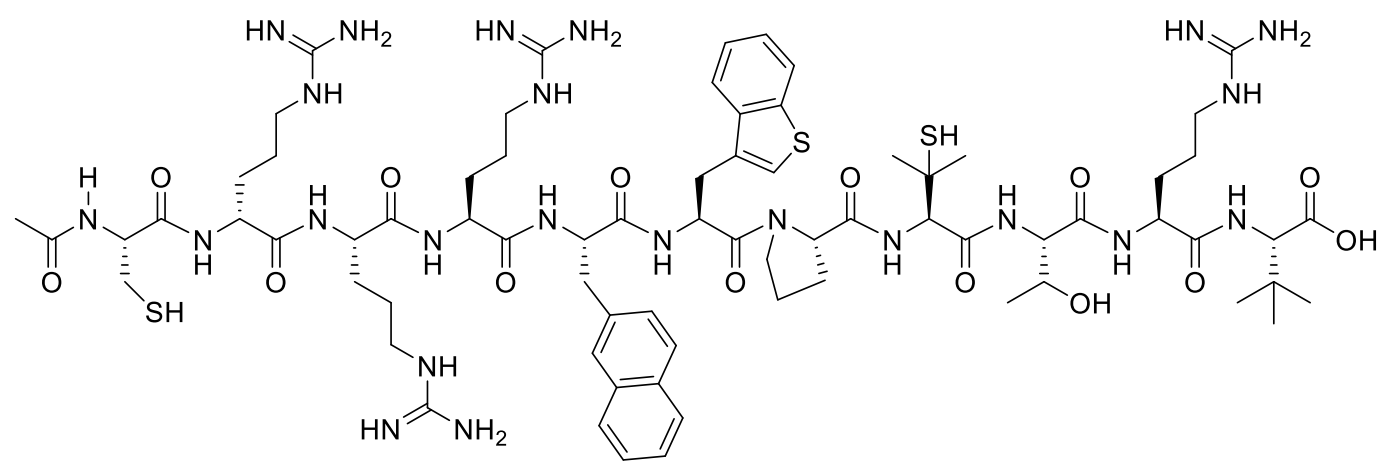

Purity assessment by UPLC $(220 \mathrm{~nm})$ :

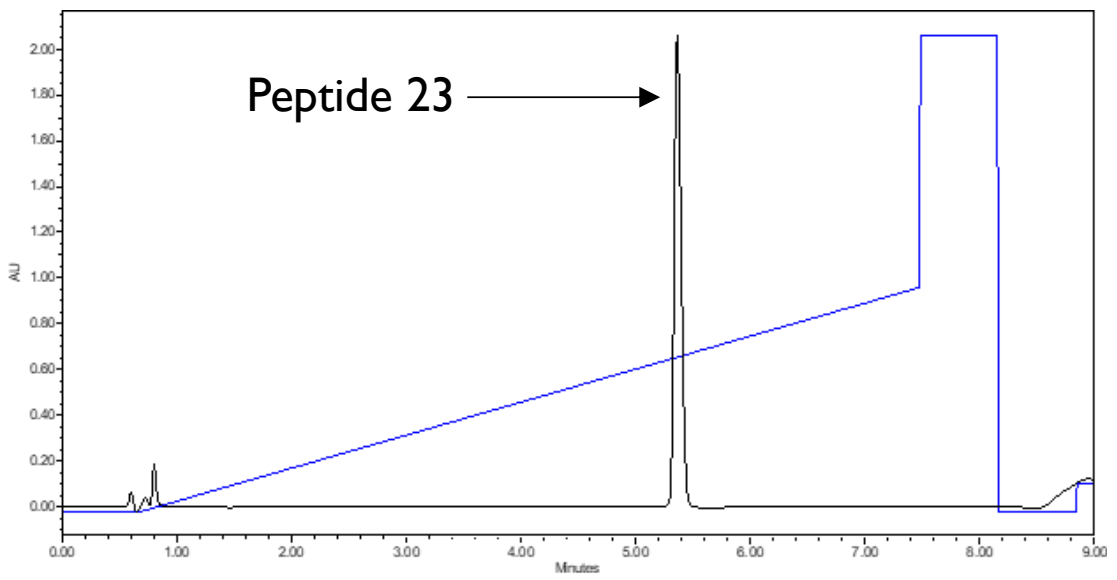

HR-MS: Calculated $[\mathrm{M}+\mathrm{H}]^{+}$1630.7910, found 1630.7840

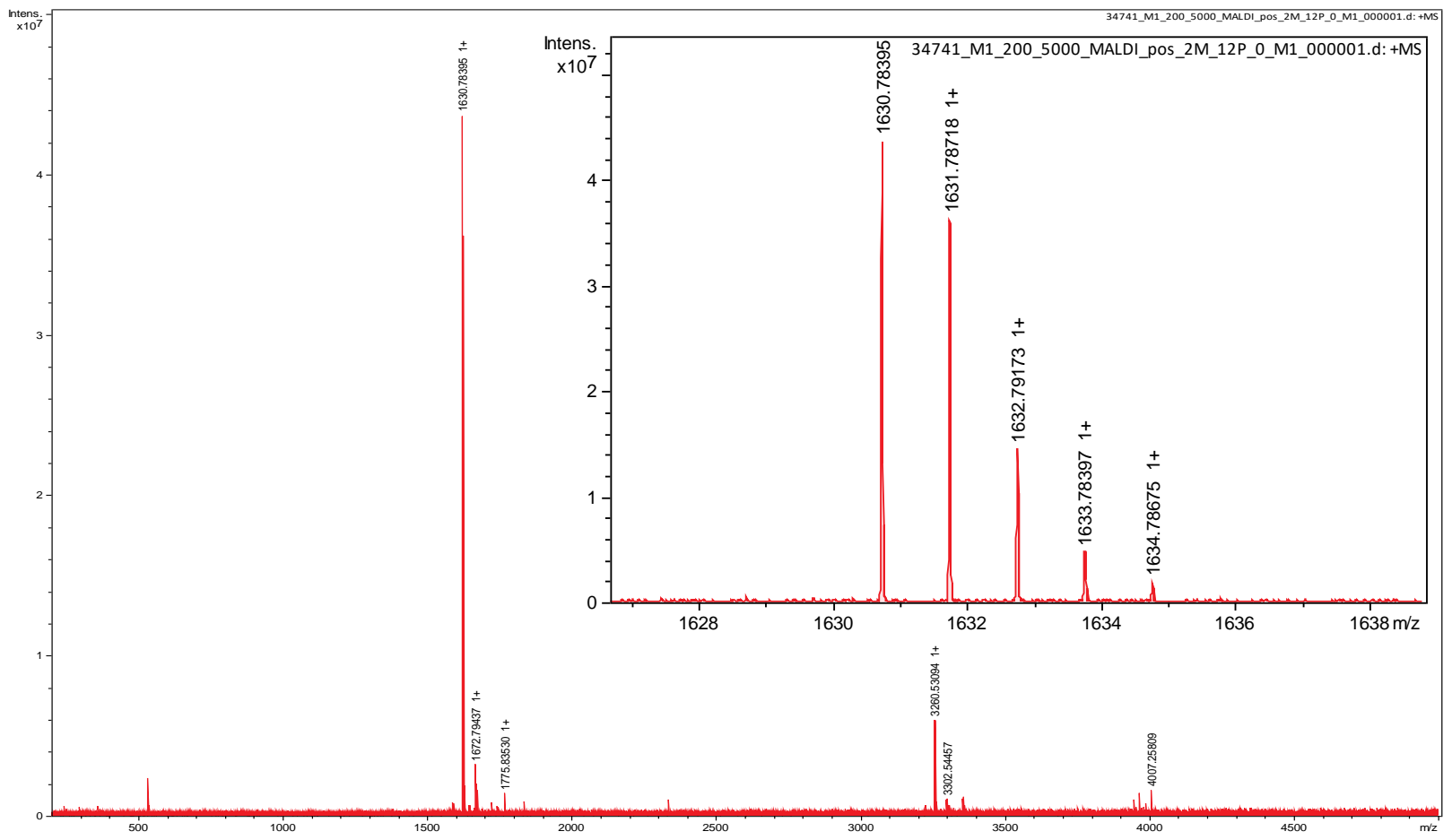




\section{Compound FAM-23}

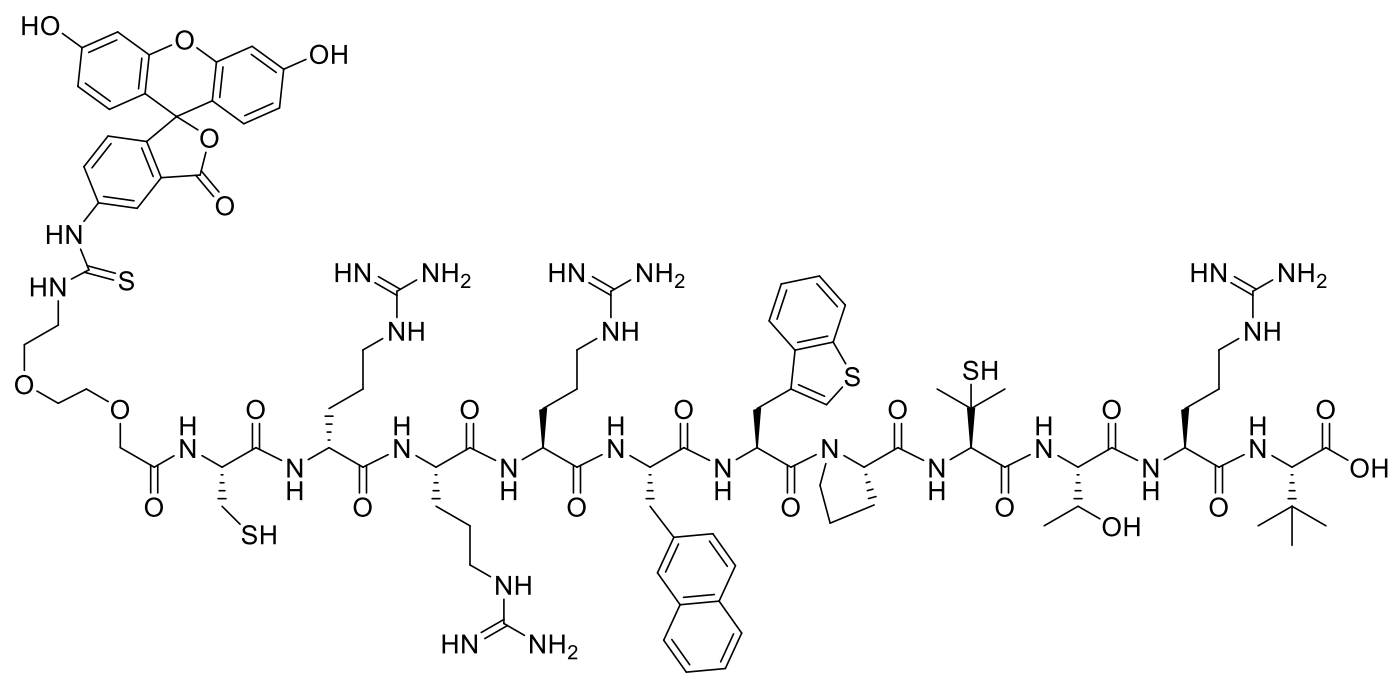

Purity assessment by UPLC (220 nm):

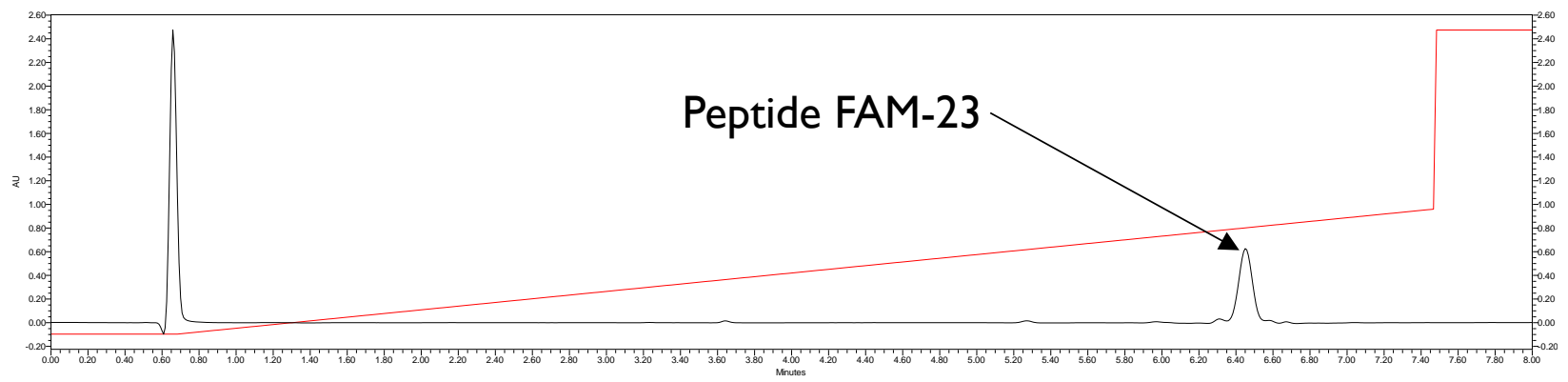

HR-MS: Calculated $[\mathrm{M}+\mathrm{H}]^{+}$2122.8912, found 2122.8976 (reduced) and 2120.8881 (oxidized)

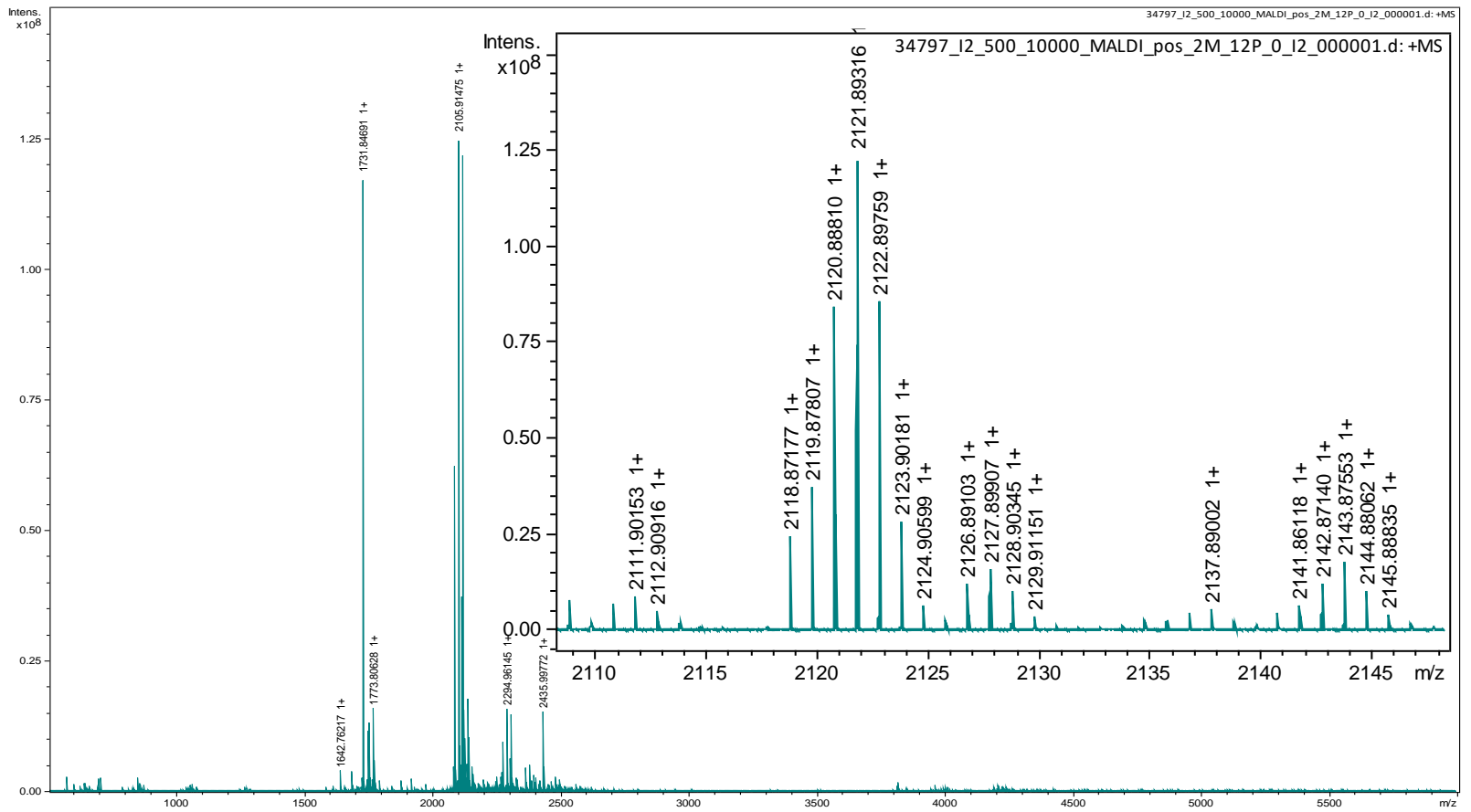




\section{Compound 24c}

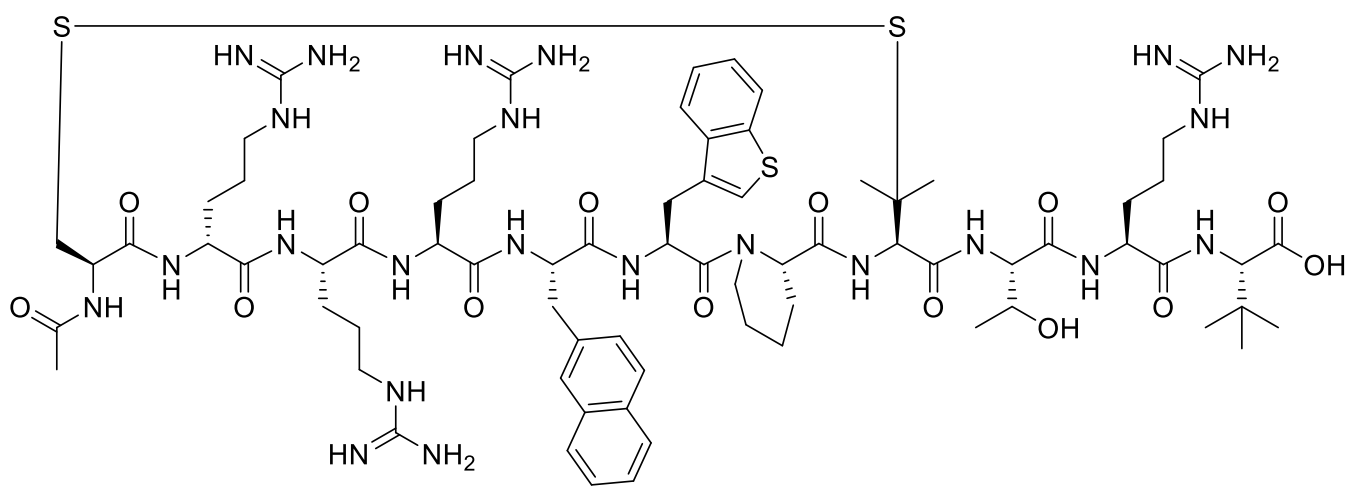

Purity assessment by analytical HPLC (214 nm):

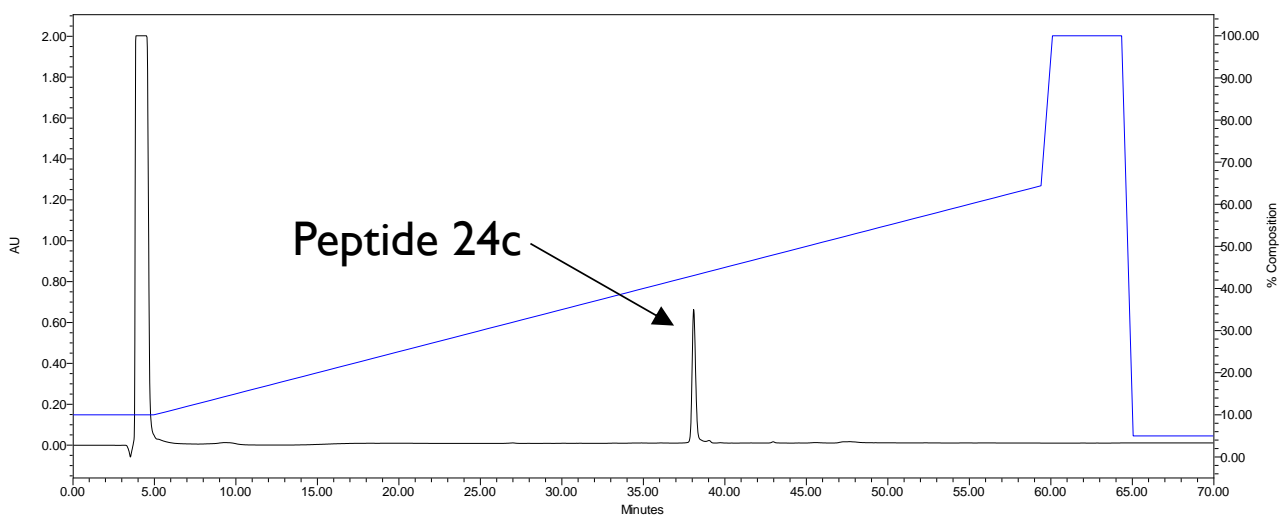

HR-MS: Calculated $[\mathrm{M}+\mathrm{H}]^{+}$1642.7921, found 1642.7966

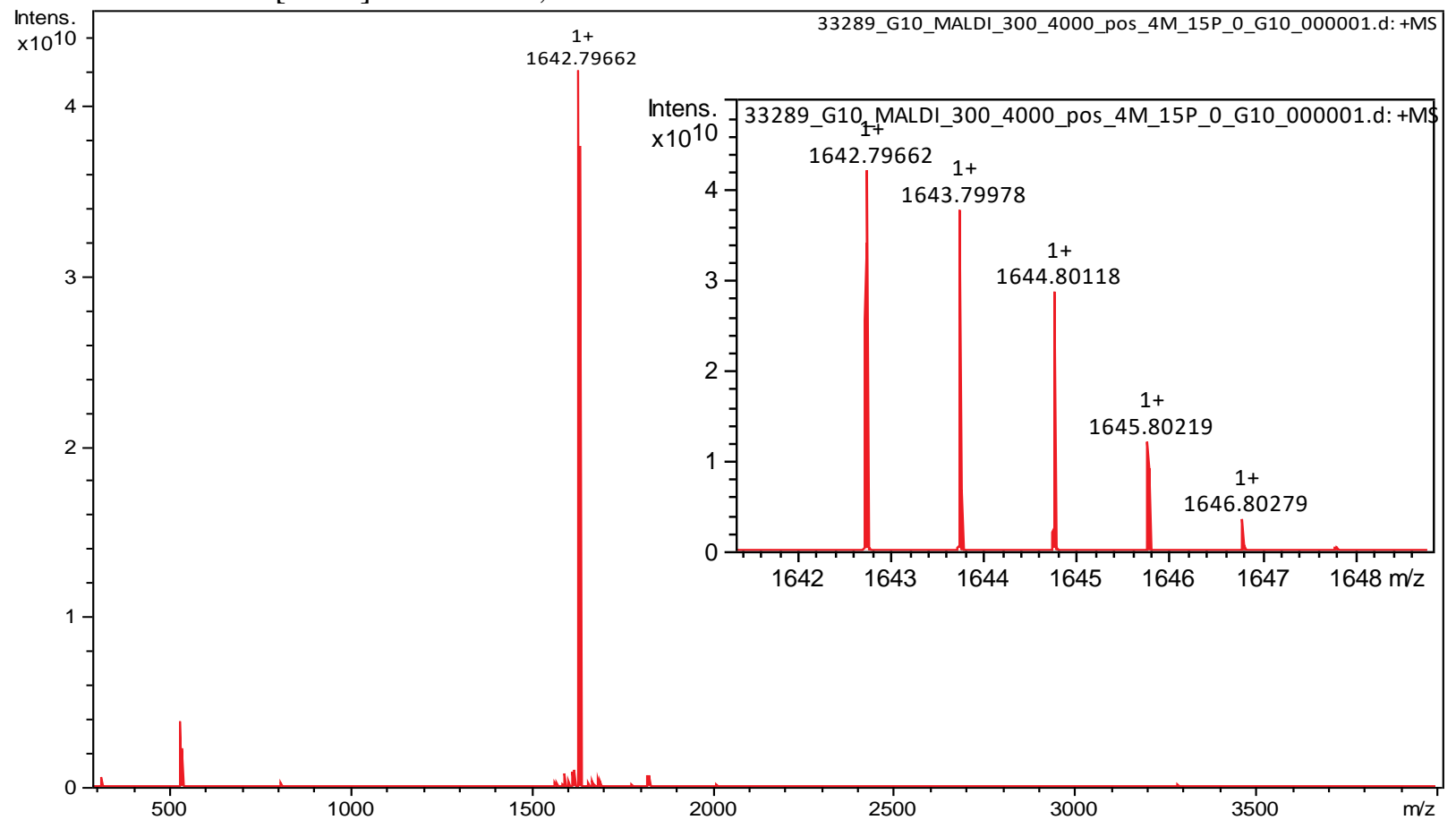




\section{Compound FAM-24}

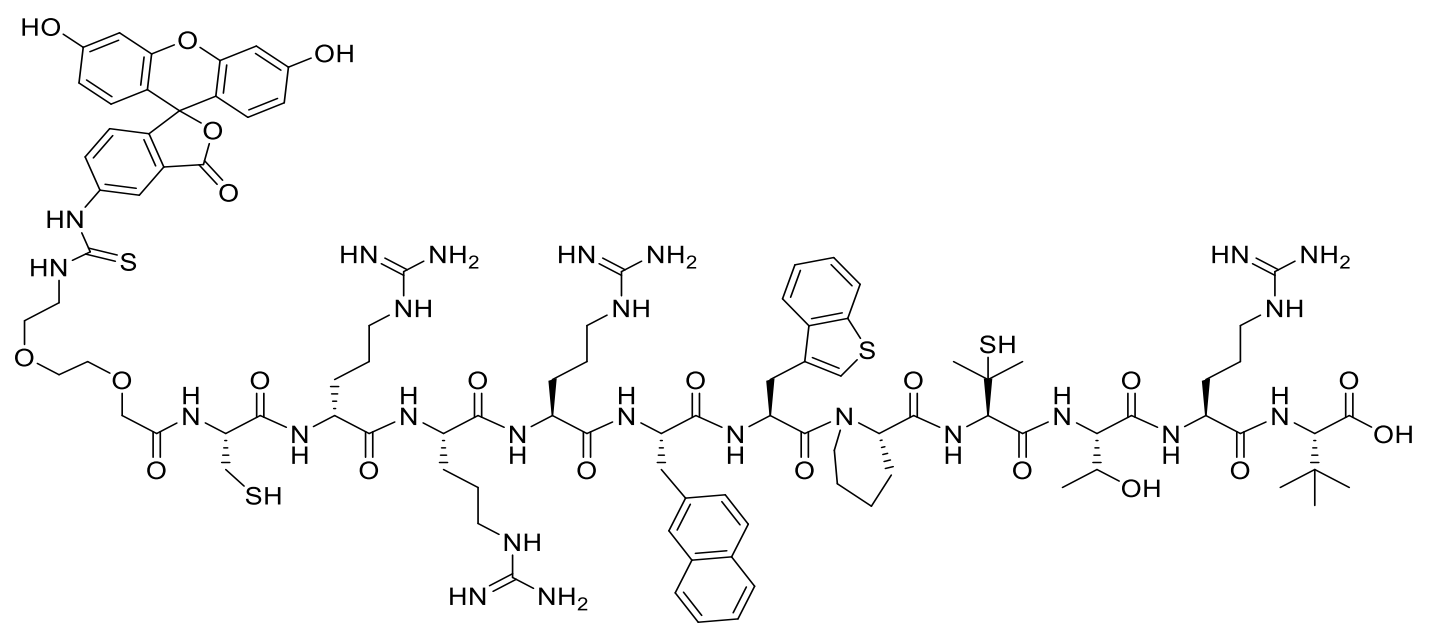

Purity assessment by UPLC $(220 \mathrm{~nm})$ :

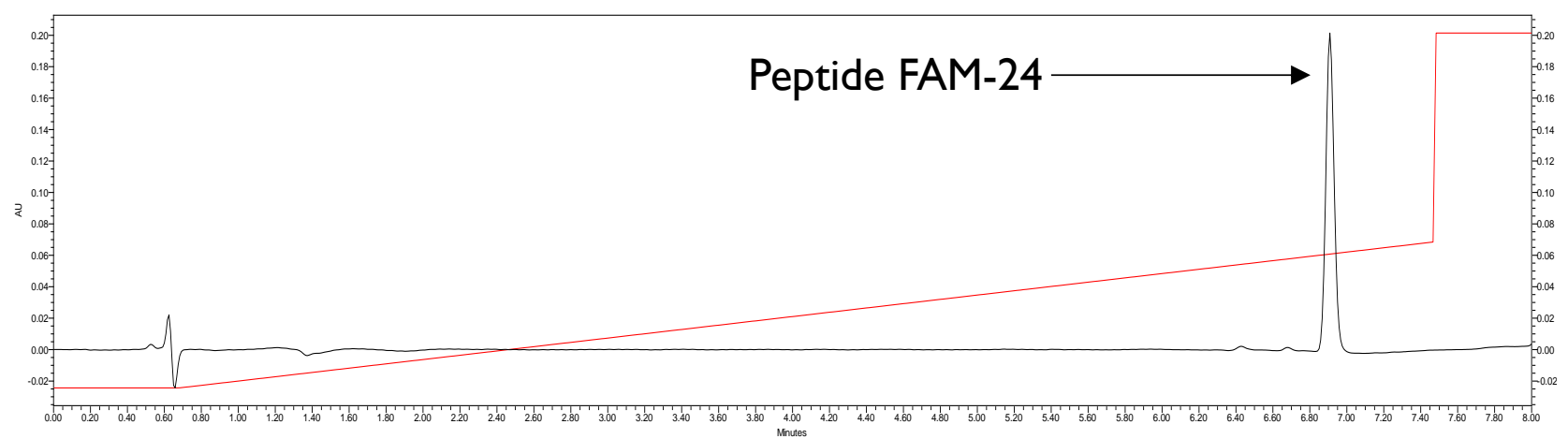

HR-MS: Calculated $[\mathrm{M}+\mathrm{H}]^{+}$2136.9063, found 2136.8992 (reduced) and 2134.8838 (oxidized)

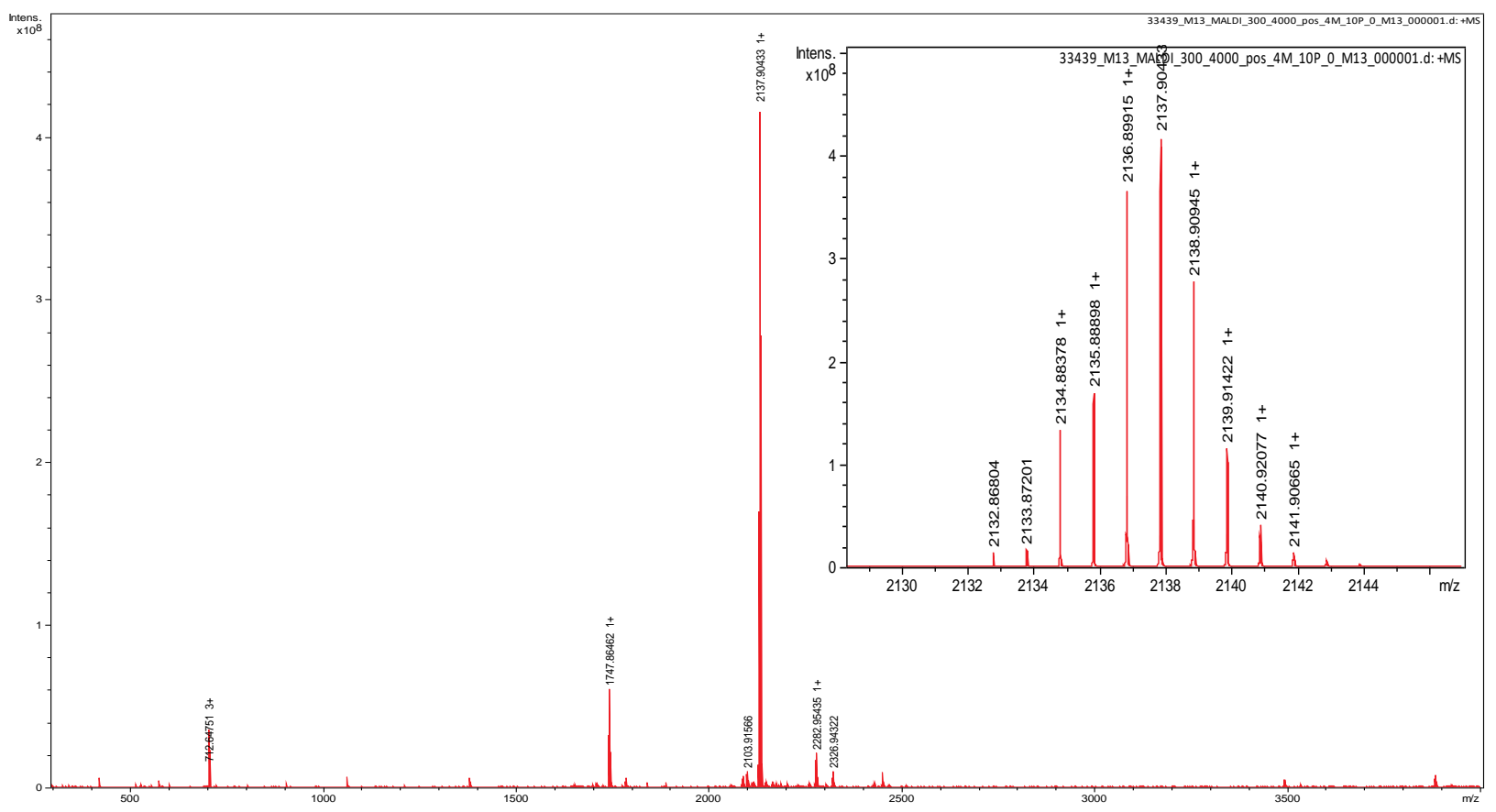




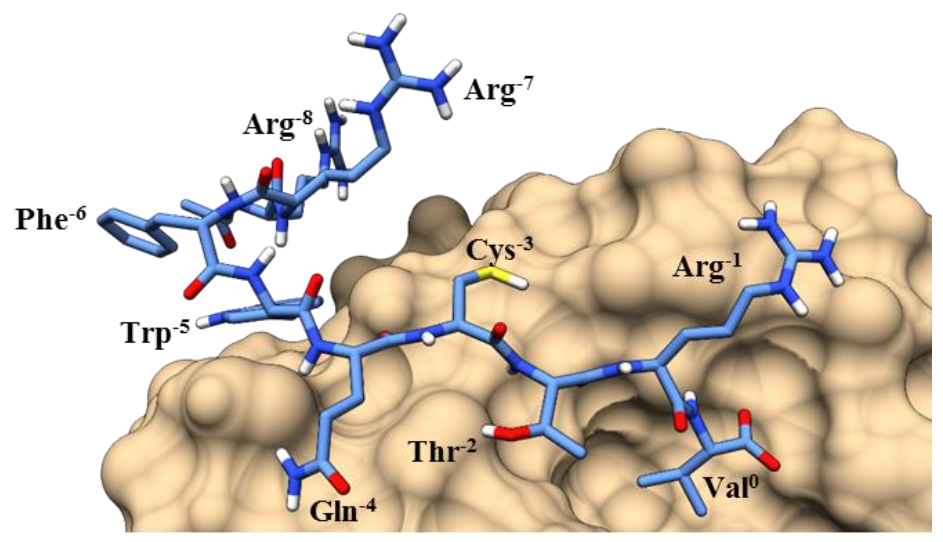

Figure S2: Docked pose of peptide $\mathbf{2}$ in complex with CAL-PDZ. The structure for peptide $\mathbf{2}$ was generated in Schrödinger Maestro ${ }^{1}$, before flexible ligand/rigid receptor docking using Schrödinger Glide $\mathrm{XP}^{2}$ employing a previously reported crystal structure of CAL-PDZ (PDBID: 4K75) ${ }^{3}$ with the crystallized ligand removed. Peptide 2 is depicted with carbon atoms colored light blue, polar hydrogens colored white and non-polar hydrogen atoms hidden nitrogen atoms colored blue, oxygen atoms colored red and sulfur atoms colored yellow while the van der Waals surface of $4 \mathrm{~K} 75$ is shown in tan.

A

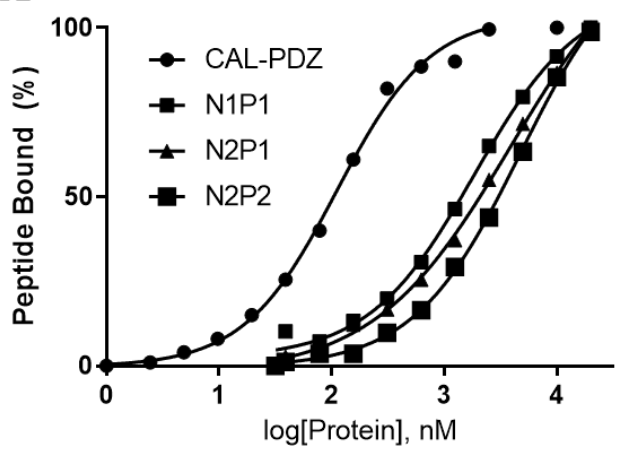

C

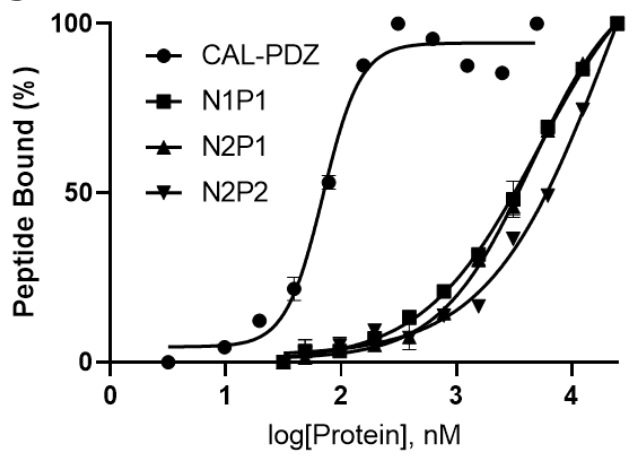

B

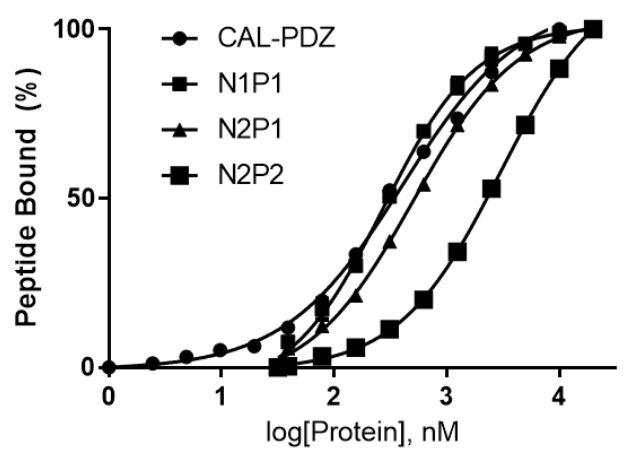

D

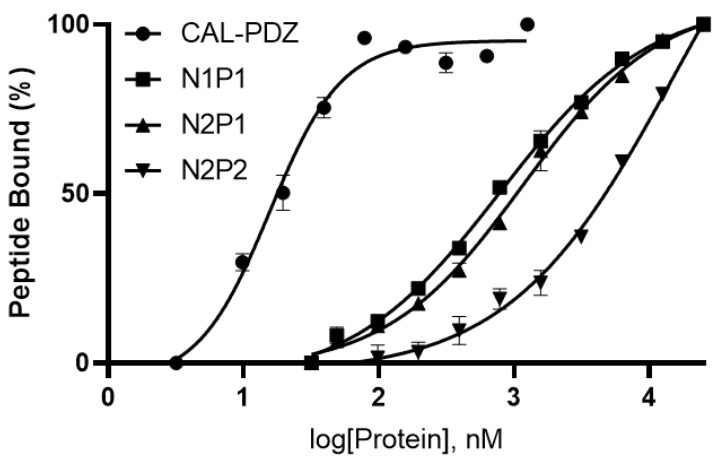

Figure S3: Representative binding curves of FAM-labeled peptides 19 (A), 22 (B), 23 (C) and 24 (D) to CAL-PDZ, NHERF1-PDZ1 (N1P1), NHERF2-PDZ1 (N2P1), or NHERF2-PDZ2 (N2P2) as determined by fluorescent polarization. Values are normalized to the FP signal at saturation and are the mean \pm SD of three independent measurements. 


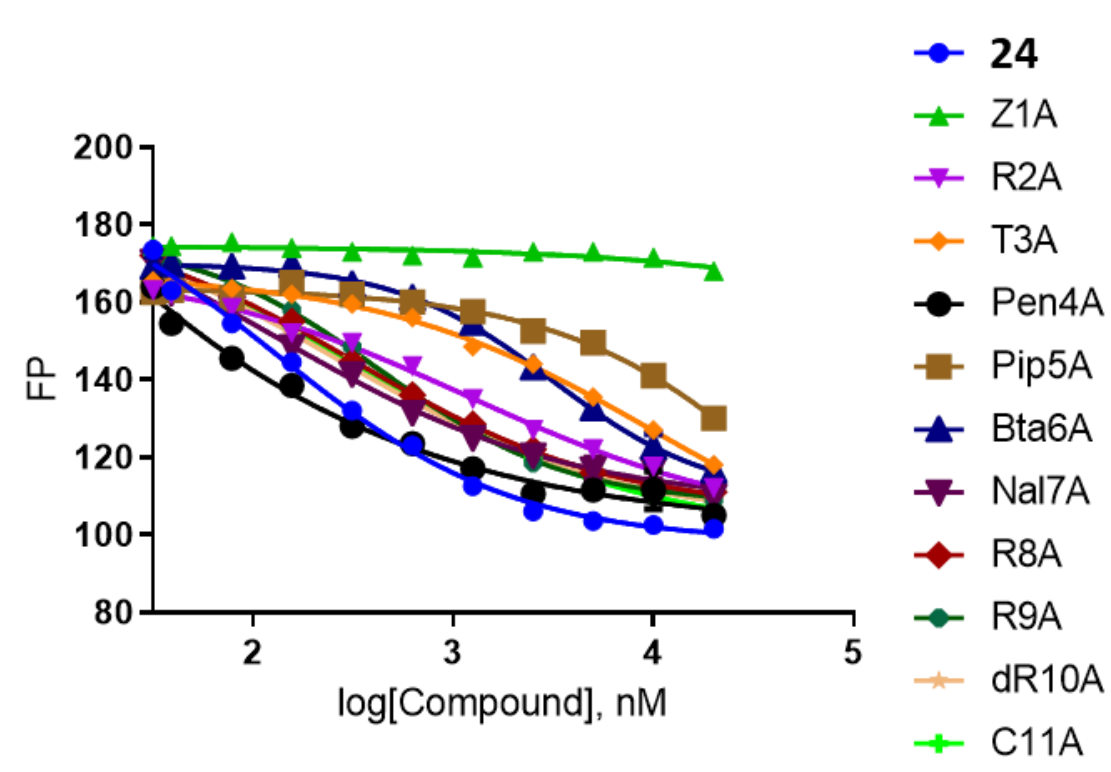

Figure S4: Alanine scan of PGD97. Each residue of peptide $\mathbf{2 4}$ was replaced with Ala (or D-Ala) and the resulting peptides were assessed for inhibition of the binding of FAM-22 to CAL-PDZ domain. CAL-PDZ $(100 \mathrm{nM})$ and the peptide probe $(50 \mathrm{nM})$ were mixed and incubated for $1 \mathrm{~h}$ in PBS (pH 7.4) containing $0.01 \%$ Triton-X100 and $2 \mathrm{mM}$ TCEP. Serial dilutions of each competitor peptide were prepared in PBS containing $0.01 \%$ Triton-X100 and added to the above solution. The combined solutions were incubated for $1 \mathrm{~h}$ at RT, after which $20 \mu \mathrm{L}$ of each sample was transferred into 384-well black-on-black microplates and fluorescence polarization (FP) was measured using a TECAN Infinite M1000 plate reader. Data ( $\mathrm{n}=$ 1) was processed to determine $\mathrm{IC}_{50}$ values using GraphPad PRISM v7.0.

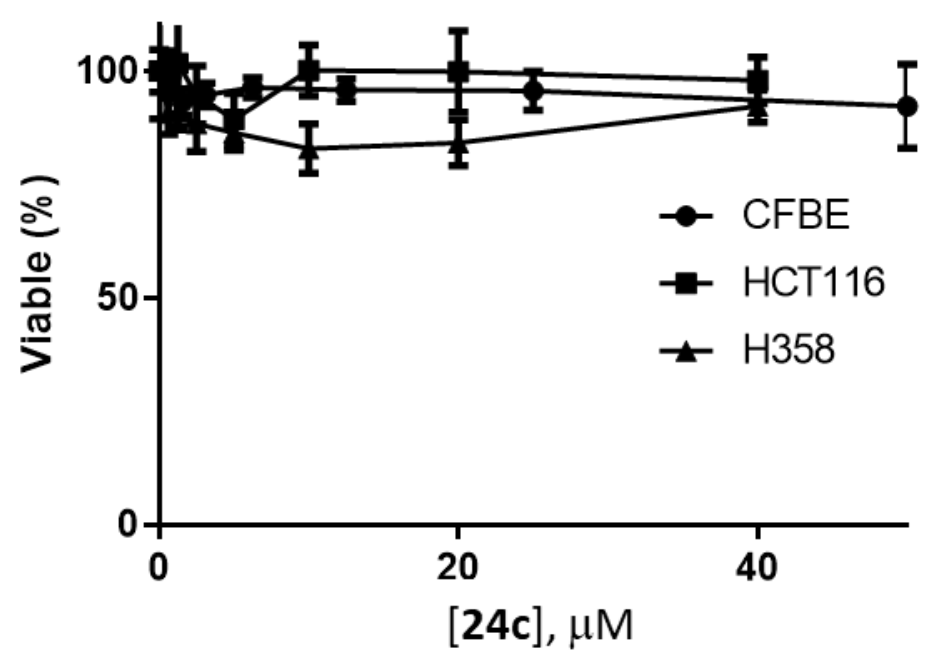

Figure S5: Effect of PGD97 (24c) on the viability of CFBE, HCT116 (human colon cancer) or H358 (nonsmall cell lung cancer) cells as monitored by the MTT assay. Cells were incubated with PGD97 for $72 \mathrm{~h}$ in the presence of 10\% FBS. Values (\% viable cells) shown are relative to vehicle (DMSO)-treated cells and represent the average $\pm \mathrm{SD}$ of three independent experiments. 


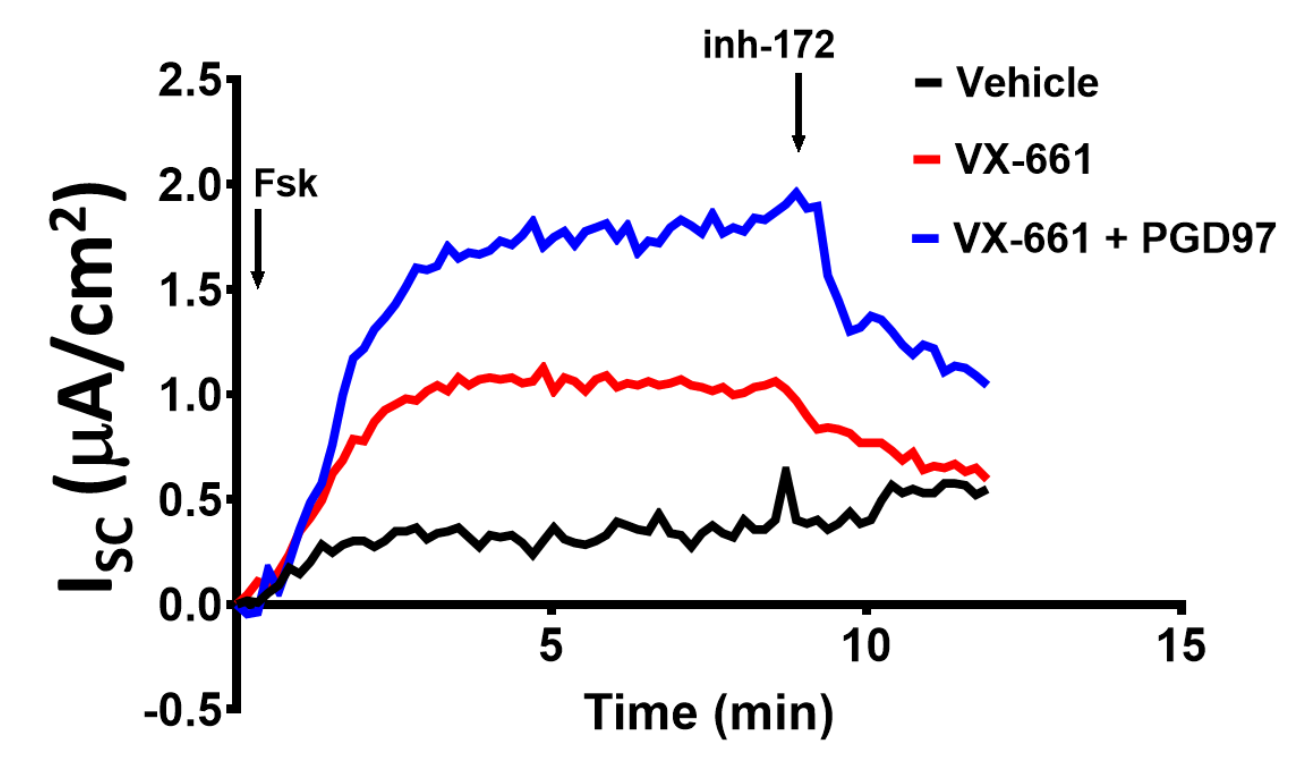

Figure S6: Representative CFTR ion channel traces of primary CF-HBE cells pre-treated with VX-661 (5 $\mu \mathrm{M}) \pm$ PGD97 $(100 \mathrm{nM})$ or vehicle. CFTR channels were activated by addition of forskolin (Fsk, $10 \mu \mathrm{M})$ and inhibited with Ihn-172 $(10 \mu \mathrm{M})$.

\section{References:}

1. Schrödinger Release 2015-2. Maestro. Schrödinger, LLC, New York, NY, 2020.

2. Friesner, R. A.; Murphy, R. B.; Repasky, M. P.; Frye, L. L.; Greenwood, J. R.; Halgren, T. A.; Sanschagrin, P. C.; Mainz, D. T.; Extra Precision Glide: Docking and Scoring Incorporating a Model of Hydrophobic Enclosure for Protein-Ligand Complexes. J. Med. Chem. 2006, 49, 6177-6196.

3. Amacher, J. F.; Cushing, P. R.; Brooks, L.; Boisguerin, P.; Madden, D. R. Stereochemical Preferences Modulate Affinity and Selectivity Among Five PDZ Domains that Bind CFTR: Comparative Structural and Sequence Analyses. Structure 2014, 22 82-93.

4. Bowers, K. J.; Chow, E.; Xu, H.; Dror, R. O.; Eastwood, M. P.; Gregersen, B. A.; Klepeis, J. L.; Kolossvary, I.; Moraes, M. A.; Sacerdoti, F. D.; et al. Scalable Algorithms for Molecular Dynamics Simulations on Commodity Clusters. Proc. ACM/IEEE Conf. Supercomputing (SC06), Tampa, Florida, 2006. 